\title{
Regulation of DNA damage repair in response to freezing and anoxia in the wood frog, Rana sylvatica
}

Zephanie Dee Lung

B.Sc. (Hons.), 2017

Carleton University

A thesis submitted to the Faculty of Graduate Studies and Research in partial fulfillment of the requirements for the degree of

\author{
Master of Science \\ Department of Biology \\ Carleton University \\ Ottawa, Ontario, Canada \\ (C) Copyright 2019 \\ Zephanie D. Lung
}


The undersigned hereby recommend to the Faculty of Graduate Studies and Research acceptance of this thesis

Regulation of DNA damage repair in response to freezing and anoxia in the wood frog, Rana sylvatica

submitted by

Zephanie Dee Lung, B.Sc.

in partial fulfillment of the requirements for the degree of Master of Science

Chair, Department of Biology

Thesis Supervisor

Carleton University 


\begin{abstract}
The wood frog, Rana sylvatica, can survive freezing up to $65 \%$ of its body water in subzero temperatures and endures anoxia due to the cessation of vital functions while frozen. Fluctuating oxygen levels, particularly upon reperfusion and reoxygenation, increase vulnerability to reactive oxygen species and oxidative damage to macromolecules, including DNA. This thesis assesses DNA damage and responses by antioxidant capacity and DNA damage repair pathways to freezing or anoxia in wood frog liver and skeletal muscle. DNA oxidation remained largely constant, with observed increased antioxidant capacity in anoxia but not freezing. Although many observed DNA repair proteins displayed constant expression through stress and recovery, the MRN complex, $\mathrm{Ku}$ heterodimer, and ligation complexes, displayed changes in expression that vary based on tissue and stress. Overall, the data indicate that DNA damage is minimized through tissue and stress specific regulation of antioxidant capacity and DNA damage repair to preserve genomic integrity.
\end{abstract}




\section{Acknowledgements}

First and foremost, I would like to thank my supervisor, Dr. Kenneth Storey, for taking on a Neuroscience kid with virtually no experience and opening up the world of molecular biology. Thank you for your guidance and for helping develop my skills in the world of academia and research. Thank you also to Jan Storey for all you do to help this lab run as smoothly as it does, and for your extreme dedication and patience in editing my thesis and answering my countless questions. You're a lifesaver.

To every Storey lab member who has crossed paths with me these past two years - thank you for making my time here so memorable. Rasha, thank you for training me, always being there to help me, all the food, and of course all the selfies. Alex, as much as I joke about it, I do appreciate your friendship - mainly for pictures and videos of Odin. Stuart, don't be alarmed if I still ask you the occasional obscure science or linguistic question. Jess, thank you for all the times you've taken off my primary on weekends, the emotional support, and the countless Tims sessions. You're simply the best. Jannelle, thanks for getting me into this lab in the first place and for getting me through the past six years of school - you always manage to make me feel better when I'm stressed.

Last but not least, I would like to thank my family for getting me where I am today and for all their love and support. 哥哥嫂嫂, thank you for the loan of your house while you guys travel, starting thesis writing there was definitely beneficial. 亭亭, my grammar is probably where it is today because of your corrections that I've learned to accept, so just this time I'll say thank you. 爸爸媽媽, 謝謝你們從小教我努力用功。也 謝謝為我所做的一切。我永遠回報不了你們從小為我的犧牲。 


\section{Table of Contents}

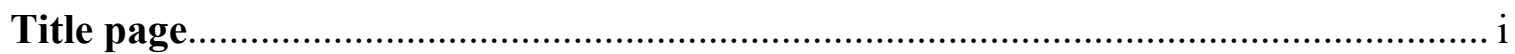

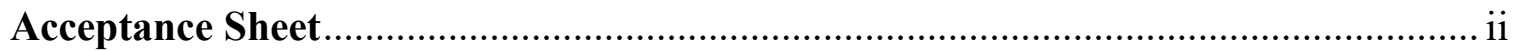

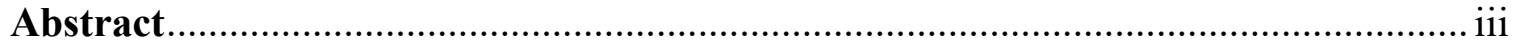

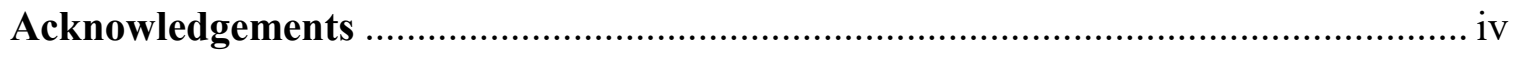

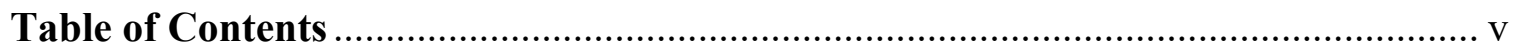

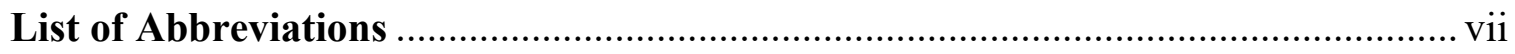

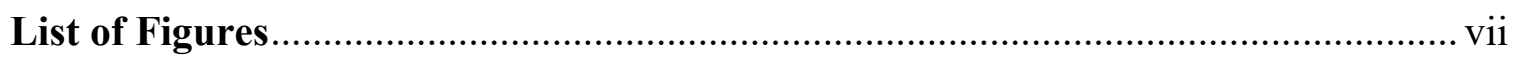

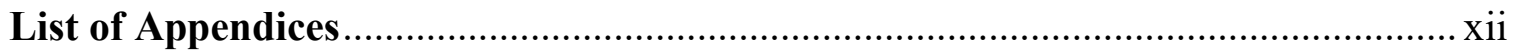

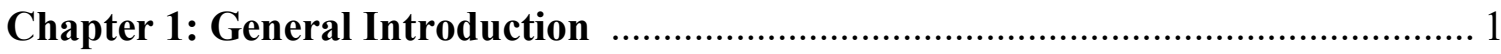

1.1 Survival strategies at extreme cold temperatures ............................................. 2

1.2 The wood frog, Rana sylvatica, as a freeze tolerant model ................................. 5

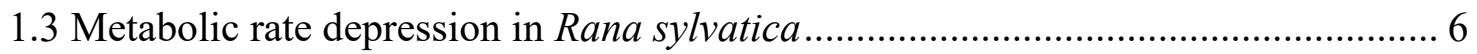

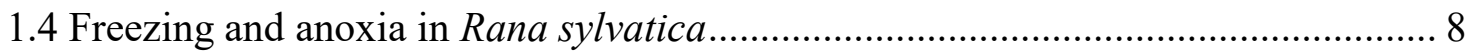

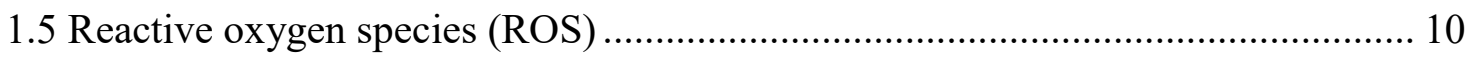

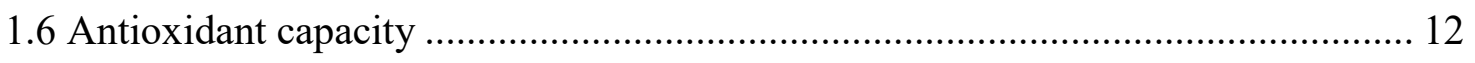

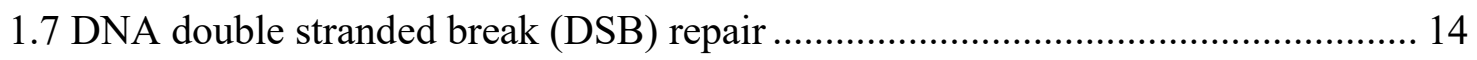

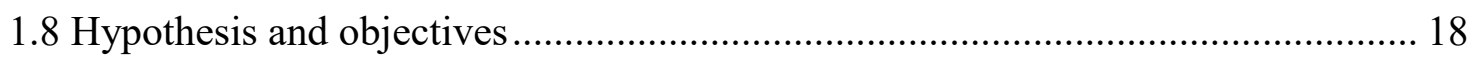

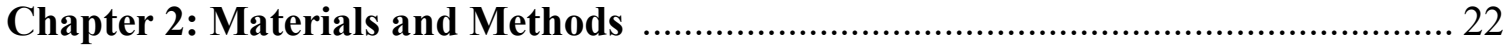

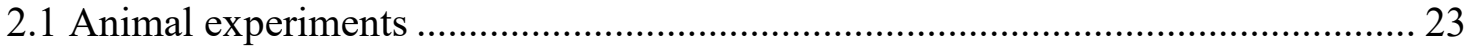

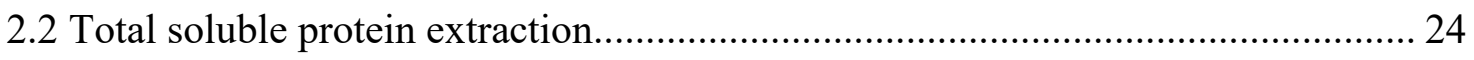

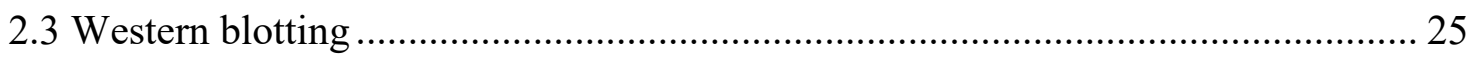

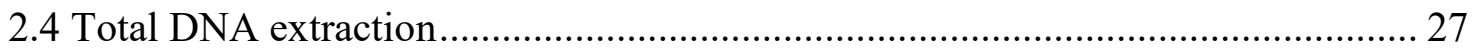

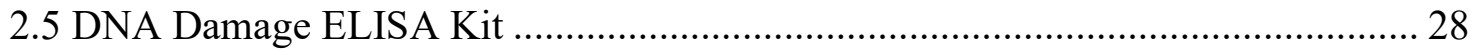

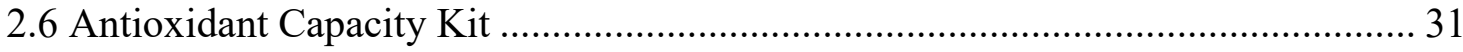

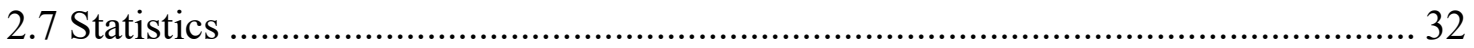

Chapter 3: DNA Damage, Antioxidant Capacity, and DNA Repair through the

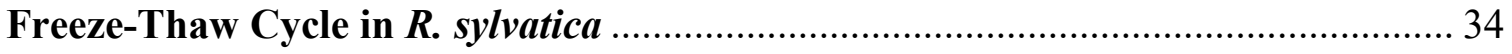

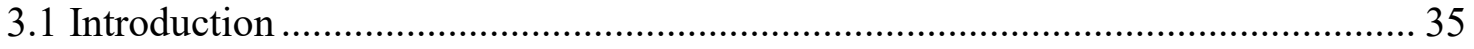

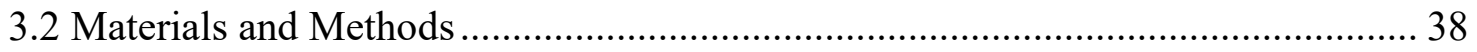

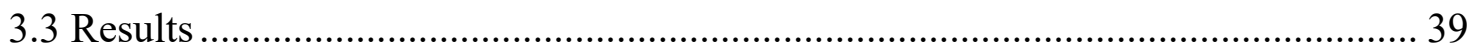

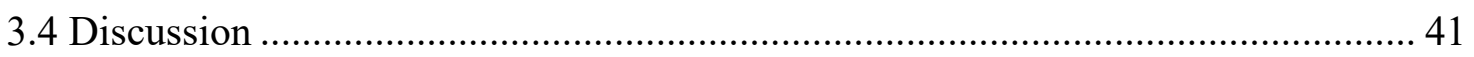


Chapter 4: DNA Damage, Antioxidant Capacity, and DNA Repair through the

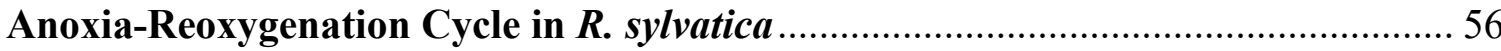

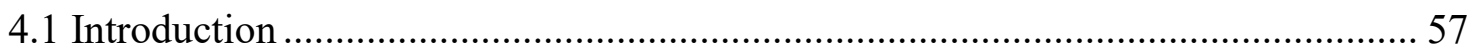

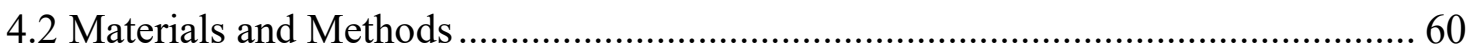

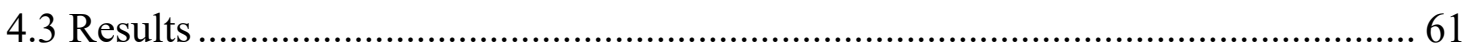

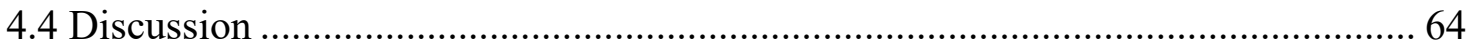

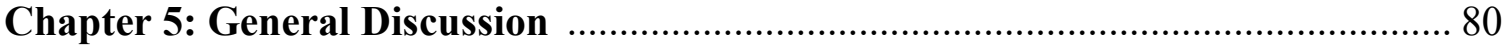

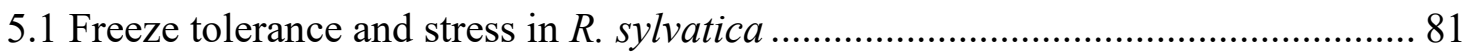

5.2 Stress specific expression of DNA damage ................................................. 83

5.3 Stress specific responses in total antioxidant capacity ..................................... 84

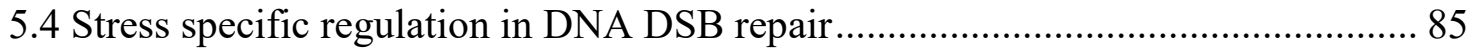

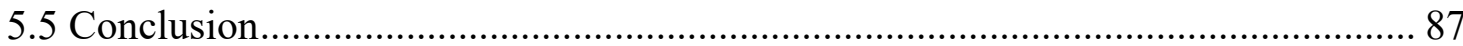

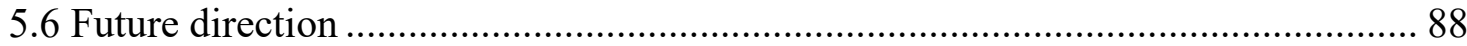

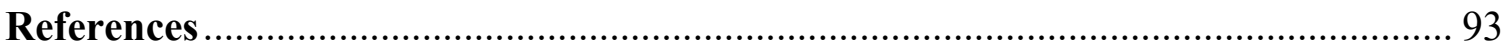

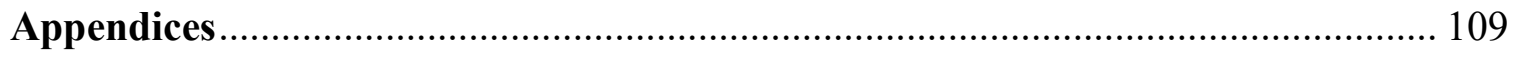




\section{List of Abbreviations}

ABTS

$\mathrm{AChE}$

ANOVA

APS

ATM

ATP

ATR

$\mathrm{B}_{\mathrm{o}}$

BER

BRCA1

BSA

DNA

DNA-PKcs

DSB

g-DNA wash buffe

EDTA

ELISA

ETC

Exo1

GR

GPx

GSTs
2,2'-Azino-di-3-ethylbenzothiazoline sulphonate

Acetylcholinesterase

Analysis of variance

Ammonium persulfate

Ataxia telangiectasia mutated

Adenosine triphosphate

Ataxia telangiectasia Rad3-related protein

Maximum binding

Base excision repair

Breast cancer type 1 susceptibility protein

Bovine serum albumin

Deoxyribonucleic acid

DNA-dependent protein kinase, catalytic subunit

Double stranded break

genomic-deoxyribonucleic acid wash buffer

Ethylenediaminetetraacetic acid

Enzyme-linked immunosorbent assay

Electron transport chain

Exonuclease 1

Glutathione reductase

Glutathione peroxidase

Glutathione transferases 


\begin{tabular}{|c|c|}
\hline HEPES & 4-(2-hydroxyethyl)-1-piperazineethanesulfonic acid \\
\hline HPR & Horseradish peroxidase \\
\hline HR & Homologous recombination \\
\hline INP & Ice nucleating proteins \\
\hline LDH & Lactate dehydrogenase \\
\hline MMEJ & Micro-homology mediated end joining \\
\hline MMR & Mismatch repair \\
\hline MRD & Metabolic rate depression \\
\hline MRN & Mre11-Rad50-Nsb1 complex \\
\hline $\mathrm{NaCl}$ & Sodium chloride \\
\hline $\mathrm{NaF}$ & Sodium fluoride \\
\hline $\mathrm{Na}_{3} \mathrm{VO}_{4}$ & Sodium orthovanadate \\
\hline NER & Nucleotide excision repair \\
\hline NHEJ & Non-homologous end joining \\
\hline PCR & Polymerase chain reaction \\
\hline PIKKs & Phosphatidylinositol 3-kinase-related kinases \\
\hline PMSF & Phenylmethyl sulfonyl fluoride \\
\hline PTM & Post-translational modification \\
\hline PVDF & Polyvinylidene difluoride \\
\hline RNA & Ribonucleic acid \\
\hline ROS & Reactive oxygen species \\
\hline SDS & Sodium dodecyl sulfate \\
\hline
\end{tabular}

SDS-PAGE Sodium dodecyl sulfate polyacrylamide gel electrophoresis 


$\begin{array}{ll}\text { Sgs1 } & \text { Slow growth suppressor 1 } \\ \text { SOD } & \text { Superoxide dismutase } \\ \text { SSB } & \text { Single stranded break } \\ \text { ssDNA } & \text { Single-stranded DNA } \\ \text { TBST } & \text { Tris-buffered saline with Tween-20 } \\ \text { TEMED } & \text { N,N,N',N'-Tetramethylethane-1,2-diamine } \\ \text { TET } & \text { Ten-eleven translocation } \\ \text { TPE } & \text { Telomere positioning silencing effect } \\ \text { Tris-HCl } & \text { Tris-hydrochloric acid buffer } \\ \text { Trolox } & \text { 6-hydroxy-2,5,7,8-tetramethylchroman-2-carboxylic acid } \\ \text { 8-oxo-Gua } & \text { 8-hydroxy-2'-deoxyguanosine } \\ \text { 8-OH-dG } & \text { X-Oray repair cross-complementing protein 4 } \\ \text { XRCC4 } & \text { 8-deoxyguanosine } \\ & \end{array}$




\section{List of Figures}

Figure 1.1 Geographical range of the wood frog, Rana sylvatica.....................20

Figure 1.2 The non-homologous end joining (NHEJ) and homologous recombination (HR) pathways of double stranded break (DSB) repair (Lans et al., 2012).

Figure 3.1: DNA damage quantification in $R$. sylvatica liver and skeletal muscle through a freeze-thaw cycle. Relative oxidized guanine species in control, 24 hour frozen, and 8 hour thaw conditions. Data are means \pm SEM, $n=3-4$ independent trials. One-way ANOVA and a Tukey's post-hoc test $(\mathrm{p}<0.05)$ was used for analysis; for each tissue, values that share the same letter are not significantly different from each other.

Figure 3.2: Total antioxidant capacity in $R$. sylvatica liver and skeletal muscle through a freeze-thaw cycle. Total relative antioxidant capacity in control, 24 hour frozen, and 8 hour thaw conditions. Data are means \pm SEM, $n=3-4$ independent trials. One-way ANOVA and a Tukey's post-hoc test $(\mathrm{p}<0.05)$ was used for analysis; for each tissue, values that share the same letter are not significantly different from each other.

Figure 3.3: Western blot quantification of DSB repair protein expression in $R$. sylvatica liver through a freeze-thaw cycle. A) Relative protein expression of protein targets in control, 24 hour frozen, and 8 hour thaw conditions. Data are means \pm SEM, $n=3-4$ independent trials. One-way ANOVA and a Tukey's post-hoc test $(p<0.05)$ was used for analysis; values that share the same letter are not significantly different from each other. B) Western blot of DSB repair protein targets in the corresponding experimental conditions.

Figure 3.4: Western blot quantification of DSB repair protein expression in $R$. sylvatica skeletal muscle through a freeze-thaw cycle. A) Relative protein expression of protein targets in control, 24 hour frozen, and 8 hour thaw conditions. Data are means \pm SEM, $n$ $=3-4$ independent trials. One-way ANOVA and a Tukey's post-hoc test $(p<0.05)$ was used for analysis; values that share the same letter are not significantly different from each other. B) Western blot of DSB repair protein targets in the corresponding experimental conditions. 55

Figure 4.1: DNA damage quantification in $R$. sylvatica liver and muscle through an anoxia-recovery cycle. Relative oxidized guanine species in control, 24 hour anoxia, and 4 hour aerobic recovery conditions. Data are means \pm SEM, $n=3-4$ independent trials. One-way ANOVA and a Tukey's post-hoc test $(\mathrm{p}<0.05)$ were used for analysis; for each tissue, values that share the same letter are not significantly different from each other. . 76 
Figure 4.2: Total antioxidant capacity in $R$. sylvatica liver and muscle through an anoxiarecovery cycle. Total relative antioxidant capacity in control, 24 hour anoxia, and 4 hour aerobic recovery conditions. Data are means $\pm S E M, n=3-4$ independent trials. Oneway ANOVA and a Tukey's post-hoc test $(\mathrm{p}<0.05)$ were used for analysis; for each tissue, values that share the same letter are not significantly different from each other. . 77

Figure 4.3: Western blot quantification of DSB repair protein expression in $R$. sylvatica liver through an anoxia-recovery cycle. A) Relative protein expression of protein targets in control, 24 hour anoxia, and 4 hour recovery conditions. Data are means $\pm S E M, n=3-$ 4 independent trials. One-way ANOVA and a Tukey's post-hoc test $(p<0.05)$ were used for analysis; for each protein target, values that share the same letter are not significantly different from each other. B) Western blot of DSB repair protein targets in the corresponding experimental conditions.

Figure 4.4: Western blot quantification of DSB repair protein expression in $R$. sylvatica skeletal muscle through an anoxia-recovery cycle. A) Relative protein expression of protein targets in control, 24 hour anoxia, and 4 hour recovery conditions. Data are means \pm SEM, $\mathrm{n}=3-4$ independent trials. One-way ANOVA and a Tukey's post-hoc test $(\mathrm{p}<$ 0.05 ) was used for analysis; for each protein target, values that share the same letter are not significantly different from each other. B) Western blot of DSB repair protein targets in the corresponding experimental conditions. 


\section{List of Appendices}

Appendix A: Western blot antibody information and supplier ................................ 110

Appendix B: Western blot experimental conditions ................................................. 111

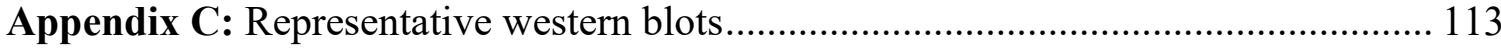




\section{Chapter 1}

\section{General Introduction}




\subsection{Survival strategies at extreme cold temperatures}

Organisms found in climates that encounter subzero temperatures face many challenges, as they typically must endure extended winter periods of physiological stress with cold temperatures, limited food supply and often low oxygen availability and limited water supply. In order to survive long-term exposure to subzero temperatures, animals typically exhibit metabolic rate depression until the environmental conditions are conducive for return to their normal active lifestyle (Storey and Storey, 2004a). However, not all animals have the necessary physiological adaptations to survive cold, harsh winters, and conditions can be detrimental for these organisms when they encounter extreme conditions. There are potential chill and freezing injuries, mainly reflected in the disruption of protein and lipid structures, that could cause irreversible damage to these organisms (Storey and Storey, 1988). As a result, organisms found in these environments have adopted a variety of strategies to survive at cold temperatures. Animals typically display either freeze avoidance or freeze tolerance in order to survive cold, harsh climates (Storey and Storey, 1988).

There are multiple adaptive strategies for dealing with cold winters. Some animals such as the Swainson's thrush (Catharus ustulatus), the willow warbler (Phylloscopus trochilus), and Monarch butterfly (Danaus plexippus) exhibit behavioural changes and seasonally migrate to warmer climates to escape the cold environment by displacing to warmer climates (Merlin and Liedvogel, 2019). Many other species that cannot make major geographic relocations use more minor moves to place themselves in safer winter locations; e.g. many species insects, arthropods and others dig underground to place themselves below the frost line whereas others retreat underwater for the winter. The red- 
eared slider turtle (Trachemys scripta elegans) is an example of a reptile that finds a thermal buffered environment to survive the cold, as they overwinter under ice-locked lakes and ponds as their freeze avoidance strategy (Wijenayake and Storey, 2016). Other species that cannot avoid exposure to subzero environments instead produce their own antifreeze, producing high levels of cryoprotectants (such as sorbitol, glycerol, ribitol, mannitol, glucose, trehalose, etc.) to prevent freezing of body fluids (Morrissey and Baust, 1976; Storey and Storey, 1988). One prominent example of both these freeze avoidance techniques is the larvae of the goldenrod gall moth (Epiblema scudderiana), which lower their supercooling point to about $-38^{\circ} \mathrm{C}$ by producing massive amounts of glycerol (levels often exceeding 2 molar) to survive the winter inside galls on the stems of goldenrod (Rickards et al., 1987; Storey and Storey, 2012).

In contrast to freeze avoidance, other organisms have developed freeze tolerance strategies in order to cope with subzero temperatures. Animals that are freeze tolerant are able to survive the physiological strain of their body fluids freezing by managing the freezing process; water exits cells at a slow rate to freeze as extracellular ice and cells respond by synthesizing osmolytes (e.g. sugars, urea) to avoid full cellular dehydration and to protect macromolecules (proteins, membranes) from damage (Storey and Storey, 1988). There is significant phylogenetic diversity in animals that exhibit freeze tolerance including marine invertebrates, insects, amphibians, and reptiles (Storey and Storey, 1988; Storey 1990; Packard and Packard, 2004). An example of a freeze tolerant reptile is the painted turtle (Chrysemys picta) hatchling; these hatch in their underground nests in late summer but overwinter within the nest until the following spring to evade predators. In remaining in their nest through the winter, painted turtle hatchlings exhibit freeze 
tolerance in some geographic locations (surviving down to approximately $-4^{\circ} \mathrm{C}$ ) whereas in parts of their geographic range they use the supercooling strategy of freeze avoidance (Storey et al., 1988; Costanzo et al., 2000).

Freeze tolerant animals share common challenges and adaptive strategies to cope with the stresses that they must endure. Since intracellular ice can cause severe structural and physiological damage to tissues, the formation of ice in freeze tolerant organisms typically occurs only in extracellular spaces (Storey and Storey, 2017). A basic tenet of freeze tolerance is the initiation of ice nucleation upon epithelial contact with ice crystals in the environment, mediated by ice nucleating proteins (INPs), or by ice-nucleating bacteria on the skin or in the gut at high subzero temperatures just below the freezing point of body fluids. The action of these ice nucleators helps ice formation to occur at a slow rate and minimizes physiological damage to the organism (Costanzo and Lee, 1996; Zachariassen and Kristiansen, 2000; Storey and Storey, 2017). The formation of ice in extracellular spaces elevates the osmolality of remaining extracellular fluid, and thereby draws out intracellular water. As such, organisms need to endure cellular dehydration, that also causes a strong reduction in organ sizes over long-term periods of freezing (Storey and Storey, 2017). The extended period of inactivity and cessation of vital functions upon freezing also causes cellular hypoxia/anoxia and ischemia. Therefore, these organisms must have a well-adapted glycolytic capacity and be able to store and manage the use of endogenous fuel reserves (Storey and Storey, 1988; Storey and Storey, 2017). The complexity of natural freeze tolerance allows for the continual discovery of molecular and physiological underpinnings of freezing, and can be used to broaden 
understanding in medical research such as cryopreservation of organs, diabetes, and conditions related to ischemia.

\subsection{The wood frog, Rana sylvatica, as a freeze tolerant model}

The wood frog, Rana sylvatica, is best studied vertebrate model of freeze tolerance. Its geographical range spans from the Arctic Circle in Alaska, through southern Canada, to the Piedmont Plateau in Ohio (Larson and Barnes, 2016; Costanzo, 2019) (Figure 1.1). These terrestrial anurans burrow under layers of leaves in the subnivean space where they freeze during the winter months. Their choice of hibernacula is crucial, as their insulated hibernacula will rarely drop below -5 to $-7^{\circ} \mathrm{C}$ even when air temperatures drop to $-30^{\circ} \mathrm{C}$ above the snowpack. By remaining in this insulated environment, $R$. sylvatica can maintain its body temperature closer to its freezing point and minimize cell dehydration (Schmid, 1982; Storey and Storey, 2013). Since $R$. sylvatica have such a vast geographical range, there is variance in freeze tolerance capacity based on their native geographical location. Wood frogs found in the subarctic region in Alaska can endure colder temperatures, surviving at $-18^{\circ} \mathrm{C}$ in comparison to populations of $R$. sylvatica in southern Canada or Ohio that only endure freezing around -3 to $-6^{\circ} \mathrm{C}$ (Middle and Barnes, 2001; Costanzo and Lee, 2013). Northern subarctic populations of $R$. sylvatica also have higher levels of cryoprotectant (glucose and urea), and freeze at a faster rate and for a longer duration than southern populations of found in Ohio (Zhang et al., 2014; Costanzo et al., 2015; Storey and Storey, 2017). 
Wood frogs can endure the freezing of up to approximately $65 \%$ of their body water during the winter, and begin to freeze when temperatures fall below the equilibrium freezing point of their body fluids (about $-0.5^{\circ} \mathrm{C}$ ) although most individuals generally supercool to about $-2^{\circ} \mathrm{C}$ before freezing is triggered. Ice nucleation in this temperature range is typically initiated upon epithelial contact with environmental ice, due to freezing of their moist surroundings in hibernacula. Ice nucleation is often triggered by the action of ice-nucleating bacteria on the skin or in the gut, as well as by INPs that are found in the blood (Costanzo and Lee, 1996; Storey and Storey, 1996). From the site of nucleation, ice propagates through the extracellular fluids of the frog and, in the process, draws water out of cells to join the extracellular ice. In order to protect their cells from shrinking too far during freezing, $R$. sylvatica greatly elevates its intracellular glucose levels to help minimize cellular volume reduction (Storey and Storey, 1984; Layne et al., 1996; Storey and Storey, 2017). Triggered in response to ice nucleation on the skin, adrenergic signals are transmitted to liver and, within minutes, a strong activation of liver glycogen phosphorylase activity can be measured along with rapid glycogenolysis and elevation of plasma and organ glucose levels (Storey and Storey, 1985). Glucose levels are maintained through the freezing period but after thawing glucose is again stored into liver glycogen reserves (Storey and Storey, 1984).

\subsection{Metabolic rate depression in Rana sylvatica}

Animals that endure extreme environmental stresses often rely on metabolic rate depression (MRD) to lower their consumption of stored metabolic fuels and prolong survival time, and R. sylvatica is no exception. For wood frogs, the cessation of vital 
functions in the frozen state (e.g. heart beat, breathing, muscle movement) would be one factor that lowers adenosine triphosphate (ATP) demand and another trigger would be oxygen depletion over time that could trigger hypoxia/anoxia induced MRD (Storey and Storey, 2017). Indeed, studies have demonstrated the accumulation of lactate in tissues of in frozen frogs, pointing towards the use of anaerobic glycolysis as the main ATPgenerating pathway in the frozen state (Storey and Storey, 1984). Furthermore, it has been demonstrated in $R$. sylvatica that levels of $\mathrm{CO}_{2}$ production are drastically reduced as frog body temperature approaches $1{ }^{\circ} \mathrm{C}$, indicating that as body temperature approaches freezing, there is a major suppression of metabolic rate (Sinclair et al., 2013). Coordinated suppression ATP use and ATP synthesis leads to strict regulation of ATP expenditure causing global suppression of energy expensive processes. This signifies that many metabolic processes will be suppressed in order to prioritize vital metabolic processes in the frozen state, and that cellular macromolecules will be preserved and stabilized to reduce the energy expenditure required for maintenance, repair, degradation, or synthesis of these molecules (Storey and Storey, 2004a; Storey, 2015). Additionally, many biomarkers, particularly of cell cycle control, are known to be suppressed in $R$. sylvatica in response to freezing, anoxia, or dehydration, demonstrating the striking similarity of the MRD response to different environmental stresses (Zhang and Storey, 2012). Similarly, irreversible and destructive mechanisms such as apoptosis can also be suppressed as part of MRD (Storey and Storey, 2007; Gerber et al., 2016). Reversible inhibitory controls used during MRD frequently take the form of reversible posttranslational modifications (PTMs) such as protein phosphorylation, and microRNA regulation (Storey, 2015). 


\subsection{Freezing and anoxia in Rana sylvatica}

The wood frog is remarkably stress tolerant; as part of its ability to survive freezing, these frogs also have well-developed capacities for enduring anoxia, dehydration, and hyperglycemia (Storey and Storey, 2017). When freezing, the formation of extracellular ice must be carefully regulated in order to avoid any physical tissue damage and to cope with the drastic osmotic changes and lack of oxygen and nutrients when blood freezes (Storey and Storey, 2001). As such, ice nucleation is triggered just slightly below $0^{\circ} \mathrm{C}$ and this leads to a slow progression of ice formation throughout the body (Costanzo and Lee, 1996; Storey and Storey, 2001). The formation of extracellular ice causes drastic osmotic changes as solutes remain in the cell. This not only induces osmotic stress, but also a reduction in cell volume, causing dehydration. Additionally, all vital functions, such as heartbeat, breathing, and muscle movement cease, which results in anoxia and ischemia (Storey and Storey, 2017). The experience of freezing, anoxia, and dehydration during the winter months signifies that the wood frog is in need of tight regulation of metabolic processes and cryoprotectants in order to survive.

As previously discussed, $R$. sylvatica uses glucose as its main colligative cryoprotectant during the winter months. They carefully regulate glucose levels from $5 \mathrm{mM}$ under normal conditions to as high as $300 \mathrm{mM}$ during freezing in order to minimize cell volume reduction that occurs due to the formation of extracellular ice (Layne Jr. et al., 1996; Storey and Storey 2001, Storey and Storey, 2017). Additionally, glucose can help stabilize proteins when the frog is frozen, and does not interfere with the enzymatic activity of glycolytic or other enzymes (Storey and Storey, 2004a). R. sylvatica 
accumulates glycogen over the summer/autumn and, in response to a freezing signal, rapidly convert their liver glycogen to glucose through glycogenolysis in the liver. In addition to glucose regulation, the liver helps to regulate glucose delivery to other organs and tissues as well by exporting glucose into the bloodstream to be distributed to all tissues before freezing halts blood flow (Storey and Storey, 1984; Costanzo et al., 1993). Although all organs and tissues do require glucose as a cryoprotectant during freezing, the propagation of glucose from the body core outwards when freezing occurs causes a differential glucose gradient to be observed between tissues. As such, internal organs and the brain have much higher concentrations of glucose than peripheral tissues such as skeletal muscle and skin during freezing (Storey and Storey, 1988; Storey and Storey 2001). Furthermore, this differential glucose gradient is part of reason that the peripheral tissues to freeze first due to blood flow being cut off, whereas internal organs, such as liver and heart (with high levels of glucose) are the last to freeze. Interestingly, thawing is equally as tightly regulated as it has also been shown that this glucose gradient causes peripheral tissues to thaw after the heart and liver (Rubinsky et al., 1994). To a lesser extent, urea is also used as a cryoprotectant, as it is also increases during freezing and aids in cellular osmotic regulation. However, urea synthesis is very energy costly as it requires ATP in addition to mitochondrial activity, making it less efficient and harder to synthesize in comparison to glucose under freezing conditions (Storey and Storey, 2017). When thawing, the wood frog will reduce glucose levels at a much slower rate than glucose synthesis, and are able to reabsorb glucose through their bladder and convert it back to glycogen for any subsequent freeze-thaw cycles (Storey and Storey, 1986; Costanzo et al., 1997). 
As previously introduced, as freezing progresses vital functions such as heart beat, breathing and blood circulation come to a halt. As a result, tissues experience ischemia and anoxia (Storey and Storey, 2017). The wood frog will have relied on anaerobic glycolysis in order to produce ATP and adapt to minimize acidosis from anaerobic metabolism while enduring prolonged stress. As such, there are adaptations of cellular metabolism in order to facilitate anaerobic survival under anoxia. In addition to being an important cryoprotectant, glucose (or glycogen) also becomes the main carbohydrate source during anoxia and so control over glycolysis is important. Many glycolytic enzymes undergo reversible phosphorylation, predominantly seen in wood frog liver as it is the main regulator and storage site of carbohydrates (Storey and Storey, 2004b; Storey and Storey, 2017). Additionally, recent studies have shown that many of these glycolytic enzymes, specifically phosphofructokinase 2, pyruvate kinase, and pyruvate dehydrogenase have anoxia and tissue specific regulation in order to facilitate prolonged anaerobic glycolysis (Al-attar et al., 2019; Hawkins et al., 2019). Lactate, the end product of anaerobic glycolysis, will lead to cellular acidosis upon accumulation. Hence, one way to minimize acidosis during long term freezing is to have an alternate fate for pyruvate, such as transamination to form alanine; indeed, both lactate and alanine accumulate in wood frog tissues during freezing (Storey and Storey, 2004b).

\subsection{Reactive oxygen species (ROS)}

As the main contributor to ATP production under most circumstances, mitochondria reduce oxygen to form water as the end product of the electron transport chain (ETC) that is coupled with oxidative phosphorylation to generate ATP. However, 
not all oxygen molecules are fully reduced, and oxygen byproducts can form what is known as reactive oxygen species (ROS) (Slimen et al., 2014). These endogenous ROS can be damaging to cellular macromolecules (including proteins, lipids and DNA) and hence organisms maintain antioxidant defences to destroy ROS. Additionally, ROS have been shown to be important in signal transduction and apoptosis signalling (Finkel, 2011; Schieber and Chandel, 2014). Production of endogenous ROS through cellular oxidative metabolism is not the sole method in which ROS can accumulate. Ionizing radiation, xenobiotics, and other exogenous environmental stressors can also trigger ROS production (Srinivas et al., 2018).

ROS are generally categorized into free radicals (which contain unpaired electrons) and non-radicals (typically formed by two radicals). Hydrogen peroxide $\left(\mathrm{H}_{2} \mathrm{O}_{2}\right)$, superoxide radicals $\left(\mathrm{O}_{2}{ }^{-}\right)$, and hydroxyl radicals $(\cdot \mathrm{OH})$ are three main ROS of biological significance known to cause oxidative damage if not neutralized (Birben et al., 2012). Superoxide can act as a reducing or oxidizing agent, and react with lipids, proteins, and DNA at a biologically insignificant rate. However, the dismutation of $\mathrm{O}_{2}{ }^{-}$ is the main source of endogenous $\mathrm{H}_{2} \mathrm{O}_{2}$, another prominent ROS. $\mathrm{H}_{2} \mathrm{O}_{2}$ has a much higher stability in comparison to $\mathrm{O}_{2}{ }^{--}$which allows it to move from the mitochondria into other cellular compartments, such as the nuclei, making it a more biologically relevant and dangerous ROS (Hermes-Lima, 2004). What makes $\mathrm{H}_{2} \mathrm{O}_{2}$ a more dangerous ROS is its conversion to $\bullet \mathrm{OH}$ upon homolysis or upon interacting with metals such as $\mathrm{Fe}^{2+}$ and $\mathrm{Cu}^{+}$. The hydroxyl radical is the most highly reactive ROS and has the potential to oxidize lipids, proteins, DNA, RNA, and carbohydrates (Hermes-Lima, 2004). ROS implicated oxidative damage can be detrimental and has been linked to many diseases and 
pathologies such as cancer, neurodegenerative diseases, diabetes, cardiovascular diseases, and many other aging related diseases (Hermes-Lima, 2004; Balaban et al., 2005; Ray et al., 2012). It is therefore imperative for organisms to be able to have the necessary antioxidant defences to be able to neutralize ROS to negate and minimize potential oxidative damage.

\subsection{Antioxidant capacity}

Since $R$. sylvatica is vulnerable to oxidative damage from ROS due to rapid changes in oxygen availability during freeze/thaw, its antioxidant defence system will be critical in preventing damage. As previously mentioned, ROS are harmful, as they can cause oxidative damage to many biological macromolecules. Studies have demonstrated that the inclusion and accumulation of antioxidant defences prior to freezing allows cells and tissues to have improved viability during thawing, demonstrating the importance of antioxidant defences in survival through the freeze-thaw cycle (Hermes-Lima et al., 2001). Animals have endogenous enzymatic antioxidant defences, such as catalase, superoxide dismutase (SOD), glutathione dependant enzymes (e.g. glutathione peroxidases (GPx), glutathione reductase (GR), and glutathione transferases (GSTs)) thioredoxin, thioredoxin reductase, and peroxisomes, among others, that work to reduce ROS and prevent oxidative stress (Hermes-Lima and Zenteno-Savín, 2002; Elias et al., 2008). Studies have demonstrated that the enzymatic antioxidants such as catalase, GR, and GPx show increased activity and phosphorylation as well as differential regulation during freezing in $R$. sylvatica to account for the increased threat of ROS (Joanisse and Storey, 1996; Dawson and Storey, 2016; Dawson and Storey, 2017). These studies have 
demonstrated the importance of enzymatic antioxidant defences in $R$. sylvatica during the freeze-thaw cycle to prevent oxidative damage.

Additionally there are non-enzymatic factors, such as ascorbic acid, vitamin E, glutathione, bilirubin, uric acid, etc. that also work in an antioxidant capacity to detoxify ROS in order to mitigate oxidative stress (Hermes-Lima and Zenteno-Savín, 2002; Wahlqvist, 2013). Ascorbic acid is endogenously made from glucose in $R$. sylvatica and is an important non-enzymatic antioxidant factor as it can neutralize $\mathrm{O}_{2}{ }^{-}, \cdot \mathrm{OH}$, singlet oxygen, and other known ROS to prevent oxidative damage of lipids, proteins, and DNA (Hermes-Lima, 2004). Ascorbic acid also has the ability to regenerate vitamin E and uric acid, further demonstrating its biological importance (Chan, 1993; Hermes-Lima 2004). Vitamin $\mathrm{E}$ is a prominent non-enzymatic antioxidant factor that cannot be endogenously made which signifies it must be obtained through diet. Vitamin E has eight known isoforms and scavenges for ROS, and is mainly attributed in the prevention of lipid peroxidation (Hermes-Lima, 2004; Niki, 2014). Although glutathione has a major role in antioxidant enzymatic activity, it also has non-enzymatic antioxidant capacity and can neutralize singlet oxygen, $\bullet \mathrm{OH}$, reactive nitrogen species (which also lead to oxidative stress), and other ROS. Glutathione is also involved in ascorbate metabolism, adding to its diverse roles (Hermes-Lima, 2004). Bilirubin is also a non-enzymatic antioxidant factor that is known to scavenge peroxyl radicals and prevent lipid peroxidation (Stocker et al., 1987). Uric acid is another major non-enzymatic antioxidant factor that is able to scavenge and neutralize many ROS and other free radicals such as $\mathrm{H}_{2} \mathrm{O}_{2}$ to prevent lipid peroxidation (Hermes-Lima 2004; Sautin and Johnson, 2008). There are many more endogenous and exogenous non-enzymatic antioxidant factors that contribute to 
minimizing and regulating ROS levels. The diversity of these non-enzymatic antioxidant factors are crucial in helping with overall antioxidant capacity, and reflect the diversity of ROS and types of oxidative damage organisms can potentially encounter.

\subsection{DNA double stranded break (DSB) repair}

When antioxidant capacity is oversaturated due to excessive rates of ROS production, there is an increased risk for oxidative stress and damage to the organism (Sies, 1986). Although animals can increase enzymatic antioxidants to deal with increased rates of ROS production (Hermes-Lima and Zenteno-Savín, 2002), oxidative damage can still occur to lipids, proteins, and DNA when levels oversaturate antioxidant capacity. Oxidative damage to DNA is particularly consequential, as it can lead to base pair modifications and DNA breaks that cause genomic instability (Hermes-Lima, 2004; Alnajjar and Sweasy, 2019). For example, oxidative damage to DNA is known to contribute to carcinogenesis and many aging-related diseases. Additionally, there are a plethora of base pair modifications and DNA breaks that are possible upon exposure to ROS, adding to the complexity of the consequences that can arise (Hermes-Lima, 2004). Damage or modification to base pairs can be repaired in three ways: by nucleotide excision repair (NER), base excision repair (BER), or mismatch repair (MMR). The general principle of these repair pathways is to identify damage or modification to base pairs, excise the identified base pairs, insert the correct base pairs, and ligate the corrected area of the strand (Friedberg, 2003). Oxidative damage in the form of DNA breaks can cause either single stranded breaks (SSB) or double stranded breaks (DSB). DSB are particularly threatening as they can lead to chromosomal discontinuity if left 
unrepaired. Additionally, there is a high risk of mutations and chromosomal rearrangement if DSB are not repaired correctly (Cannan and Pederson, 2016). As such, there are repair mechanisms for DSB that are imperative for maintaining genomic stability, and are important amid the experience of oxidative stress, especially when antioxidant defences are overwhelmed.

The two main pathways of DSB repair are non-homologous end joining (NHEJ) and homologous recombination (HR). Both these repair pathways include identifying DSB, having nuclease and polymerase activity to correct the damage, and having proteins that ligate the two strands of DNA back together (Friedberg, 2003). NHEJ is the most commonly chosen repair pathway and works by essentially rejoining the two broken strands of DNA at the DSB (Friedberg, 2003; Chang et al., 2017). In NHEJ, the Ku heterodimer, formed by Ku70 and Ku80, mark the site of the DSB, stabilize the broken ends, act as a scaffold for subsequent repair proteins, and recruit proteins involved in the pathway, namely the DNA-dependent protein kinase, catalytic subunit (DNA-PKcs), a protein kinase that can activate signaling transduction of DSB repair (Chang et al., 2017). Additionally, the Mre11-Rad50-Nsb1/p-95 complex (MRN complex) is another important protein complex involved in identifying double-stranded breaks, tethering and stabilizing broken ends, and signaling ataxia telangiectasia mutated (ATM), one of the main protein kinases that signals and activates DSB repair (Lamarche et al., 2010). ATM can be phosphorylated by DNA-PKcs in attempt to regulate the choice of DSB repair pathway (NHEJ or HR), showing the interaction between protein kinases and their ability to help direct the repair pathway choice (Chang et al., 2017). 
After the broken strands are identified and tethered, the repair can occur. If the area of the DSB contains any mismatched or damaged nucleotides, end processing must take place to repair the nucleotides. There are nucleases that are activated in order to resect the mismatched or damaged nucleotides. The main nuclease activity in NHEJ is found through DNA-PKcs (previously activated by the Ku heterodimer) activating Artemis, an endonuclease which then removes the nucleotides (Ma et al., 2005; Chang et al., 2017). There are many other proteins that may have nuclease activity at this point, including the MRN complex, however these nucleases have not been well characterized in the context of NHEJ, and the activity of DNA-PKcs and Artemis have been shown to be the primary source of nucleation (Lamarche et al., 2010; Chang et al., 2017). When the mismatched or damaged area is removed, polymerases then add in correct nucleotides. In the context of NHEJ, this is mainly attributed to DNA polymerase $\mu$ and DNA polymerase $\lambda$ (Chang et al., 2017). When the repair is finished, ligation then must take place to join the broken ends. Ligation is completed through the interaction of DNA Ligase IV, X-ray repair cross-complementing protein 4 (XRCC4), and XRCC4-like factor (XLF) (Koch et al., 2004; Chang et al., 2017).

As previously mentioned, homologous recombination (HR) is the other main repair pathway for DSB. The basis of HR in the context of DSB repair is to use an undamaged template strand to be able to determine the correct nucleotides needed in order to correctly reconstruct the DSB (Mao et al., 2008). This method of repair based on a template sequence allows for an extremely accurate repair since HR requires a template strand from the sister chromatid and therefore can only occur during the S and G2 phases of the cell cycle (Arnoult et al., 2017). HR begins with the MRN complex marking the 
DSB and initiating end resection through recruiting and working in tandem with CtIP (Jasin and Rothstein, 2013). After initial end resection, slow growth suppressor 1 (Sgs1), a helicase, works to unwind the DNA at the break, and exonuclease 1(Exo1) is a nuclease that cuts the unwound single stranded DNA (ssDNA) (Mimitou and Symington, 2008). Filament formation and pairing then occurs by binding of Rad51 onto ssDNA, with the help of other proteins such as breast cancer type 1 susceptibility protein (BRCA1), Rad52 and other Rad51 paralog proteins, to form a nucleoprotein and initiate strand invasion to form what is known as a D-loop (Suwaki et al., 2011; Jasin and Rothstein, 2013). The newly formed nucleoprotein has the critical role of aligning with the homologous DNA strand that acts as a template for repair (Suwaki et al., 2011). After strand invasion, Rad52 then promotes strand exchange through the formation of the Holliday junction. Subsequent migration and resolution of the Holliday junction is regulated by Rad54, GEN1, and SLX1/4. The resolution of the Holliday junction can cause exchange of information from the opposite strand and results in the repaired DSB having a crossover or non-crossover sequence (Suwaki et al., 2011; Grabarz et al., 2012).

There are still many studies aimed at determining details of the exact mechanisms of both NHEJ and HR, the interactions between both DSB repair pathways, and the regulation of repair pathway choice. HR is known to be the more accurate and reliable method of repair due to its dependence on the homologous strand for repair. By contrast, is has been shown that there is a risk of mutations through NHEJ since this pathway of DSB repair works to ligate broken ends with no analysis of homology (Mao et al., 2008). However, NHEJ is by far the more dominant pathway of DSB repair since it is efficient and much faster than HR, and unlike HR, can occur during any point of the cell cycle 
(Rothkamm et al., 2003; Mao et al., 2008). This present study thesis aims to characterize non-enzymatic antioxidant capacity and DNA DSB repair in $R$. sylvatica tissues under freezing and anoxia stresses.

\subsection{Hypothesis and objectives}

Hypothesis: Oxidative damage to the genome in the wood frog is minimized through both stress specific and tissue specific regulation of antioxidant defences and DNA DSB repair pathways.

Since $R$. sylvatica endures freezing and anoxia stresses while preserving complete cellular viability, this implies that the frog is able to maintain genomic integrity amid these stresses. Previous studies have demonstrated that each tissue has a unique role that leads to tissue specific regulation of many pathways through stress and recovery. Additionally, studies have demonstrated stress-specific responses in many pathways in $R$. sylvatica. Therefore, this thesis aims to test this hypothesis by examining genomic integrity through measurements of DNA oxidative damage, total antioxidant capacity, and protein markers of DSB repair.

In order to test this hypothesis, Chapter $\mathbf{3}$ analyzes the relative expression of oxidized guanine species as a measure of DNA oxidative damage occurring over the freeze-thaw cycle in the liver and skeletal muscle of wood frogs. Total relative antioxidant capacity of these two tissues is assessed to determine if oxidative damage is

minimized through non-enzymatic antioxidant responses. Additionally, the expression of eight prominent NHEJ and HR protein markers (Mre11, Rad50, phospho-p95, DNA 
Ligase IV, XRCC4, XLF, Ku70, and Rad51) are quantified to determine the involvement of DNA DSB repair responses in liver and skeletal muscle during freeze-thaw. Chapter 4 further tests the hypothesis by analyzing how these same parameters (DNA damage, total antioxidant capacity, DSB repair markers) respond to the related stress of an anoxiareoxygenation cycle in the two tissues. Anoxia-reoxygenation is well known to generate oxidative damage and modulate antioxidant defenses in many species. A comparison of freeze versus anoxia responses could suggest the origin of DNA damage and antioxidant responses to freezing and determine if freezing initiates unique adaptive responses. 


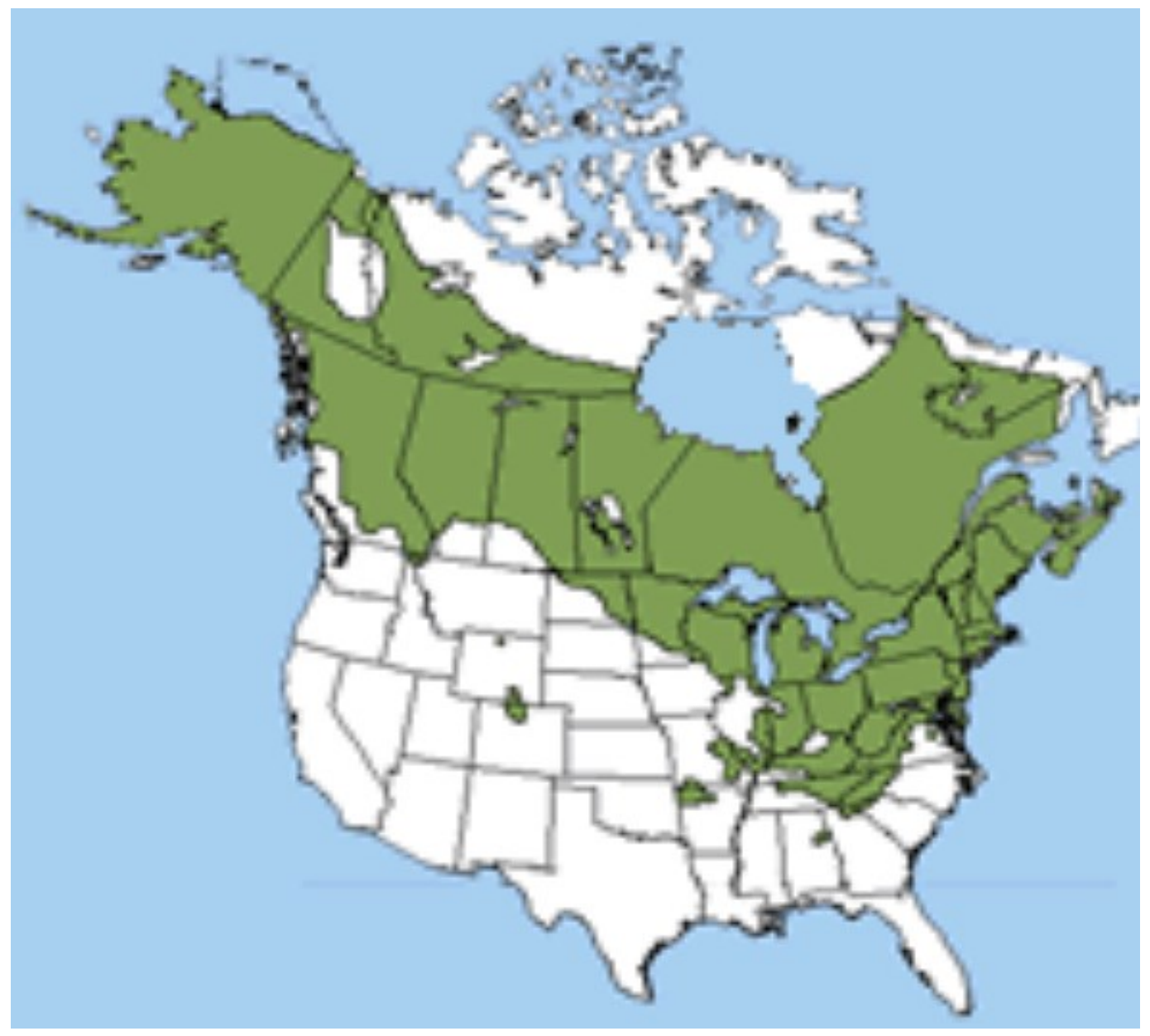

Figure 1.1 Geographical range of the wood frog, Rana sylvatica.

(Image retrieved from https://nhpbs.org/wild/woodfrog.asp) 


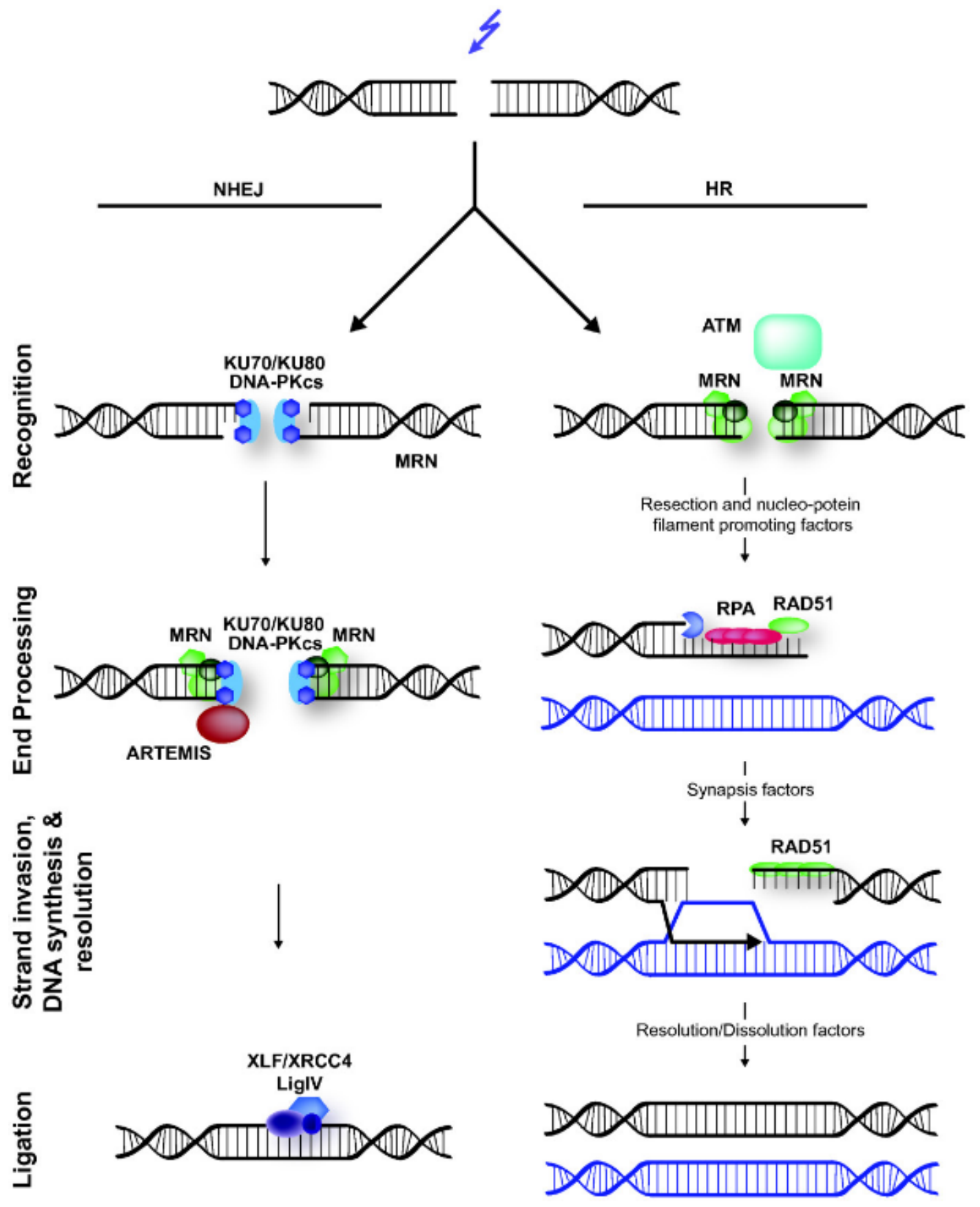

Figure 1.2 The non-homologous end joining (NHEJ) and homologous recombination (HR) pathways of double stranded break (DSB) repair (Lans et al., 2012). 


\section{Chapter 2}

\section{Materials and Methods}




\subsection{Animal experiments}

Adult male wood frogs (Rana sylvatica) were collected during springtime from breeding ponds in the Ottawa region and transported to Carleton University on ice. All frogs were treated in a tetracycline bath for $\sim 10 \mathrm{~min}$ and subsequently placed in plastic containers lined with damp sphagnum moss. Frogs were then acclimated at $5^{\circ} \mathrm{C}$ for a two week period before use. Control frogs were sampled from this condition, euthanized by pithing, and then tissues were rapidly dissected and immediately flash frozen in liquid nitrogen and stored at $-80^{\circ} \mathrm{C}$ for future use.

For freezing exposure, a subset of frogs were placed in plastic containers lined with damp paper towels and placed in an incubator at $-4^{\circ} \mathrm{C}$ for 45 minutes to lower their temperature below the supercooling point of body fluids and trigger freezing. After this initial cooling period, the temperature of the incubator was raised to $-2.5^{\circ} \mathrm{C}$ for 24 hours and then half of the frozen frogs were sampled at random as the frozen condition. The rest of the frogs were then returned to an incubator at $5^{\circ} \mathrm{C}$ for 8 hours before sampling as the thawed condition. Euthanasia and tissue sampling were as described above for controls.

For anoxia exposure, the following setup was used. A beaker of distilled water was bubbled with $100 \%$ nitrogen gas for 30 minutes and then small amounts were used to dampen paper towels that were used as the lining for plastic jars to hold the frogs. After securing the lid, $100 \%$ nitrogen gas was flushed into the jars for approximately $15-20$ minutes while the jars sat in crushed ice. Groups of 5-6 frogs that had been previously acclimated at $5^{\circ} \mathrm{C}$ were then placed into each container and then lids were sealed with parafilm. The lid to each container had two openings, one to allow nitrogen gas to enter 
and the other to vent out of the container. Jars were flushed with nitrogen gas for a further 30 minutes, then the vents were closed and the containers were returned to a $5^{\circ} \mathrm{C}$ incubator for 24 hours. After 24 hours, half the frogs were sampled as the anoxia group. To do this, jars were returned to a crushed ice bath, flushing with nitrogen gas was reinstated and then frogs were very quickly sampled to minimize exposure to air. The remaining frogs were transferred to new plastic chambers (with room air), and incubated at $5^{\circ} \mathrm{C}$ for 4 hours to allow for recovery from their anoxia exposure. Euthanasia and tissue sampling were as described above for controls.

All animal care and experimentation protocols had the approval of the Carleton University Animal Care Committee and followed guidelines of the Canadian Council of Animal Care.

\subsection{Total soluble protein extraction}

Total soluble protein was extracted from liver and leg skeletal muscle samples of control, 24 hour frozen, 8 hour thaw, 24 hour anoxia, and 4 hour recovery conditions. Liver and skeletal muscle samples ( $\mathrm{n}=4$ independent biological replicates) were weighed, then crushed with a mortar and pestle under liquid nitrogen, and homogenized 1:2 w:v using a Polytron homogenizer and ice-cold homogenization buffer: $20 \mathrm{mM}$ HEPES pH 7.4, $100 \mathrm{mM} \mathrm{NaCl}, 0.1 \mathrm{mM}$ EDTA, $10 \mathrm{mM} \mathrm{NaF}, 1.0 \mathrm{mM} \mathrm{Na} 3 \mathrm{VO}_{4}, 10 \mathrm{mM} \beta-$ glycerophosphate, with a few crystals of phenylmethylsulfonyl fluoride (PMSF) and 1.0 $\mu \mathrm{L} / \mathrm{mL}$ of protease inhibitor cocktail (BioShop Canada Inc., Burlington, ON, Canada; Catalogue \# PIC002) added immediately before homogenizing. Homogenates were then 
centrifuged at $10,000 \mathrm{x}$ g for 15 minutes at $4^{\circ} \mathrm{C}$, and the supernatants containing soluble proteins were collected.

Quantification of protein concentration in each sample was performed using the BioRad prepared protein assay (BioRad Laboratories, Hercules, CA, USA; Catalogue \# 5000006) and color development was read at 595nm on a MR5000 microplate reader (Dynatech Laboratories, Chantilly, VA, USA). All liver and control skeletal muscle protein concentrations were then standardized to a final concentration of $10 \mu \mathrm{g} / \mu \mathrm{L}$ by adding small aliquots of the aforementioned homogenization buffer. For samples from 24 hour frozen, 8 hour thaw, 24 hour anoxic, and 4 hour recovery skeletal muscle, protein concentrations were standardized to $5 \mu \mathrm{g} / \mu \mathrm{L}$ using homogenization buffer. Standardized protein extract samples were then mixed 1:1 v/v with SDS buffer (pH 6.8) containing 100 $\mathrm{mM}$ Tris- $\mathrm{HCl}, 4 \% \mathrm{w} / \mathrm{v}$ SDS, $20 \% \mathrm{v} / \mathrm{v}$ glycerol, $0.2 \% \mathrm{w} / \mathrm{v}$ bromophenol blue, and $10 \%$ $\mathrm{v} / \mathrm{v} \beta$-mercaptoethanol. All liver and control skeletal muscle samples had a final concentration of $5 \mu \mathrm{g} / \mu \mathrm{L}$, and 24 hour frozen, 8 hour thaw, 24 hour anoxic, and 4 hour recovery skeletal muscle samples had a final concentration of $2.5 \mu \mathrm{g} / \mu \mathrm{L}$. All samples were boiled for 5-10 minutes, cooled on ice for $\sim 5$ minutes to allow for denaturation and linearization of proteins, and then stored at $-40^{\circ} \mathrm{C}$ until use.

\subsection{Western blotting}

Sodium dodecyl sulfate polyacrylamide gel electrophoresis (SDS-PAGE) was carried out on all liver and skeletal muscle samples by loading equal amounts (25-50 $\mu \mathrm{g})$ 
of total protein into wells on SDS-polyacrylamide gels. A lane containing 5-7 $\mu \mathrm{L}$ of PiNK Plus pre-stained protein ladder (10.5 - 175 kDa; FroggaBio, Toronto, ON, Canada, Catalogue \# PM005-0500K) or BLUeye pre-stained protein ladder (10-245 kDa; FroggaBio, Toronto, ON, Canada, Catalogue \# PM007-0500) was also loaded as the first lane on each gel for protein size reference, along with a second lane loaded with $4 \mu \mathrm{L}$ of a positive control sample of either a liver or skeletal muscle extract from 13-lined ground squirrels. The discontinuous SDS-polyacrylamide gels were composed of an upper stacking gel containing Tris buffer $\mathrm{pH} 6.8,4 \% \mathrm{v} / \mathrm{v}$ acrylamide, $0.1 \% \mathrm{w} / \mathrm{v}$ SDS, $0.1 \% \mathrm{w} / \mathrm{v}$ ammonium persulfate (APS), and 0.1\% N,N,N',N'-Tetramethylethane-1,2-diamine (TEMED), and a lower resolving gel containing Tris buffer $\mathrm{pH} 8.8,6-12 \%$ acrylamide $\mathrm{v} / \mathrm{v}$ (depending on the molecular weight of the target protein), $0.1 \% \mathrm{w} / \mathrm{v}$ SDS, $0.1 \% \mathrm{w} / \mathrm{v}$ APS, and $0.1 \% \mathrm{v} / \mathrm{v}$ TEMED. Using a BioRad Mini Protean III system (BioRad Laboratories, Hercules, CA, USA), SDS-PAGE was then carried out at $180 \mathrm{~V}$ for $45-200$ minutes in 1X Tris-glycine SDS running buffer containing $25 \mathrm{mM}$ Tris-base, $190 \mathrm{mM}$ glycine, and $0.1 \% \mathrm{w} / \mathrm{v}$ SDS, $\mathrm{pH} 8.3-8.5$. Resolved gels were then transferred onto a 0.45 $\mu \mathrm{m}$ pore polyvinylidene difluoride (PVDF) membrane (Millipore, Etobicoke, ON, Canada, Catalogue \#IPVH00010) by electroblotting with transfer buffer (containing 25 $\mathrm{mM}$ Tris-base, $192 \mathrm{mM}$ glycine and 10\% v/v methanol, $\mathrm{pH} 8.5$ ) for $90-950$ minutes.

Transferred PVDF membranes were then washed and equilibrated in Trisbuffered saline with Tween-20 (TBST) containing $20 \mathrm{mM}$ Tris-base, $140 \mathrm{mM} \mathrm{NaCl}$, and $0.05 \% \mathrm{v} / \mathrm{v}$ Tween-20, $\mathrm{pH} 7.6$ for 5 minutes and subsequently blocked with $2-6 \%$ milk dissolved in TBST for or left unblocked in TBST for 30 minutes at room temperature. PVDF membranes were washed three times in TBST for 5 minutes, and then incubated 
with the primary antibody of interest, diluted at $1: 1000 \mathrm{v} / \mathrm{v}$ in TBST overnight or for two nights at $4^{\circ} \mathrm{C}$. Following incubation, PVDF membranes were washed three times in TBST for 5 minutes, and then incubated with 1:6000 or 1:7000 diluted horseradish peroxidase (HPR)-conjugated anti-rabbit secondary antibody (BioShop Canada Inc., Burlington, ON, Canada; Catalogue \#APA007.2) for 30 minutes at room temperature, followed by washing three times in TBST for 5 minutes. Membranes were then visualized by chemiluminescence using $600 \mu \mathrm{L}$ of hydrogen peroxide and $600 \mu \mathrm{L}$ of luminol, and subsequently imaged using a ChemiGenius Bioimaging System (Syngene, Frederick, MD, USA). After imaging, PVDF membranes were stained with Coomassie blue $(0.25 \% \mathrm{w} / \mathrm{v}$ Coomassie brilliant blue, $7.5 \%$ acetic acid, $50 \%$ methanol) and then a group of blue bands that was present and common in each lane but were not close to the target band of interest were imaged and used for standardization. The immunoblot band density was then expressed relative to the combined density of the group of Coomassie stained bands in the same lane. Analysis of band intensities was then completed using Gene Tools software (Syngene, Frederick, MD, USA) including standardizing the immunoreactive bands in each lane against the corresponding Coomassie stained image. Statistical analysis was completed using RBioPlot (Zhang and Storey, 2016).

\subsection{Total DNA extraction}

Total DNA extraction was completed using an extraction kit (Zymo Research, Irvine, CA, USA; Catalogue\# D4068). All buffers, reagents, columns, and collection tubes used during DNA extraction were provided in the kit. Samples (25-38 mg) of liver and skeletal muscle tissues from control, 24 hour frozen, 8 hour thaw, 24 hour anoxic, or 
4 hour recovery conditions were weighed and put into microcentrifuge tubes. Aliquots of $95 \mu \mathrm{L}$ distilled water, $95 \mu \mathrm{L}$ solid tissue buffer, and $10 \mu \mathrm{L}$ of Proteinase $\mathrm{K}$ were then added to each tube and then samples were incubated at $55^{\circ} \mathrm{C}$ for $\sim 20$ hours in an incubator. They were then centrifuged at $12000 \mathrm{xg}$ for one minute to remove any insoluble debris and subsequently transferred to a clean microcentrifuge tube. A $400 \mu \mathrm{L}$ aliquot of genomic binding buffer was then added to each supernatant and mixed. The mixture was then layered onto a column placed in a collection tube, and centrifuged at 12 000xg for one minute, after which these collection tubes were discarded and replaced with new tubes. DNA pre-wash buffer $(400 \mu \mathrm{L})$ was then added to each column followed by centrifugation at $12000 \mathrm{xg}$ for one minute, and then removal of the eluate from the collection tube. A $700 \mu \mathrm{L}$ aliquot of g-DNA wash buffer was then added to each column and centrifuged again at $12000 \times \mathrm{xg}$ for one minute, and the contents in the collection tube were emptied. A final $200 \mu \mathrm{L}$ of g-DNA wash buffer was then added to the column and centrifuged at $12000 \mathrm{xg}$ for one minute, at which point the contents in the collection tube were discarded. Next, $50 \mu \mathrm{L}$ of DNA elution buffer was added to the column in a clean microcentrifuge tube and incubated for five minutes at room temperature to allow for DNA elution. The samples were then centrifuged a final time at $12000 \mathrm{xg}$ for one minute. All samples were then stored at $-40^{\circ} \mathrm{C}$ until use.

\subsection{DNA Damage ELISA Kit}

A DNA/RNA Oxidative Damage ELISA kit (Cayman Chemical, Ann Arbor, MI, USA; Catalogue \#589320) was used to assess stress-induced oxidative damage to liver and skeletal muscle tissues. This assay is an acetylcholinesterase competitive ELISA that 
measures the three forms of oxidized guanine species (8-hydroxy-2'-deoxyguanosine from DNA, 8-hydroxyguanine from DNA or RNA, and 8-hydroxyguanosine from RNA) by detecting the binding of the oxidatively damaged guanine in competition with an 8 $\mathrm{OH}-\mathrm{dG}-\mathrm{acetylcholinesterase}$ conjugate. All buffers and reagents used during the assay were provided in the kit by the manufacturer. DNA extraction from liver and skeletal muscle tissues was performed as described in Chapter 2.4, and DNA concentrations were determined using a Take 3 Micro Volume Plate (Biotek Intruments Inc., Winooski, VT, USA). DNA concentrations in liver and skeletal muscle DNA extracts were normalized to 15 and $14 \mu \mathrm{g} / \mu \mathrm{L}$, respectively, through the addition of small volumes of ELISA buffer that varied depending on the original sample concentration. Nuclease $\mathrm{p} 1$ $(1 \mu \mathrm{L})$ (Sigma-Aldrich, St. Louis, MO, USA; Catalogue\# N8630-IVL) was added to all samples and then samples were incubated at $55^{\circ} \mathrm{C}$ for one hour in a thermocycler (Eppendorf, Hamburg, Germany; Catalogue\# 6335000020). Subsequently, alkaline phosphatase (New England BioLabs, Ipswich, MA, USA; Catalogue\# M0290S) was added to the samples followed by a further incubation in the thermocycler at $37^{\circ} \mathrm{C}$ for 30 minutes.

In order to validate results, the kit-supplied microplate contained a blank well, a non-specific binding well (containing $100 \mu \mathrm{L}$ of ELISA buffer and $50 \mu \mathrm{L}$ of DNA/RNA Oxidative Damage AChE Tracer), a maximum binding well (containing $50 \mu \mathrm{L}$ of ELISA buffer, $50 \mu \mathrm{L}$ of DNA/RNA Oxidative Damage AChE tracer, and $50 \mu \mathrm{L}$ of DNA/RNA Oxidative Damage ELISA Monoclonal Antibody), and a final total activity well (containing $5 \mu \mathrm{L}$ of DNA/RNA Oxidative Damage AChE Tracer added after incubation of the plate). A set of standards diluted to $3000 \mathrm{pg} / \mathrm{mL}, 1333 \mathrm{pg} / \mathrm{mL}, 592.6 \mathrm{pg} / \mathrm{mL}, 263.4$ 
$\mathrm{pg} / \mathrm{mL}, 117.1 \mathrm{pg} / \mathrm{mL}, 52.0 \mathrm{pg} / \mathrm{mL}, 23.1 \mathrm{pg} / \mathrm{mL}$, and $10.3 \mathrm{pg} / \mathrm{mL}$ were prepared, and 50 $\mu \mathrm{L}$ of each dilution was added to each standard well, followed by $50 \mu \mathrm{L}$ of DNA/RNA Oxidative Damage AChE Tracer, and $50 \mu \mathrm{L}$ of DNA/RNA Oxidative Damage ELISA Monoclonal Antibody. Sample wells were prepared by addition of $50 \mu \mathrm{L}$ aliquots of the liver or skeletal muscle samples, followed by $50 \mu \mathrm{L}$ of DNA/RNA Oxidative Damage AChE Tracer, and $50 \mu \mathrm{L}$ of DNA/RNA Oxidative Damage ELISA Monoclonal Antibody. The microplate was then covered with a plastic film and incubated at $4^{\circ} \mathrm{C}$ for 18 hours.

After incubation, the wells in the microplate were emptied and rinsed five times with wash buffer. Then, $200 \mu \mathrm{L}$ of Ellman's Reagent was added to each well, and $5 \mu \mathrm{L}$ of DNA/RNA Oxidative Damage AChE Tracer was also added to the total activity well. The plate was then covered with a plastic film, wrapped in aluminum foil, and incubated on an orbital shaker for 90 minutes. After development, the plate was then read on a MR5000 microplate reader (Dynatech Laboratories, Chantilly, VA, USA) at $412 \mathrm{~nm}$. In accordance with the instructions provided by the manufacturer, the analysis of the data was carried out by plotting a standard curve based on the following equation:

$$
\operatorname{logit}\left(\frac{\mathrm{B}}{\mathrm{B}_{0}}\right)=\ln \left[\frac{\mathrm{B}}{\mathrm{B}_{0}} /\left(1-\frac{\mathrm{B}}{\mathrm{B}_{0}}\right)\right]
$$

The expression of oxidized guanine species in each sample was then determined based on the standard curve. 


\subsection{Antioxidant Capacity Kit}

In order to determine total antioxidant capacity, an antioxidant assay kit (Cayman Chemical, Ann Arbor, MI, USA; Catalogue \#709001) was utilized to assess liver and skeletal muscle tissues. This assay measures the total combined capacity of known antioxidant constituents (such as vitamin, proteins, lipids, glutathione, uric acid, etc) by detecting the ability of antioxidant constituents to inhibit the oxidation of ABTS $(2,2$ 'Azino-di-3-ethylbenzothiazoline sulphonate) to $\mathrm{ABTS}^{+}$by metmyoglobin. All buffers and reagents used during the assay were provided in the kit by the manufacturer. Total soluble protein extraction was performed as previously detailed in Chapter 2.2 with the exception of addition of SDS buffer after extraction. Protein concentrations of all samples were determined using the BioRad protein assay (BioRad Laboratories, Hercules, CA, USA; Catalogue \# 5000006) at $595 \mathrm{~nm}$ on a MR5000 microplate reader (Dynatech Laboratories, Chantilly, VA, USA) and then sample protein concentrations were standardized to $1.9 \mu \mathrm{g}$ via addition of $1 \mathrm{x}$ antioxidant assay buffer.

In accordance with the manufacturer's instructions, a standard curve for validation was prepared with dilutions of Trolox ( $0 \mathrm{mM}, 0.045 \mathrm{mM}, 0.090 \mathrm{mM}, 0.135$ $\mathrm{mM}, 0.180 \mathrm{mM}, 0.225 \mathrm{mM}$, and $0.330 \mathrm{mM}$ ) and absorbance readings were measured on a MR5000 microplate reader (Dynatech Laboratories, Chantilly, VA, USA) at $405 \mathrm{~nm}$. Additionally, a dilution curve was performed to determine the optimal protein concentration to use for the assay. A $10 \mu \mathrm{L}$ volume of each sample was then added into the wells, followed by $10 \mu \mathrm{L}$ of metmyoglobin, and $150 \mu \mathrm{L}$ of chromogen. Then $40 \mu \mathrm{L}$ of $441 \mu \mathrm{M}$ hydrogen peroxide was added to each well to initiate the reaction. The microplate was covered and incubated for five minutes at room temperature on a shaker 
and then read on a MR5000 microplate reader (Dynatech Laboratories, Chantilly, VA, USA) at $405 \mathrm{~nm}$. To analyze the results, absorbances of the standards were plotted as a function of the final Trolox concentration, and the antioxidant concentrations in samples were determined using the slope of the equation of the standard substituted into the following equation provided by the manufacturer:

$$
\text { Antioxidant }(\mathrm{mM})=\left[\frac{(\text { sample absorbance })-(\mathrm{y}-\text { intercept })}{\text { slope }}\right] \times \text { dilution }
$$

\subsection{Statistics}

For western blotting, statistical analysis was performed on the data obtained $(n=3-4$ independent biological replicates) to assess differences in relative protein expression between the different experimental conditions. This was completed by performing a oneway ANOVA with a Tukey post-hoc test; using RBioPlot, with $\mathrm{p}<0.05$ accepted as significant (Zhang and Storey, 2016).

Total oxidized guanine species were determined from the standard curve developed based on the equation provided by the kit manufacturer. Statistical analysis assessed relative oxidized guanine species among the different treatment conditions in liver and skeletal muscle ( $\mathrm{n}=3-4$ independent biological replicates) using a one-way ANOVA with a Tukey post-hoc test ( $\mathrm{p}<0.05)$ using RBioPlot (Zhang and Storey, 2016).

Relative total antioxidant capacity was determined using a standard curve in conjunction with the equation provided by the manufacturer in the antioxidant assay kit 
(Cayman Chemical, Ann Arbor, MI, USA; Catalogue \#709001) (see Antioxidant

Capacity Kit). Statistical analysis compared relative total antioxidant capacity among the different conditions in liver and skeletal muscle tissue $(n=3,4$ independent biological replicates) through the use of a one-way ANOVA with a Tukey's post-hoc test $(\mathrm{p}<0.05)$ using RBioPlot (Zhang and Storey, 2016). 


\section{Chapter 3}

\section{DNA Damage, Antioxidant Capacity, and DNA Repair through the Freeze-Thaw \\ Cycle in R. sylvatica}




\subsection{Introduction}

Organisms that live in environments with harsh winters must develop overwintering strategies in order to survive. As discussed in Chapter 1, some animals can evade the winter through migration, or have developed endogenous freeze avoidance strategies that allow them to cool far below $0^{\circ} \mathrm{C}$ without freezing. By contrast, other animals have developed freeze tolerance strategies to endure subzero winter temperatures, and Rana sylvatica is a prime example of a freeze tolerant vertebrate. These frogs are able to endure extended periods of freezing in their winter hibernacula that varies from year to year based on environmental temperature, precluding them from having the ability to predict the length of their frozen state. Given the nature of their freeze tolerance strategy, $R$. sylvatica must also endure the component stresses associated with freezing: anoxia, cellular dehydration, and hyperglycemia while frozen. To aid survival of these stresses, $R$. sylvatica enters an extended state of metabolic rate depression (MRD) (Storey and Storey, 2004a; Storey and Storey, 2017), and because freezing halts blood circulation, the organs of the frog have to switch to anaerobic glycolysis for ATP production. As such, these frogs have incredible adaptations to be able to maintain physiological function and survive across freeze-thaw cycles.

As mentioned in Chapter 1, nature of freeze-thaw cycles increases wood frog vulnerability to reactive oxygen species (ROS) and the oxidative stress and damage caused by ROS. Oxidative damage can take the form of protein oxidation, lipid oxidation, or DNA oxidation (Balaban et al., 2005), and can be extremely harmful if experienced at high levels, which can occur when there are rapid changes in oxygen availability such as when frogs thaw and resume breathing and blood circulation. However, enzymatic and 
non-enzymatic antioxidant defences can prevent and minimize the negative consequences of oxidative damage (Hermes-Lima and Zenteno-Savín, 2002). Additionally, DNA repair mechanisms can be put in place to repair oxidative damage to DNA in order to preserve genomic integrity. Since $R$. sylvatica is able to fully recover and be restored to its normal physiological function after thawing, it is apparent that they must be able to avoid excessive oxidative damage to DNA over cycles of freezing and thawing. Therefore, exploring the antioxidant capacity and DNA damage repair mechanisms of wood frogs across the freeze-thaw cycle will provide insight how genomic integrity is maintained amid the threat of oxidative stress.

Many studies of R. sylvatica have demonstrated tissue-specific responses by various metabolic pathways across the freeze-thaw cycle. These differences are attributed to the unique and varying roles that each organ plays in freezing survival. The liver is heavily involved in mediating cryoprotection since it is the main regulator of glucose metabolism. In the context of the freeze-thaw cycle in R. sylvatica, the liver is the site of glycogen storage prior to freezing, and converts glycogen to glucose through glycogenolysis and exports glucose to the rest of the body to be taken up as the main cryoprotectant during freezing. These frogs have been shown to elevate their glucose levels from $5 \mathrm{mM}$ under normal conditions to over $300 \mathrm{mM}$ during whole body freezing (Storey and Storey, 1984; Costanzo et al., 1993; Layne Jr. et al., 1996). The liver has also been shown to be an important site of synthesis for another osmolyte (urea) that can accumulate to help regulate cellular osmolality (Costanzo, 2005; Storey and Storey, 2017) and retard water loss from tissues. For example, liver can lose up to $59 \%$ of its intracellular water during freezing (Lee et al., 1992). The liver has been shown to be the 
last organ to freeze and the first organ to thaw, demonstrating the importance of this organ in cryoprotectant storage, synthesis and regulation. Furthermore, $R$. sylvatica in Alaska have been shown to store greater amounts of glycogen and regulate higher levels of glucose in comparison to those found in Ohio (Costanzo et al., 2015), showing the importance of liver to the winter adaptation of this species. Additionally, studies have also shown that glucose production can be greatly increased through multiple freeze-thaw cycles (Larson and Barnes, 2016). This demonstrates the importance of liver in regulating the cryoprotectants during freezing but also in adapting the freezing response based on environmental conditions.

During freezing, skeletal muscle is unable to contract and is completely inactive since extracellular ice causes physical obstruction but, nonetheless, muscle is able to fully restore its function and display normal contractions within $24 \mathrm{~h}$ of thawing (Storey and Storey, 1984; Layne, 1992). The formation of extracellular ice causes $22-36 \%$ loss of tissue water content during freezing (Lee et al., 1992). Therefore the transportation of glucose from the liver and its uptake by muscle (and other tissues) is vital to help minimize intracellular water loss (Costanzo et al., 1993). Glycogen levels remain stagnant in skeletal muscle of $R$. sylvatica as a result of the dormant state during freezing, prompting anaerobic glycolysis to be fuelled by alternative sources such as creatine phosphate (Storey and Storey, 1984; Hemmings and Storey, 2001). These metabolic differences allow the skeletal muscle to be an interesting comparative tissue to study in conjunction to liver. Additionally, studies have shown an increased response by antioxidant enzymes during freezing in the skeletal muscle of R. sylvatica (Joanisse and Storey, 1996). Prominent antioxidant enzymes have also been shown to have specific 
regulation during freezing. For example, catalase, has been shown to be regulated through reversible phosphorylation across the freeze-thaw cycle (Dawson and Storey, 2016). With these tissue specific differences seen across the freeze-thaw cycle in $R$. sylvatica, exploring further pathways such as total antioxidant capacity and DNA repair mechanisms in the liver and skeletal muscle in a comparative manner will allow a broadened understanding of the physiological effects of freezing.

This study will aim to determine how genomic stability is maintained through freezing in $R$. sylvatica by analyzing levels of DNA oxidation, total antioxidant capacity response, and the proposed role of DNA damage repair pathways during freeze/thaw in wood frog liver and skeletal muscle.

\subsection{Materials and Methods}

All methods were performed as described in Chapter 2; including animal freezing and thawing experiments, tissue sampling, protein and DNA extraction, western blotting, DNA damage ELISA kit, antioxidant capacity kit, and data handling and statistics. Refer to Appendix A for the full list of antibodies used in western blotting, supplier and catalogue numbers, and Appendix B for a detailed list of western blotting conditions. 


\subsection{Results}

3.3.1 Effects of freezing and thawing on the relative oxidized guanine species in liver and skeletal muscle of wood frogs.

The relative expression of oxidized guanine species was measured in liver and skeletal muscle samples using a Cayman Chemical DNA/RNA Oxidative Damage ELISA kit as described in Chapter 2.5. Data comparing $5^{\circ} \mathrm{C}$-acclimated controls, $24 \mathrm{~h}$ frozen $\left(\right.$ at $-2.5^{\circ} \mathrm{C}$ ) frogs, and $8 \mathrm{~h}$ thawed frogs are shown in Figure 3.1. In the liver, there was no significant change in the relative expression of oxidized guanine species after $24 \mathrm{~h}$ freezing (mean values were $1.13 \pm 0.11)$ or after $8 \mathrm{~h}$ thawing $(1.15 \pm 0.01)$, as compared with the controls $(1.00 \pm 0.02)$. Similarly, in skeletal muscle, there was no significant change in the relative expression of oxidized guanine species after $24 \mathrm{~h}$ freezing $(1.07 \pm 0.02)$ or after $8 \mathrm{~h}$ thawing $(1.03 \pm 0.05)$ in comparison to controls $(1.00 \pm$ $0.07)$.

\subsubsection{Effects of freezing and thawing on the relative total antioxidant capacity in liver} and skeletal muscle of wood frogs

Total antioxidant capacity was measured in liver and skeletal muscle samples across the freeze-thaw cycle (Figure 3.2) using a Cayman Chemical Antioxidant Assay Kit as described in Chapter 2.6. In the liver, there was a significant decrease in relative total antioxidant capacity after $8 \mathrm{~h}$ thawing $(0.91 \pm 0.05)$ in comparison to $24 \mathrm{~h}$ freezing $(1.13 \pm 0.01)$. However, there was no difference in relative total antioxidant capacity in either of these two treatment groups in comparison to the controls $(1.00 \pm 0.01)$. In the 
skeletal muscle, there was no significant change in relative total antioxidant capacity after $24 \mathrm{~h}$ of freezing $(0.89 \pm 0.08)$ or after $8 \mathrm{~h}$ of thawing $(0.94 \pm 0.13)$ in comparison to controls $(1.00 \pm 0.22)$.

3.3.3 Analysis of Double-Stranded Break (DSB) DNA repair protein expression in liver and skeletal muscle of wood frogs over the freeze-thaw cycle.

The relative protein expression of eight DSB DNA repair protein markers (Mre11, Rad50, Phospho-p95, XLF, Rad51, Ku70, DNA Ligase IV, XRCC4) in wood frog liver were assessed over the freeze-thaw cycle using western blotting (Figure 3.3), as described in Chapter 2.3. Preliminary trials confirmed that the antibodies for each protein (Appendix A) cross-reacted with a single band or double band (Mre11, due to isoforms) at the expected subunit molecular weight of the protein. Figure 3.3A shows the relative protein expression levels in liver from control, frozen, and thawed frogs, and Figure 3.3B shows the corresponding western blot images. Mre11, Rad50, Phospho-p95, XLF, DNA Ligase IV, XRCC4, and Rad51 showed no significant changes in protein expression after $24 \mathrm{~h}$ freezing or $8 \mathrm{~h}$ thawing in comparison to the controls. However, $\mathrm{Ku} 70$ showed a significant decrease in relative protein expression after $24 \mathrm{~h}$ freezing $(0.12 \pm 0.04)$ in comparison to the controls $(1.00 \pm 0.09) . \mathrm{Ku} 70$ expression increased again after $8 \mathrm{~h}$ thawing $(0.54 \pm 0.24)$ but had not returned to the control levels and was not significantly different from either controls or $24 \mathrm{~h}$ frozen treatment groups.

The relative protein expression of the eight DSB DNA repair markers was also assessed in skeletal muscle over the freeze-thaw cycle. As for liver, the antibodies used 
(Appendix A) cross reacted with a single band at the expected subunit molecular weight of each protein. Figure 3.4 shows the responses of these DSB DNA repair markers to freezing and thawing; Figure 3.4A shows the relative protein expression levels in skeletal muscle from control, frozen, and thawed frogs with corresponding western blot images shown in Figure 3.4B. Rad50, Phospho-p95, XLF, DNA Ligase IV, and XRCC4 showed no significant changes in protein expression after $24 \mathrm{~h}$ freezing or $8 \mathrm{~h}$ thawing in comparison to the controls. Mre11 showed a strong significant increase in expression after $8 \mathrm{~h}$ of thawing $(2.25 \pm 0.36)$ in comparison to the controls $(1.00 \pm 0.12)$. However, there was no significant change in expression of Mre11 after 24 hours of freezing $(1.24 \pm$ 0.24) in comparison to the control. Rad51 showed a significant decrease in protein expression after $24 \mathrm{~h}$ freezing $(0.35 \pm 0.02)$ in comparison to controls $(1.00 \pm 0.18)$. Rad51 expression had increased after $8 \mathrm{~h}$ thawing $(0.76 \pm 0.16)$ but had not fully regained control values and was not significantly different in comparison to either controls or $24 \mathrm{~h}$ frozen treatment groups.

\subsection{Discussion}

The study of natural freeze tolerant animal models, such as $R$. sylvatica, can broaden insight into many aspects of medical research. One prime example is the potential application of information gathered from freeze tolerant models to organ preservation and to extend organ viability prior to organ transplantation. Additionally, since $R$. sylvatica uses glucose as a cryoprotectant and becomes hyperglycemic while freezing (Costanzo et al., 1993), these studies have additional parallels into diabetes research. As previously mentioned, $R$. sylvatica enters an extended period of metabolic 
rate depression when undergoing freezing, causing a global suppression of non-essential pathways through tight transcriptional and translational regulation in order to conserve energy (Storey and Storey, 2004a; Storey, 2015). Although reactive oxygen species (ROS) are produced as a result of normal aerobic respiration, organisms that endure extended periods of stress and MRD are at a higher risk of having to deal with rapidly increased levels of ROS when they transition out of a hypometabolic state. For example, when freezing occurs in the organism, the oxygen depletion signifies that the cell has a reduced capacity for oxidizing hydrogen ions, which leaves the electron transport chain in a reduced state (Joanisse and Storey, 1996). As such, this leaves the organism particularly vulnerable to ROS production during freezing. An increasing level of ROS can threaten the organism as proteins, lipids, and DNA can be subjected to damage through oxidization (Cooke et al., 2003; Balaban et al., 2005). However, pathways and defences that are crucial for survival and can help to negate the consequences of ROS formation, such as enzymatic antioxidant defences, are maintained and upregulated during freezing (Dawson and Storey, 2016; Dawson and Storey, 2017). The potential interference from ROS during freezing also signifies that the organisms' DNA is at risk for damage. Although the role of certain enzymatic antioxidant defences have been explored in the context of freezing in $R$. sylvatica, the role of DNA repair mechanisms in the context of freezing has not been characterized.

During the onset of freezing, different organs can display varying tissue-specific responses in certain pathways. These differences in tissue response can be largely attributed to the roles that each organ has in maintaining cellular viability. The liver has a critical role in metabolism, particularly for glucose regulation. Since $R$. sylvatica elevates 
glucose levels to use as its main cryoprotectant during freezing, the liver has an indispensable role in winter survival as it stores huge reserves of glycogen and regulates glucose production and distribution in order to preserve all organs (Storey and Storey, 1986; Costanzo et al., 1993). Additionally, when $R$. sylvatica begins to thaw, they begin to restore activity to all organs, and the liver must also clear excess glucose in order for normal metabolic activity to be restored and maintained (Layne et al., 1996).

Contrastingly, skeletal muscle has been shown to have its own small internal storage of glycogen and glucose regulation during freezing (Hemmings and Storey, 2001). Skeletal muscle is also restricted from contractions due to its interaction with environmental ice, and by the ischemic state that develops upon freezing (Irwin et al., 2003). Due to the differences between the liver and skeletal muscle, the observation of antioxidant capacity and DNA damage repair in these two tissues will provide contrast to further understand of these mechanisms during freezing.

As previously mentioned, $R$. sylvatica is vulnerable to ROS damage during freezing. Genomic integrity can be threatened as higher levels of ROS can potentially cause oxidative damage. It has been well established that out of all the base pairs, guanine is the most susceptible to oxidative damage and is therefore a prominent marker of DNA oxidative damage, as it is most commonly oxidized into 8-hydroxy-2'deoxyguanosine (8-oxo-dG) (Burrows and Muller, 1998). The relative expression of oxidized guanine species including 8-oxo-dG and 8-hydroxyguanine (8-oxo-Gua) was measured using a DNA damage ELISA kit to determine if DNA damage occurred in $R$. sylvatica over the freeze-thaw cycle. As seen in Figure 3.1, the relative expression of oxidized guanine species was measured in the liver and muscle over freeze-thaw. 
However, there was no evidence of increased oxidation of guanine during freeze-thaw cycle in either tissue since the relative expression of oxidized guanine species did not change significantly between control, 24 hour frozen, or 8 hour thaw treatment groups. This result suggests that freezing did not elevate the oxidation of guanine species, and that the organism is potentially capable of mitigating the oxidative damage through antioxidant defences or through DNA repair mechanisms. However, only the relative expression of oxidized guanine species were measured in this study, and the potential oxidation of other base pairs might occur. Therefore, it cannot be fully concluded that all forms of DNA oxidation remained constant through the freeze-thaw cycle in liver and muscle, and further investigation might be required.

There are many enzymatic and non-enzymatic components of the antioxidant response system that defend against the oxidation of lipids, proteins, and DNA which makes it a very complex system. Multiple enzymes play a critical roles in antioxidant defence including superoxide dismutase (SOD), catalase, and glutathione-dependant enzymes (such as GR, GPx, and GSTs) (Marrocco et al., 2017). Additionally, there are numerous endogenous non-enzymatic molecules (such as uric acid, ascorbic acid, vitamin E, etc.) that act as antioxidants both directly or indirectly by stimulating the activity of endogenous enzymatic antioxidants (Wahlqvist, 2013; Marrocco et al., 2017). Therefore, to get an overview of the combined total antioxidant capacity of non-enzymatic antioxidant components, a Cayman antioxidant assay kit that was utilized to measure the summed antioxidant capacity of glutathione, ascorbic acid, vitamin E, Trolox, bilirubin, uric acid, and albumin. As seen in Figure 3.2, there was no significant change in the relative total antioxidant capacity in the skeletal muscle of $R$. sylvatica through the 
freeze/thaw cycle. This result implies that the antioxidant response in skeletal muscle is kept constant in order to maintain tissue viability through stress and recovery. This constancy could also imply that the muscle tissue is exposed to relatively consistent ROS levels and does not need to increase its antioxidant defence during freeze/thaw stress by depleting its antioxidant resources. Interesting, in $R$. sylvatica liver, there were no changes in relative total antioxidant capacity between the control and 24 hour frozen treatment groups, but there was a decreased total antioxidant response in the 8 hour thaw group (Figure 3.2). This decreased total antioxidant capacity implies that the liver could be exposed to enhanced ROS levels that depleted antioxidant resources. Since the liver plays such a significant role in the freezing response of the frog by regulating glucose levels, it could be more prone to oxidative species upon reperfusion and require an increased antioxidant response.

When encountering elevated ROS production, organisms can respond with enhanced antioxidant defences that directly detoxify ROS or alternately by upregulating repair mechanisms to fix macromolecules that are damaged by ROS. DNA repair mechanisms are particularly important. As mentioned in Chapter 1.7, there are different types of DNA damage and varying DNA damage repair mechanisms associated with specific types of breaks and damage to DNA (Fleck and Nielsen, 2004). ROS can cause damage by breaking both strands of the DNA which blocks replication, leading to potentially lethal consequences depending on the location of the break. Non-homologous end joining (NHEJ) and homologous recombination (HR) are the two most frequently used mechanisms of DSB repair (Ceccaldi et al., 2016), and are discussed in more depth in Chapter 1.7. Due to an increased threat of enhanced ROS generation during freezing, 
the effects of freeze/thaw on DNA DSB repair mechanisms is a pertinent pathway area to explore to further knowledge of the effects of long term stress and how DNA repair mechanisms function through stress and recovery. As previously discussed, the liver and skeletal muscle are particularly relevant tissues to assess due to their roles and known responses during the freeze-thaw cycle.

As seen in Figure 3.3, many of the observed protein targets involved in DNA DSB repair did not show any significant changes across the freeze-thaw cycle. Mre11, Rad50, and Phospho-p95 are three targets that did not demonstrate any significant change in relative expression across the freeze-thaw cycle in comparison to the controls. These three targets form what is known as the MRN complex, which binds to DNA to mark the site of DSB and can act as a tether to stabilize both ends of the break prior to NHEJ, or initiate resection prior to $\mathrm{HR}$, which demonstrates the importance of this complex in DNA DSB repair (Williams et al., 2007). Although they do have individualized roles, the similarity in expression of these three proteins forming the MRN complex suggests that they are performing their normal function and activity through the freeze-thaw cycle. Sequencing in many other organisms has shown the possibility of isoforms of Mre11, validating the two tight bands seen at the expected molecular weight of this protein in wood frog tissues (Figure 3.3B). The western blot of liver Rad50 showed a clear expression of one single band around 100-110kDa (Figure 3.3B), which was 40kDa lower than the expected molecular weight of the protein. Protein sequencing of the African clawed frog (Xenopus laevis) showed there to be an additional homolog of Rad50 around $90 \mathrm{kDa}$, signifying that the observed protein band in this study could be a 
homolog. Further analysis of this protein or the MRN complex could be completed to validate the protein expression of $\operatorname{Rad} 50$.

XLF, DNA Ligase IV, and XRCC4 are the three main proteins that work in tandem to ligate DNA in NHEJ (Ahnesorg et al., 2006), and did not display any significant change across the freeze-thaw cycle in comparison to controls (Figure 3.3). This result again suggests that ligation through the NHEJ pathway is conserved through the freeze-thaw cycle in the liver. Ku70 is part of the Ku heterodimer (with Ku80) that acts as a scaffold for other proteins in NHEJ and additionally is involved in telomere length regulation and transcriptional silencing through telomere positioning silencing effect (TPE) (Fell and Schild-Poulter, 2015). Results from this study show decreased expression of Ku70 through $24 \mathrm{~h}$ freezing, and an increase after $8 \mathrm{~h}$ of thawing which did not completely return to control levels (Figure 3.3). Although this pattern of expression does not seem in line with the results of the aforementioned proteins involved in ligation in NHEJ, the additional role of Ku70 in telomere length regulation and in transcription and replication through the TPE were shown to be independent from NHEJ (Fell and Schild-Poulter, 2015), and might be supressed during freezing to conserve energy. This is in line with the literature that has shown evidence of cell cycle suppression during freezing in R. sylvatica as a method to conserve energy during MRD (Zhang and Storey, 2012a).

The majority of the aforementioned protein targets act as initial markers of DSB prior to DNA repair, or are involved in the NHEJ pathway of DNA repair. To gain a better understanding of DSB repair, the expression of Rad51 was evaluated as a preliminary study of the regulation of HR across the freeze-thaw cycle in the liver. Rad51 
is an important protein in $\mathrm{HR}$ as it is involved in searching for homologous sections and in pairing the strands (Godin et al., 2016). As seen in Figure 3.3, there was a slight decrease in expression after $24 \mathrm{~h}$ of freezing, with expression recovering to control levels after $8 \mathrm{~h}$ thaw, but this difference was not statistically significant. Therefore, the results show that Rad51 is still relatively active through the freeze thaw cycle, suggesting that HR is used through the freeze-thaw cycle. A more comprehensive analysis of additional proteins involved in HR should be completed to better understand the HR pathway and activity through the freeze-thaw cycle in the liver.

DNA DSB repair proteins were also assessed in skeletal muscle using western blotting to provide a tissue comparison of the DSB repair pathway across the freeze-thaw cycle. The results seen in Figure 3.4 show slight increases in Rad50 and Phospho-p95 expression in the $24 \mathrm{~h}$ frozen and $8 \mathrm{~h}$ thaw group, compared to the controls, but these were not significant. However, Mre11 displayed an increase after $8 \mathrm{~h}$ of thawing that was significantly different from the controls, but not significantly different from the $24 \mathrm{~h}$ frozen group (Figure 3.4). As previously mentioned, these three proteins form the MRN complex and work together to localize DSB prior to NHEJ or HR. The significant upregulation in Mre11 relative expression in the $8 \mathrm{~h}$ thaw group is possibly due to an alternative DSB repair pathway known as micro-homology mediated end joining (MMEJ) being active during thawing. Studies have shown that Mre11 nuclease activity is required in MMEJ for short end resection of DNA (Truong et al., 2013). Further study of the MMEJ pathway in R. sylvatica will be required for validation of MMEJ activity across the freeze-thaw cycle. The difference seen in the relative expression of Mre11 in skeletal muscle as compared to the liver during thawing shows evidence of a tissue 
specific response by the MRN complex in $R$. sylvatica across the freeze-thaw cycle, and can be further explored.

As seen in Figure 3.4, the three proteins involved in DNA ligation (XLF, DNA Ligase IV, and XRCC4) did not display any significant changes across the freeze-thaw cycle in the skeletal muscle. This result is similar to that for liver (Figure 3.3), suggesting that ligation through the NHEJ pathway is relatively conserved in both tissues across the freeze-thaw cycle. Surprisingly, the relative expression of Ku70 showed a significant decrease in the $8 \mathrm{~h}$ thaw condition (Figure 3.4), which is opposite to the expression pattern seen in liver, which showed a significant decrease in the $24 \mathrm{~h}$ frozen condition (Figure 3.3). As previously mentioned, $\mathrm{Ku} 70$ is part of the $\mathrm{Ku}$ heterodimer and is an integral part of NHEJ but is also involved in telomere regulation. However, studies have shown that proteins of the MRN complex (particularly Mre11 and p-95) are also involved in telomere regulation (Rai et al., 2017; Oh and Symington, 2018). Therefore, it is possible that $\mathrm{Ku} 70$ activity is conserved through freezing, but is then downregulated during thawing in an attempt to avoid redundancy in the role of maintaining telomeres, as Mre11 is upregulated in the tissue during thawing. Additional study of the $\mathrm{Ku}$ heterodimer and telomere regulation is needed to provide more insight into its regulation across the freeze-thaw cycle in $R$. sylvatica.

As with the liver, the relative expression of Rad51 was observed to provide an initial look into the HR pathway of DNA DSB repair in skeletal muscle across the freezethaw cycle. As seen in Figure 3.4, there was a significant decrease in Rad51 relative expression after $24 \mathrm{~h}$ of freezing, with relative expression increasing after $8 \mathrm{~h}$ of thawing but did not fully return to control levels. Although HR does provide a more reliable repair 
in comparison to NHEJ, it can only occur during the G2 and S phase of the cell cycle when there is a sister chromatid to act as a guideline for repair (Jasin and Rothstein, 2013; Her and Bunting, 2018). As previously mentioned, studies have shown that there is cell cycle suppression over the freeze-thaw cycle in R. sylvatica (Zhang and Storey, 2012). Since HR activity is cell cycle dependent, the suppression of Rad51 activity seen in the skeletal muscle through the freeze-thaw cycle could be attributed to cell cycle suppression. Cells that are not in the correct phase of the cell cycle prior to suppression will not be able to use the HR pathway to repair DNA DSB. Additionally, since the skeletal muscle is mostly post-mitotic and largely only regenerates to replace any damaged tissue, its cell cycle regulation vastly differs from other tissues that show continual cell cycle activation (Grounds, 1991). This major difference could account for the tissue specific difference in regulation in comparison to the liver through the freezethaw cycle in regards to Rad51 activity. Additional study of the HR pathway will be required to further validate this finding and to provide more information of the HR pathway in skeletal muscle across the freeze-thaw cycle.

In summary, this study provided insight into DNA damage, antioxidant capacity and DNA DSB repair mechanisms in the liver and skeletal muscle of $R$. sylvatica across the freeze-thaw cycle. The results of this study suggest that there is no increase in DNA oxidized species over freezing and thawing, but that the prevention of increased oxidization of DNA could be due to antioxidant and DNA DSB repair mechanisms. Antioxidant capacity through the freeze-thaw cycle is relatively constant in both the liver and skeletal muscle, with the exception of a decrease seen in the liver during thawing, suggesting a tissue specific response in the use of exogenous and endogenous antioxidant 
mechanisms when the organism is particularly vulnerable to ROS. Additionally, the relative expression of DNA DSB repair proteins observed in this study demonstrate an overall constant expression of many proteins, suggesting a conservation of many DSB repair proteins through the freeze-thaw cycle to address any potential threat of DSB. The results do show some tissue-specific and pathway-specific differences between the liver and skeletal muscle that could be attributed to the regulation of the cell cycle through freezing and thawing. Additional studies will be required to explicate the antioxidant response and DNA DSB repair mechanisms in R. sylvatica that support freezing survival. 


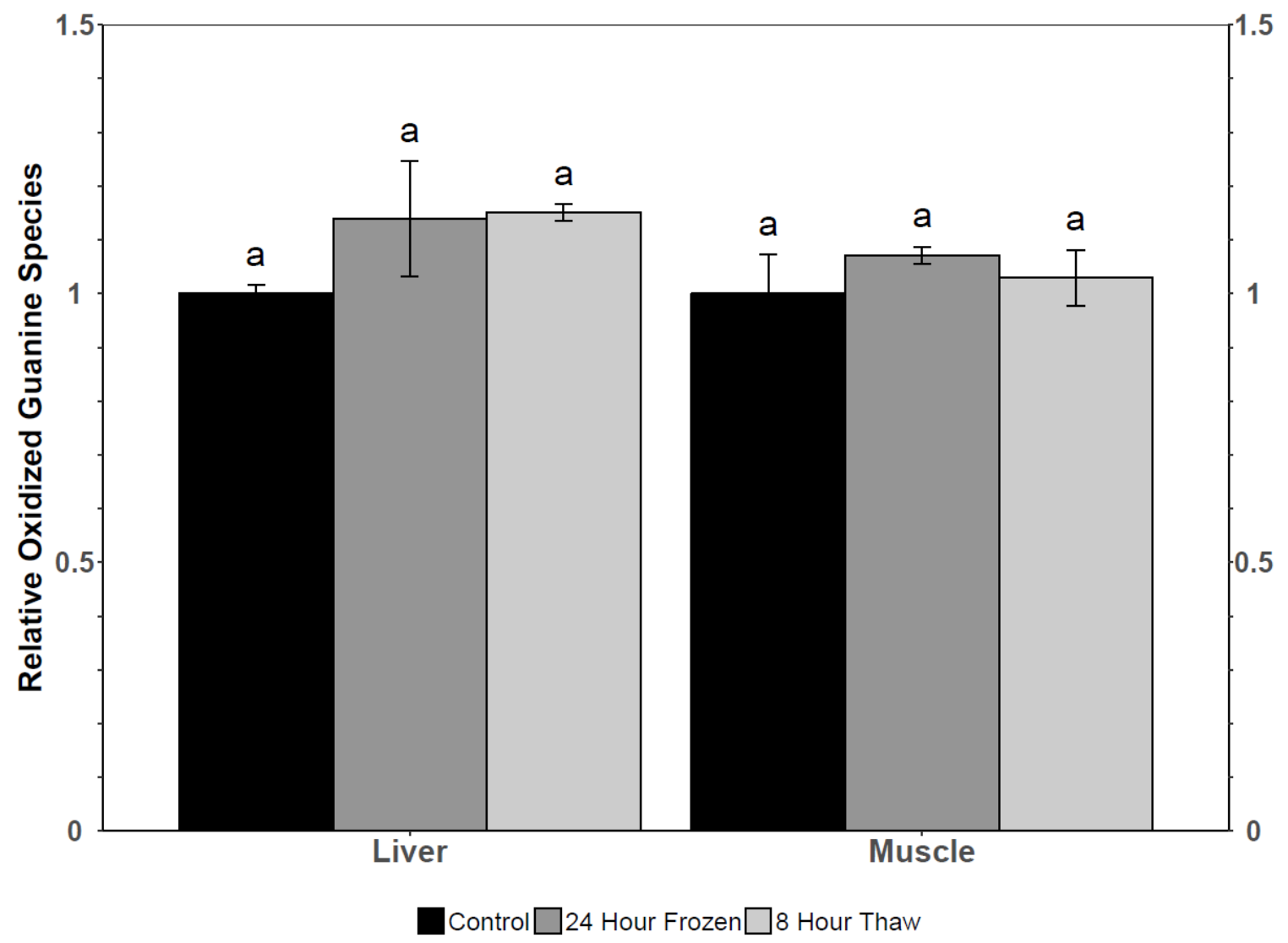

Figure 3.1: DNA damage quantification in $R$. sylvatica liver and skeletal muscle through a freeze-thaw cycle. Relative oxidized guanine species in control, 24 hour frozen, and 8 hour thaw conditions. Data are means \pm SEM, $n=3$ - 4 independent trials. One-way ANOVA and a Tukey's post-hoc test $(\mathrm{p}<0.05)$ was used for analysis; for each tissue, values that share the same letter are not significantly different from each other. 


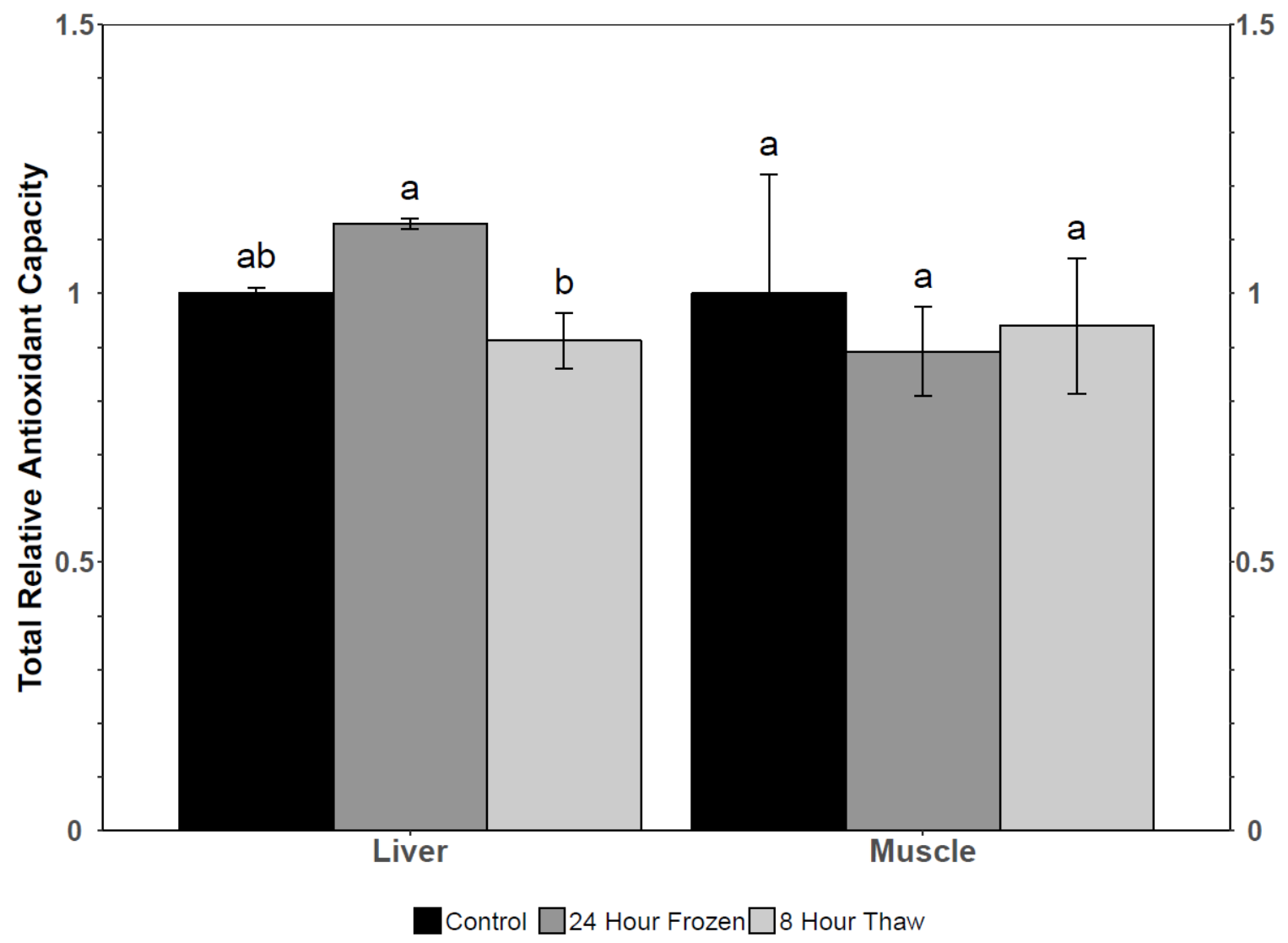

Figure 3.2: Total antioxidant capacity in $R$. sylvatica liver and skeletal muscle through a freeze-thaw cycle. Total relative antioxidant capacity in control, 24 hour frozen, and 8 hour thaw conditions. Data are means \pm SEM, $n=3-4$ independent trials. One-way ANOVA and a Tukey's post-hoc test $(\mathrm{p}<0.05)$ was used for analysis; values that share the same letter are not significantly different from each other. 
A

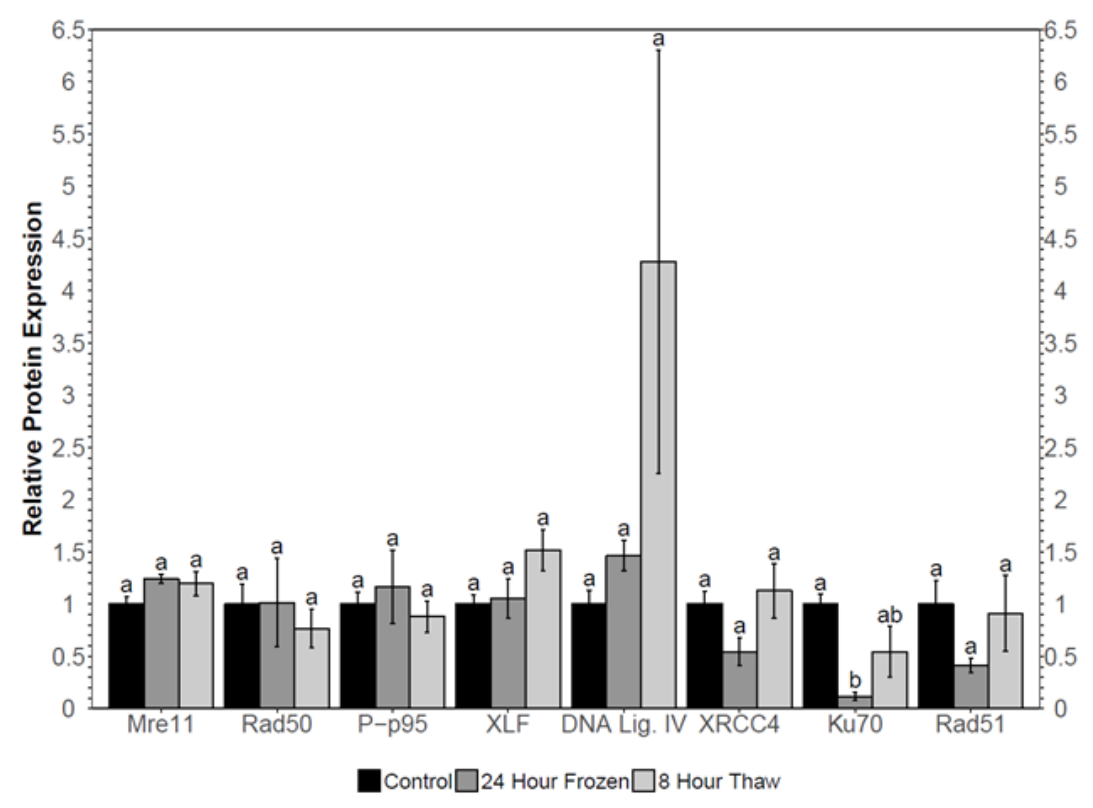

B

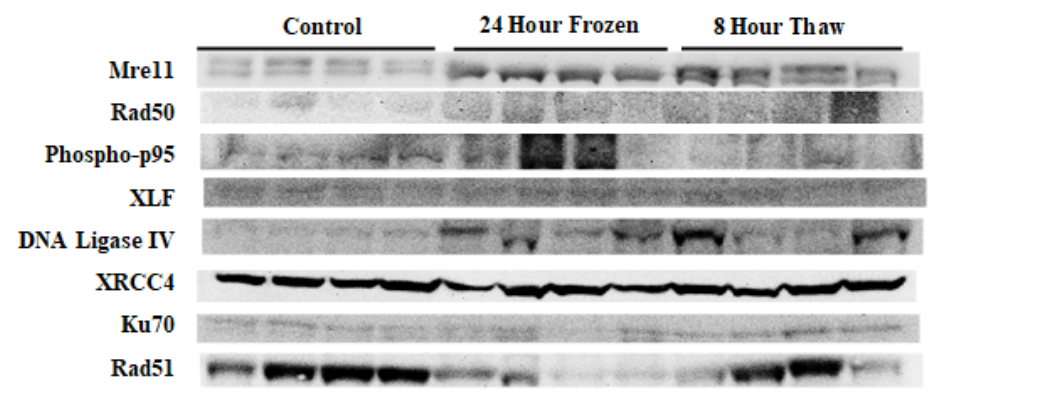

Figure 3.3: Western blot quantification of DSB repair protein expression in $R$. sylvatica liver through a freeze-thaw cycle. A) Relative protein expression of protein targets in control, 24 hour frozen, and 8 hour thaw conditions. Data are means \pm SEM, $\mathrm{n}=3-4$ independent trials. One-way ANOVA and a Tukey's post-hoc test $(\mathrm{p}<0.05)$ was used for analysis; values that share the same letter are not significantly different from each other. B) Western blot of DSB repair protein targets in the corresponding experimental conditions. 
A

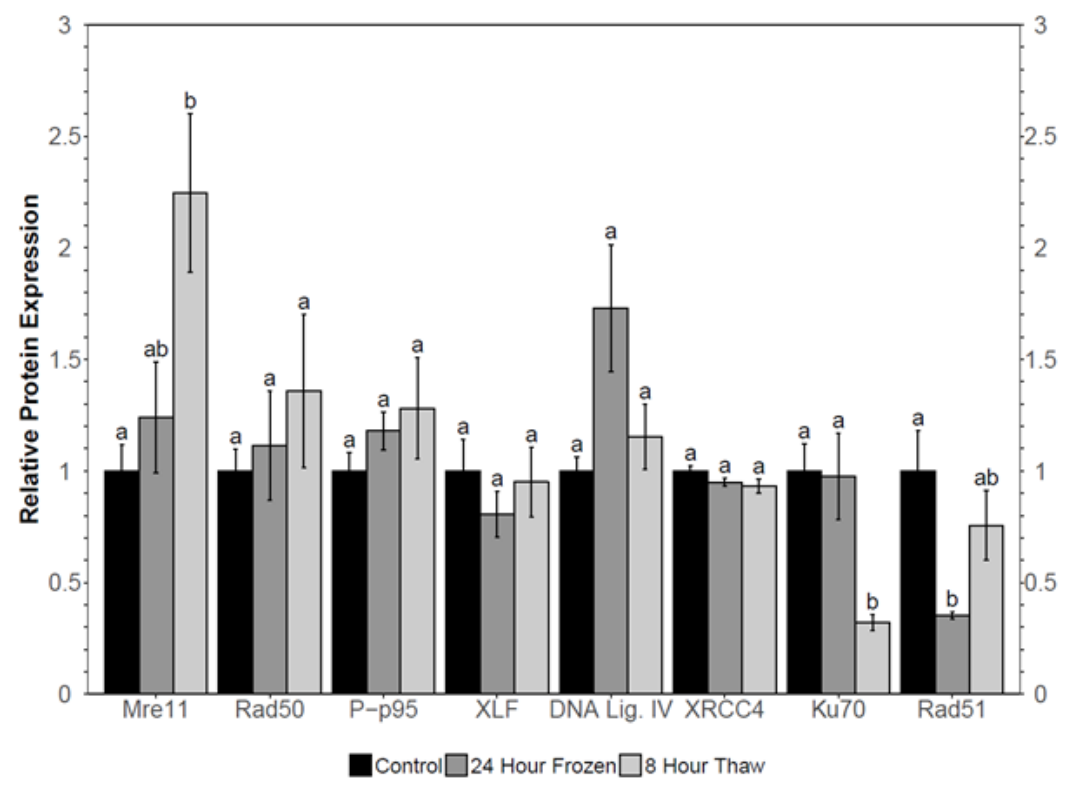

B

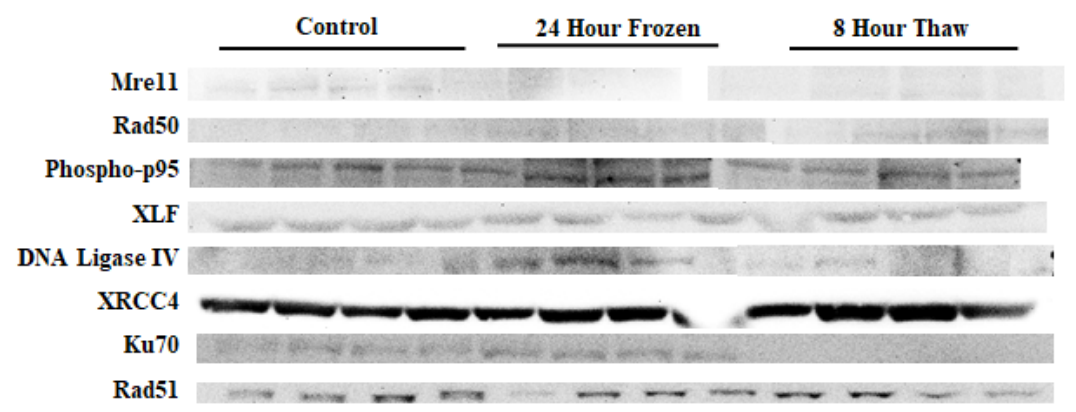

Figure 3.4: Western blot quantification of DSB repair protein expression in $R$. sylvatica skeletal muscle through a freeze-thaw cycle. A) Relative protein expression of protein targets in control, 24 hour frozen, and 8 hour thaw conditions. Data are means \pm SEM, $n$ $=3-4$ independent trials. One-way ANOVA and a Tukey's post-hoc test $(\mathrm{p}<0.05)$ was used for analysis; values that share the same letter are not significantly different from each other. B) Western blot of DSB repair protein targets in the corresponding experimental conditions. 


\section{Chapter 4}

DNA Damage, Antioxidant Capacity, and DNA Repair through the AnoxiaReoxygenation Cycle in $R$. sylvatica 


\subsection{Introduction}

Oxygen is necessary to sustain life for most organisms, as it is imperative to maximize ATP production from metabolic fuels. However, certain animals such as the naked mole rat (Heterocephalus glaber) and red-eared slider turtle (Trachemys scripta elegans) are known have unique adaptive responses to their environments that allow them to endure extended periods in hypoxia (low oxygen) or anoxia (oxygen depleted) (Fago and Jensen, 2015; Pamenter et al., 2019). This ability to adapt to hypoxic or anoxic conditions is partly due to entry into a state of hypometabolism that minimizes ATP use as well as to a well-developed capacity to produce ATP from anaerobic glycolysis and buffer the acidosis that is typically associated with lactate production (Jackson and Ultsch, 2010; Storey, 2015). As previously discussed in Chapter 1, wood frogs endure the subzero temperatures of winter with their capacity for freeze tolerance, one component of which is the ability to endure the anoxia that develops due to the cessation of vital functions while frozen (Storey and Storey, 1992). This is validated by the observed accumulation of lactate and L-alanine (end products of anaerobic glycolysis) and the depletion of ATP and other adenylates that occurs during freezing (Storey and Storey, 1986; Storey and Storey, 2017). As such, wood frogs must have developed adaptations to cope with anoxia and the fluctuations in oxygen availability during the anoxia-recovery cycle to conserve physiological function and cellular viability.

Rapid changes in oxygen availability through an anoxia-reoxygenation cycle, especially during reperfusion, greatly increases the wood frog's susceptibility to oxidative damage from reactive oxygen species (ROS). In order to counteract the possible consequences of ROS, selected antioxidant enzymes are upregulated during 
freezing (probably to deal with freeze-induced anoxia), presumably as a pre-emptive response to prepare for oxidative stress/damage during the recovery and reperfusion phase (Joanisse and Storey, 1996; Hermes-Lima and Zenteno-Savín, 2002). Freeze tolerant wood frogs also show constitutively higher activities of antioxidant enzymes compared with leopard frogs that overwinter under water (Joanisse and Storey, 1996). However, if antioxidant defences are overwhelmed, there are DNA repair mechanisms in place to repair damage to DNA from oxidation and conserve genomic integrity. Wood frogs are able to fully recover and restore their normal physiological function after thawing or recovery from anoxia, showing that they must be able to avoid excessive oxidative damage to DNA when exposed to major changes in oxygen availability. Therefore, exploring the antioxidant capacity and DNA damage repair mechanisms of wood frogs across the anoxia-recovery cycle will provide insight into how genomic integrity is maintained amid the threat of oxidative stress.

As mentioned in Chapter 3.1, many studies have shown tissue specific responses during stress and recovery in $R$. sylvatica. These are mainly attributed to the unique roles played by each tissue, particularly in terms of glucose regulation and metabolism (Storey and Storey, 2017). As previously discussed, the liver is a crucial organ in terms of stress adaptation for wood frogs as it is the site of glycogen storage prior to winter, and the site of glycogenolysis for glucose production and delivery to other tissues as the cryoprotectant (Storey and Storey, 1984; Layne Jr. et al., 1996). Being the last organ to freeze and the first to thaw, the liver has an important role in recovery as it must mediate clearing excess amounts of glucose upon reperfusion. Additionally, liver may be one of the first organs to encounter rapid changes in oxygen levels upon reperfusion, and must 
therefore be able to have sufficient defence mechanisms in place to counteract potential ROS formation (Rubinsky et al., 1994; Joanisse and Storey, 1996). As seen in Chapter 3.1, skeletal muscle is dependent on cellular metabolism for the energy to contract, and therefore the uptake of glucose delivered from the liver during freezing is important to protect muscle cells while skeletal muscle is frozen. Furthermore, the dependence on anaerobic glycolysis during metabolic rate depression has to be tightly regulated since glucose levels are shown to be consistent during freezing (Costanzo et al., 1993; Hemmings and Storey, 2001). Animals that routinely endure anoxia exposures and undergo anaerobic glycolysis have to be able to minimize acidosis associated with lactate production (Mayer and Vaupel, 2013). Studies have shown that during anoxia exposure, the turtle Trachemys scripta elegans, shows posttranslational modifications (PTMs) of LDH (Xiong and Storey, 2012). Additionally, it has been shown that LDH is posttranslationally modified during dehydration in R. sylvatica (Abboud and Storey, 2013). Although it has not yet been studied in the context of anoxia, the changes seen in LDH demonstrate the importance of its regulation during MRD when the organism relies on anaerobic glycolysis.

As previously discussed in Chapter 1, freezing in R. sylvatica is a multi-faceted stress, since wood frogs experience anoxia, dehydration, and hyperglycemia as a byproduct of freezing. Although there are many similarities, since each stress is associated with MRD and anaerobic glycolysis, the unique limitations with the onset of each stress require specific adaptations to promote survival (Storey and Storey, 2017). Studies of wood frogs have demonstrated that many metabolic pathways display stressspecific responses. For example, it has been shown recently that there are stress-specific 
responses in the regulation and PTMs of enzymes involved in glycolysis and the urea cycle in the wood frog in response to freezing, anoxia, and dehydration stresses; these cause stress specific changes in metabolism (Hawkins et al., 2019). Additionally, it has been shown that markers of antioxidant defence (catalase and superoxide dismutase 1) and heat shock proteins display differential stress specific responses across freezing, anoxia, and dehydration in R. sylvatica (Wu et al., 2018). In Chapter 3, the levels of DNA oxidation, total antioxidant capacity, and DNA damage repair markers were analyzed in the liver and skeletal muscle across the freeze-thaw cycle. Anoxia is particularly threatening as rapid fluctuation in oxygen levels can increase ROS and oxidative stress. Therefore, analyzing these same pathways across the anoxiareoxygenation cycle and comparing them to the effects of the freeze-thaw cycle will allow for determination of any stress-specific regulation of these processes and potentially delineate the origin of DNA damage and antioxidant responses.

The studies described in this chapter aim to determine how genomic stability is maintained during anoxia exposure in $R$. sylvatica by analyzing levels of DNA oxidation, total antioxidant capacity response, and the proposed role of DNA damage repair pathways during anoxia and recovery in wood frog liver and skeletal muscle.

\subsection{Materials and Methods}

All methods were performed as described in Chapter 2; including animal anoxia exposure and recovery experiments, tissue sampling, protein and DNA extraction, western blotting, DNA damage ELISA kit, antioxidant capacity kit, and data handling 
and statistics. Refer to Appendix A for the full list of antibodies used in western blotting, supplier and catalogue numbers, and Appendix B for a detailed list of western blotting conditions.

\subsection{Results}

4.3.1 Effects of anoxia and recovery on the relative oxidized guanine species in liver and skeletal muscle of wood frogs.

The relative expression of oxidized guanine species was measured in liver and skeletal muscle samples across the anoxia-recovery cycle using a Cayman Chemical DNA/RNA Oxidative Damage ELISA kit as described in Chapter 2.5. Data comparing control frogs, 24 hour anoxic frogs, and 4 hour aerobic recovery frogs are shown in Figure 4.1. In the liver, there was a significant increase in the relative expression of oxidized guanine species after $4 \mathrm{~h}$ recovery $(1.18 \pm 0.03)$ in comparison to $24 \mathrm{~h}$ of anoxia $(0.98 \pm 0.06)$. However, these two treatment groups did not show any significant changes in comparison to controls $(1.00 \pm 0.02)$. In the skeletal muscle, there was no significant change in the relative expression of oxidized guanine species after $24 \mathrm{~h}$ anoxia $(1.08 \pm$ $0.07)$ or after $4 \mathrm{~h}$ recovery $(0.90 \pm 0.02)$ in comparison to controls $(1.00 \pm 0.07)$. 
4.3.2 Effects of anoxia and recovery on the relative total antioxidant capacity in liver and skeletal muscle of wood frogs

Total antioxidant capacity was measured in the liver and skeletal muscle across the anoxia-recovery cycle (Figure 4.2) using a Cayman Chemical Antioxidant Assay Kit as described in Chapter 2.6. In the liver, there was a significant increase in antioxidant capacity after 4 hours of recovery $(1.33 \pm 0.11)$ in comparison to 24 hours of anoxia ( 0.79 $\pm 0.08)$. However, there was no difference in the total antioxidant capacity of these two treatment groups in comparison to controls $(1.00 \pm 0.01)$. In skeletal muscle, there was a significant change in total antioxidant capacity after 24 hours of anoxia $(1.65 \pm 0.12)$ and after 4 hours of recovery $(1.81 \pm 0.13)$ in comparison to controls $(1.00 \pm 0.22)$. However, there was no significant change in antioxidant capacity between 24 hours of anoxia and 4 hours of recovery.

4.3.3 Analysis of Double-Stranded Break (DSB) DNA repair protein expression in liver and skeletal muscle of wood frogs over the anoxia-recovery cycle

The relative protein expression of eight DSB DNA repair protein markers (Mre11, Rad50, Phospho-p95, XLF, Rad51, Ku70, DNA Ligase IV, XRCC4) in wood frog liver was assessed over the anoxia-recovery cycle using western blotting (Figure 4.3), as previously described in Chapter 2.3. As seen in Chapter 3.3, the antibodies used (Appendix A) cross reacted with a single or double band (Mre11, due to isoforms) at the expected subunit molecular weight of each protein. Figure 4.3A shows the relative protein expression levels in liver from control, anoxic, and recovered frogs, and Figure 
4.3B shows the corresponding western blot images. Rad50, Phospho-p95, XLF, and Rad51 did not show any significant difference in relative protein expression after $24 \mathrm{~h}$ of anoxia or $4 \mathrm{~h}$ recovery in comparison to the controls. By contrast, Mre11 demonstrated a significant increase in relative protein expression after $24 \mathrm{~h}$ anoxia $(2.71 \pm 0.10)$ and $4 \mathrm{~h}$ recovery $(2.38 \pm 0.40)$ in comparison to controls $(1.00 \pm 0.06)$. However, there was no significant difference between $24 \mathrm{~h}$ anoxia and $4 \mathrm{~h}$ recovery. DNA Ligase IV showed a significant increase in relative protein expression after $24 \mathrm{~h}$ of anoxia $(2.25 \pm 0.21)$ that was sustained after $4 \mathrm{~h}$ aerobic recovery $(2.57 \pm 0.48)$ in comparison to controls $(1.00 \pm$ 0.06). XRCC4 demonstrated a significant decrease in relative protein expression after 24 $\mathrm{h}$ anoxia $(0.07 \pm 0.01)$ in comparison to controls $(1.00 \pm 0.35)$. However, XRCC4 content had rebounded somewhat after $4 \mathrm{~h}$ recovery $(0.23 \pm 0.17)$ but had not fully reached control values and was not significantly different from either the control or $24 \mathrm{~h}$ anoxia situation. $\mathrm{Ku} 70$ did not show any significant difference between control $(1.00 \pm 0.11)$ and $24 \mathrm{~h}$ anoxia $(0.72 \pm 0.08)$ conditions, but did show a significant increase in relative protein expression after $4 \mathrm{~h}$ of recovery $(2.24 \pm 0.23)$.

The relative protein expression of the same eight DSB DNA markers was also assessed in skeletal muscle across the anoxia-recovery cycle. As seen in Chapter 3.3, the antibodies used (Appendix A) cross reacted with a single band at the expected subunit molecular weight of each protein. Figure 4.4 shows the relative protein expression of these DSB DNA repair proteins in response to anoxia and recovery. Figure 4.4A shows the relative protein expression levels in liver from control, anoxic, and recovered frogs, and Figure 4.4B shows the corresponding western blot images. Mre11, Rad50, Phosphop95, DNA Ligase IV, and XRCC4 showed no significant difference in relative protein 
expression after $24 \mathrm{~h}$ anoxia and $4 \mathrm{~h}$ recovery. XLF demonstrated a significant decrease in protein expression after $24 \mathrm{~h}$ anoxia $(0.23 \pm 0.06)$ in comparison to controls $(1.00 \pm$ $0.27)$ and remained at that low relative expression after $4 \mathrm{~h}$ recovery $(0.18 \pm 0.04) . \mathrm{Ku} 70$ showed a significant decrease in protein expression after $24 \mathrm{~h}$ of anoxia $(0.64 \pm 0.03)$ in comparison to the controls $(1.00 \pm 0.03)$, and remained at a lower expression level after 4 $\mathrm{h}$ recovery $(0.47 \pm 0.08)$. Similarly, $\operatorname{Rad} 51$ also showed a significant decrease after $24 \mathrm{~h}$ of anoxia $(0.29 \pm 0.06)$ in comparison to the controls $(1.00 \pm 0.25)$ and remained at a low relative expression level after $4 \mathrm{~h}$ recovery $(0.14 \pm 0.04)$.

\subsection{Discussion}

Falling oxygen concentrations as frogs freeze ( \& blood circulation is increasingly restricted) will trigger pro-survival mechanisms by wood frogs such as MRD and a switch to a reliance on anaerobic glycolysis as the primary ATP-generating pathway (Storey and Storey, 2017). Both of these responses are also well known among other frog species, especially among other northern ranid species that winter underwater. Although these frogs can take up oxygen across their skin in cold water, as winter progresses the water in ice-locked ponds/lakes becomes increasingly hypoxia as organisms (animals, plants, microbes) deplete oxygen. Hence, anoxia tolerance and MRD are well developed in a variety of frog species. Studying these animals in their hypoxia/anoxic states has the potential to be applied into medical research of conditions related to oxygen deprivation such as ischemia and hypoxia-related conditions and injuries. As seen when the $R$. sylvatica undergoes freezing, the reliance on anaerobic glycolysis during MRD signifies that the electron transport chain (ETC) is in a reduced state (Joanisse and Storey, 1996, 
Storey and Storey 2004b). This signifies that the organism is extremely vulnerable to excess production of reactive oxygen species (ROS) during anoxia. Additionally, when $R$. sylvatica recovers from their state of hypometabolism and anoxia, there is also a risk of high ROS exposure threatening the organism as oxygen floods back into the frog's body. Exposure to elevated levels of ROS in turn raises vulnerability to oxidative damage, such as protein, lipid, or DNA damage. To counteract these stresses, antioxidant defence systems are in place that can minimize and ideally negate potential oxidative damage. Additionally, repair pathways are available to resolve oxidative damage to macromolecules. Since genomic integrity is crucial for an organism's survival, one of the most prominent and important repair system is the DNA repair pathway. Other studies have assessed antioxidant defences in $R$. sylvatica under anoxic conditions (Wu et al., 2018), but the role of non-enzymatic antioxidant factors and the DSB pathway of DNA repair has not previously been explored.

The nature of freezing-induced anoxia in $R$. sylvatica can cause tissue-specific responses/damage that require tissue-specific regulation. As previously mentioned, since each organ has a unique role in maintaining cellular viability, this can account for the tissue specific responses that are observed in the DNA damage and repair systems. As previously discussed, the liver is an imperative organ during the winter months for wood frogs as it is the site of glucose regulation, which is the main cryoprotectant used to preserve the frog at subzero temperatures. The wood frog's freeze tolerant ability is heavily dependent on liver's ability to covert stored glycogen into glucose prior to freezing, and clear glucose to restore normal metabolic function during thawing and recovery. In contrast to liver, studies have also shown that $R$. sylvatica's skeletal muscle 
has its own internal storage and regulation of glycogen and glucose and experiences an added layer of stress since external ice restricts muscle contraction and leads to an ischemic state of the muscle. As with the previous study in Chapter 3, the differences between the liver and skeletal muscle allow for a tissue comparison of non-enzymatic antioxidant capacity and DNA damage repair mechanism to further understand adaptation to anoxic conditions. Additionally, many studies of wood frogs have demonstrated that certain pathways have stress specific adaptions in the organism. Therefore, the comparison of these pathways between frozen and anoxic conditions allow for the observation of potential stress specific adaptations in these tissues, since this has yet to be explored in the context of antioxidant capacity and DNA repair.

As previously discussed, $R$. sylvatica is vulnerable to ROS damage during anoxia and recovery when there are drastic and rapid changes in oxygen availability. Increasing levels of ROS during this cycle can cause oxidative damage to DNA and interfere with genomic stability and integrity. As discussed in Chapter 3.4, guanine is the nucleotide that is most susceptible to oxidative damage and can be oxidized into 8-hydroxy-2'deoxyguanosine (8-oxo-dG), leading this oxidized form to be prominently used as marker of DNA oxidative damage (Burrows and Muller, 1998). The relative expression of oxidized guanine species including 8-oxo-dG and 8-hydroxyguanine (8-oxo-Gua) was measured using a DNA damage ELISA kit to determine if DNA damage occurred in $R$. sylvatica liver and muscle over the anoxia-recovery cycle (Figure 4.1). Interestingly, liver showed an increase in the relative expression of oxidized guanine species after 4 hour aerobic recovery in comparison to the 24 hour anoxia treatment group but was not different from the controls. This increase in oxidized guanine species during recovery 
from anoxia could be due to the rapid reperfusion that occurs when oxygen is reintroduced. However, this increase was not significantly different from control levels, suggesting that the observed guanine oxidation during recovery is still a relatively minimal level in which endogenous antioxidant and DNA repair mechanisms are not overwhelmed. There was no evidence of increased oxidation of guanine during the anoxia-recovery cycle in skeletal muscle as the relative expression of oxidized guanine species did not change significantly between control, 24 hour anoxia, or 4 hour recovery treatment groups (Figure 4.1). This result suggests that anoxia exposure did not increase oxidation of guanine species, and that $R$. sylvatica is potentially capable of mitigating the oxidative damage through antioxidant defences or through DNA repair mechanisms in muscle during the anoxia-recovery cycle. It is important to note that only the relative expression of oxidized guanine species was measured in this study, and that there could still be oxidation of other nucleotide bases. Therefore, it cannot be concluded that all forms of DNA oxidation have the same expression as oxidized guanine species through the anoxic cycle in liver and muscle seen in Figure 4.1, and further investigation might be required.

Antioxidant defence includes both enzymatic and non-enzymatic factors that work in tandem to minimize lipid, protein, and DNA oxidative damage. As previously discussed in Chapter $\mathbf{1}$ and Chapter 3, there are multiple enzymatic pathways and endogenous non-enzymatic molecules that act as antioxidants both directly or indirectly to reduce oxidative stress (Wahlqvist, 2013; Marrocco et al., 2017). In order to characterize the combined total antioxidant capacity of non-enzymatic antioxidant components, a Cayman antioxidant assay kit that was used to measure the summed 
antioxidant capacity of glutathione, ascorbic acid, vitamin E, trolox, bilirubin, uric acid, and albumin. The relative total antioxidant capacity was measured in liver and skeletal muscle (Figure 4.2). Interesting, in $R$. sylvatica liver, there was an increase in total relative antioxidant capacity after 4 hour recovery in comparison to the 24 hour anoxia group, with both treatment groups showing no significant difference in comparison to controls. This expression pattern matches the expression of oxidized guanine species seen in Figure 4.1. The results of both Figure 4.1 and Figure 4.2 suggest that the increase in total relative antioxidant capacity may be an antioxidant defence response to the increase in relative oxidized guanine species in order to minimize oxidative damage to DNA. Since the liver is the first organ to melt and apparently regain function during recovery (Storey and Storey, 2001), it is one of the first organs to deal with reperfusion and hence could be more at risk for general oxidative damage in comparison to other tissues, and in turn elevate antioxidant production to mitigate the consequences of ROS. Skeletal muscle showed an increase in total relative antioxidant capacity in the 24 hour anoxia and 4 hour recovery treatment groups in comparison to controls, with no significant difference between the 24 hour anoxia and 4 hour recovery group (Figure 4.2). This result suggests that antioxidant production is elevated during anoxia and recovery in order to counteract ROS and minimize oxidative damage from ROS during the recovery after oxygen is reintroduced. In all, it seems that the liver and skeletal muscle attempt to regulate production of non-enzymatic antioxidants in conjunction with rapid changes in oxygen availability during the anoxia-recovery cycle in order to minimize damage by ROS. These results only observe recovery after 4 hours, and further studies monitoring a longer recovery time course could provide more insight as to 
whether these antioxidant factors are being used and provide clearer overview of antioxidant capacity regulation during aerobic recovery.

As previously discussed, when levels of ROS production overwhelm antioxidant defences, organisms can turn to different repair mechanisms to fix macromolecules that have succumbed to oxidative damage. As discussed in detail in Chapter 1.7, DNA repair mechanisms are very important to maintain genomic integrity amid oxidative stress. The choice and method of DNA repair depends on the type of damage (Fleck and Nielsen, 2004). One particular type of damage that can be lethal is double stranded breaks (DSB) to DNA, as they can block replication and greatly interfere with genomic stability if not repaired promptly and correctly. The two main pathways for DSB repair are nonhomologous end joining (NHEJ) and homologous recombination (HR) (Ceccaldi et al., 2016). The high threat of ROS generation during fluctuating oxygen levels, especially upon reoxygenation, allows for DNA DSB repair mechanisms to be a very relevant pathway to study in the context of anoxia tolerance. The liver and skeletal muscle are pertinent tissues to study due to their varying roles during stress and recovery in the wood frog, as previously discussed. Studying DNA DSB repair across the anoxia/reoxygenation cycle allows for the exploration of the effects of long term stress on DNA repair. Additionally, the comparison of these pathways during anoxia to freezing (Chapter 3) will allow stress-specific responses to be observed.

As previously discussed in Chapter 1.7, Mre11, Rad50, and p-95 form the MRN complex that is involved in both NHEJ and HR (Rothkamm et al., 2003; Williams et al., 2007). As seen in Figure 4.3, Rad50 and Phospho-p95 displayed no significant changes between $24 \mathrm{~h}$ anoxia and $4 \mathrm{~h}$ recovery groups in comparison to the controls in liver, 
indicating constant expression through the anoxia-reoxygenation cycle. Similar to the results for frozen liver (Chapter 3.4 and Figure 3.3), the western blot of liver Rad50 showed a clear expression of one single band around 100-110kDa (Figure 4.3B), that was $40 \mathrm{kDa}$ lower than the expected molecular weight of the protein. Protein sequencing of the African clawed frog (Xenopus laevis) showed there to be an additional homolog of Rad50 around 90kDa, implying that the observed protein band in wood frogs could be a homolog, and that anurans might generally express a Rad protein of a lower molecular weight. Further analysis could be completed to validate the protein expression of Rad50 seen in the liver. In contrast to the other two proteins, Mre11 displayed a significant increase during $24 \mathrm{~h}$ anoxia and $4 \mathrm{~h}$ recovery in comparison to controls (with no significant difference between the two conditions). The significant upregulation of Mre11 relative expression in both $24 \mathrm{~h}$ anoxia and $4 \mathrm{~h}$ recovery could potentially be due to a reliance on the micro-homology mediated end joining (MMEJ) pathway through stress and recovery, as also seen in the skeletal muscle during thawing (Chapter 3.4). Studies have shown that Mre11 nuclease activity is also needed in the MMEJ pathway for short end resection of DNA (Truong et al., 2013; Dutta et al., 2017). To validate this finding, further investigation of the MMEJ pathway in $R$. sylvatica liver will be required.

$\mathrm{XLF}$, DNA Ligase IV, and XRCC4 are the primary proteins involved in DNA ligation in the NHEJ pathway (Ahnesorg et al., 2006). XLF did not show any significant change through $24 \mathrm{~h}$ anoxia and 4 hour recovery in comparison to controls in the liver (Figure 4.3), suggesting its continued and conserved action through the anoxiareoxygenation cycle. However, DNA Ligase IV showed an upregulation in protein expression in $24 \mathrm{~h}$ anoxia and $4 \mathrm{~h}$ recovery. Since DNA Ligase IV is the primary protein 
involved in ligation in NHEJ (Grawunder et al., 1997), an increase in its expression implies ligation through the NHEJ is being upregulated. However, XRCC4 showed the opposite response and was strongly downregulated during $24 \mathrm{~h}$ anoxia, but partially recovered after $4 \mathrm{~h}$ recover. Since many studies have established that XRCC4 forms a complex with DNA Ligase IV and stimulates its activity (Grawunder et al., 1997; Koch et al., 2004), it seems counterintuitive that XRCC4 would be downregulated during anoxia when DNA Ligase IV is upregulated. However, studies have shown that although XLF forms a complex with XRCC4 to stimulate DNA Ligase IV activity, XLF can also do so independently (Roy et al., 2015). Therefore DNA Ligase IV activity during anoxia is potentially stimulated by both XLF and XRCC4, with XRCC4 being downregulated in order to conserve energy amid stress. Additionally, Figure 4.3 shows that Ku70 has an increase in protein expression during $4 \mathrm{~h}$ recovery. As previously discussed in Chapter 1.7, Ku70 is part of the Ku heterodimer that is crucial in marking points of DSB and for recruiting other repair proteins in the NHEJ pathway (Nick McElhinny et al., 2000; Fell and Schild-Poulter, 2015). Therefore, the increase in Ku70 content seen during $4 \mathrm{~h}$ recovery suggests that NHEJ activity is upregulated during recovery to repair DSB. This is in line with the increase in oxidized guanine species observed during $4 \mathrm{~h}$ recovery seen in Figure 4.1. More studies will have to be completed in order to fully delineate NHEJ activity and the ligation activity seen in this pathway through the anoxia-reoxygenation cycle and to validate these findings.

Since the majority of the aforementioned protein targets act as initial markers of DSB prior to DNA repair, or are involved in the NHEJ pathway of DNA repair, the expression of Rad51 was evaluated as a preliminary observation of HR activity across the 
anoxia-reoxygenation cycle in the liver. As previously stated, Rad51 is a critical component of $\mathrm{HR}$ as it is involved in searching for homologous sections and in strand invasion (Godin et al., 2016; Sullivan and Bernstein, 2018). Rad51 protein expression did not differ significantly across the anoxia-reoxygenation cycle in the liver (Figure 4.3). Therefore, this result suggests that Rad51 function is maintained and that HR is used through in the anoxia-reoxygenation cycle in the liver. Analyzing other proteins involved in HR should be completed in the liver to validate this finding and to better understand the HR pathway and its activity across the anoxia-reoxygenation cycle.

The same eight DNA DSB repair proteins were assessed in skeletal muscle over the anoxia-reoxygenation cycle to allow for tissue comparison of these protein targets. As seen in Figure 4.4, Mre11, Rad50, and Phospho-p95 did not display any significant changes in relative protein expression over $24 \mathrm{~h}$ anoxia and $4 \mathrm{~h}$ recovery in comparison to the controls. As previously discussed, these three proteins are part of the MRN complex, and therefore having similar and consistent expression across control, anoxia, and recovery suggests that their function is conserved through the anoxia-reoxygenation cycle. The difference between in Mre11 expression in skeletal muscle (constant) versus in liver (Figure 4.3) again demonstrates evidence of tissue-specific responses by the MRN complex to anoxic exposure.

In terms of the three main proteins involved in end processing and ligation in the NHEJ pathway, it was shown that DNA Ligase IV and XRCC4 did not change significantly in relative expression over $24 \mathrm{~h}$ anoxia and $4 \mathrm{~h}$ recovery in comparison to the controls (Figure 4.4). However, XLF showed very strong and significant downregulation during $24 \mathrm{~h}$ anoxia that was sustained through the $4 \mathrm{~h}$ recovery period. 
Although XLF plays a crucial role in ligation in the NHEJ pathway, its role is similar to that of XRCC4, since both of these proteins can recruit DNA Ligase IV in tandem and independently (Roy et al., 2015). Therefore, this suppression of XLF could be due to the redundancy in its function or perhaps to upstream regulation of XLF versus XRCC4 expression in the specific response to a low oxygen mediated signal. Recent studies have shown that XLF may be involved in other upstream and downstream processes, namely in the choice of the DSB repair pathway, but that it does not provide an essential role in these processes as other proteins are heavily involved (Fattah et al., 2014). Many proteins involved in NHEJ are also involved in V(D)J recombination for lymphocyte development. Studies have shown that in this particular pathway, XLF provides a redundant function as well (Kumar et al., 2016). The redundancy in XLF's role could explain its downregulation as $R$. sylvatica has shown evidence of downregulating many proteins in order to reduce non-essential energy expenditure during anoxic exposure. Additional studies of these proteins involved in ligation and $\mathrm{V}(\mathrm{D}) \mathrm{J}$ recombination will be required to further validate these findings. Expression of $\mathrm{Ku} 70$ decreased significantly during $24 \mathrm{~h}$ anoxia and $4 \mathrm{~h}$ recovery (Figure 4.4), which differs from the liver where $\mathrm{Ku} 70$ increased during recovery (Figure 4.3). As previously mentioned $\mathrm{Ku} 70$ is part of the $\mathrm{Ku}$ heterodimer that works to mark DSBs and has also been shown to be involved in telomere regulation. However, as seen in Chapter 3.4, proteins of the MRN complex are also involved in telomere regulation (Rai et al., 2017; Oh and Symington, 2018).

Therefore, it is possible that $\mathrm{Ku} 70$ is downregulated during anoxia and reoxygenation in an attempt to avoid redundancy in the role of maintaining telomeres, since both Mre11 and Phospho-p95 are conserved through the anoxia-reoxygenation cycle. Future study of 
the role of the $\mathrm{Ku}$ heterodimer in telomere regulation is needed to provide more insight into its roles in $R$. sylvatica in response to anoxia stress.

To provide a glimpse into the regulation of the HR pathway, the relative protein expression of Rad51 was analyzed in muscle and showed a strong decrease in protein expression through $24 \mathrm{~h}$ anoxia and $4 \mathrm{~h}$ recovery (Figure 4.4), that also suggests a reduced function of the protein. As previously discussed in Chapter 1.7, although HR is the more reliable DBS repair pathway, it is limited as it can only occur during the G2 and S phase of the cell cycle when there is a sister chromatid template (Lamarche et al., 2010; Her and Bunting, 2018). Therefore, cells that are not in the appropriate cell cycle phase will not be able to use the HR pathway for DSB repair. Studies have shown that the cell cycle is suppressed in skeletal muscle in response to anoxia in wood frogs (Roufayel et al., 2011; Zhang and Storey, 2012). This suppression could account for the downregulation in Rad51, and could also suggest that HR is suppressed during the anoxia-reoxygenation cycle in skeletal muscle. Cell cycle activity in skeletal muscle also differs vastly from other tissues that undergo continual cell cycle activity as muscle is mostly post-mitotic and depends on satellite cells for regeneration (Grounds, 1991). This could account for the tissue specific difference in Rad51 regulation observed between the skeletal muscle and liver through the anoxia-reoxygenation cycle. Additional studies of the HR pathway through the anoxia-reoxygenation cycle will be required to confirm and validate this finding.

In conclusion, the work presented in this chapter observed DNA damage, antioxidant capacity and DNA DSB repair mechanisms in the liver and skeletal muscle of R. sylvatica across the anoxia-reoxygenation cycle. The results suggest that there are 
tissue specific differences in DNA damage since only the liver exhibited increased oxidative species during recovery. The increase of antioxidant capacity during recovery seen in both tissues could act as a preventative measure in minimizing oxidative stress effects on DNA and other macromolecules when the organism is vulnerable to ROS. The apparent increase in antioxidant capacity during anoxia exposure seen in the skeletal muscle that is absent from the liver demonstrates evidence of a tissue specific response in non-enzymatic antioxidant defence. Furthermore, the relative expression of DNA DSB repair markers suggests that some proteins are conserved to repair DSB, but that there are certain tissue-specific and pathway-specific differences between the liver and skeletal muscle through the anoxia-reoxygenation cycle. These differences can be attributed to an overall attempt to conserve metabolic energy and differences in cell cycle control. Future studies will be required to further observe the antioxidant response and DNA DSB repair mechanisms in R. sylvatica that support survival under oxygen deprivation. 


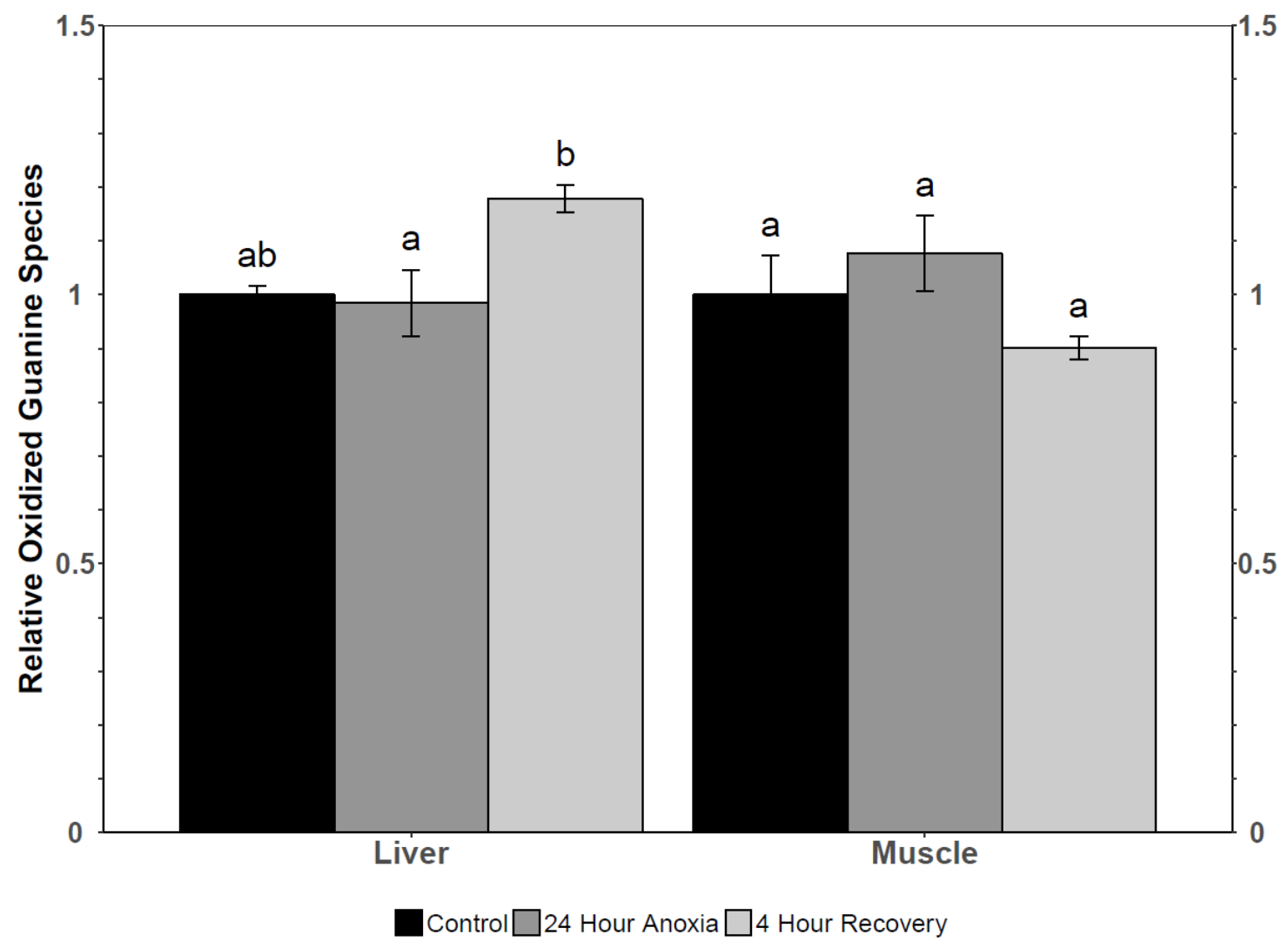

Figure 4.1: DNA damage quantification in $R$. sylvatica liver and muscle through an anoxia-recovery cycle. Relative oxidized guanine species in control, 24 hour anoxia, and 4 hour aerobic recovery conditions. Data are means $\pm S E M, n=3-4$ independent trials. One-way ANOVA and a Tukey's post-hoc test $(\mathrm{p}<0.05)$ were used for analysis; for each tissue, values that share the same letter are not significantly different from each other. 


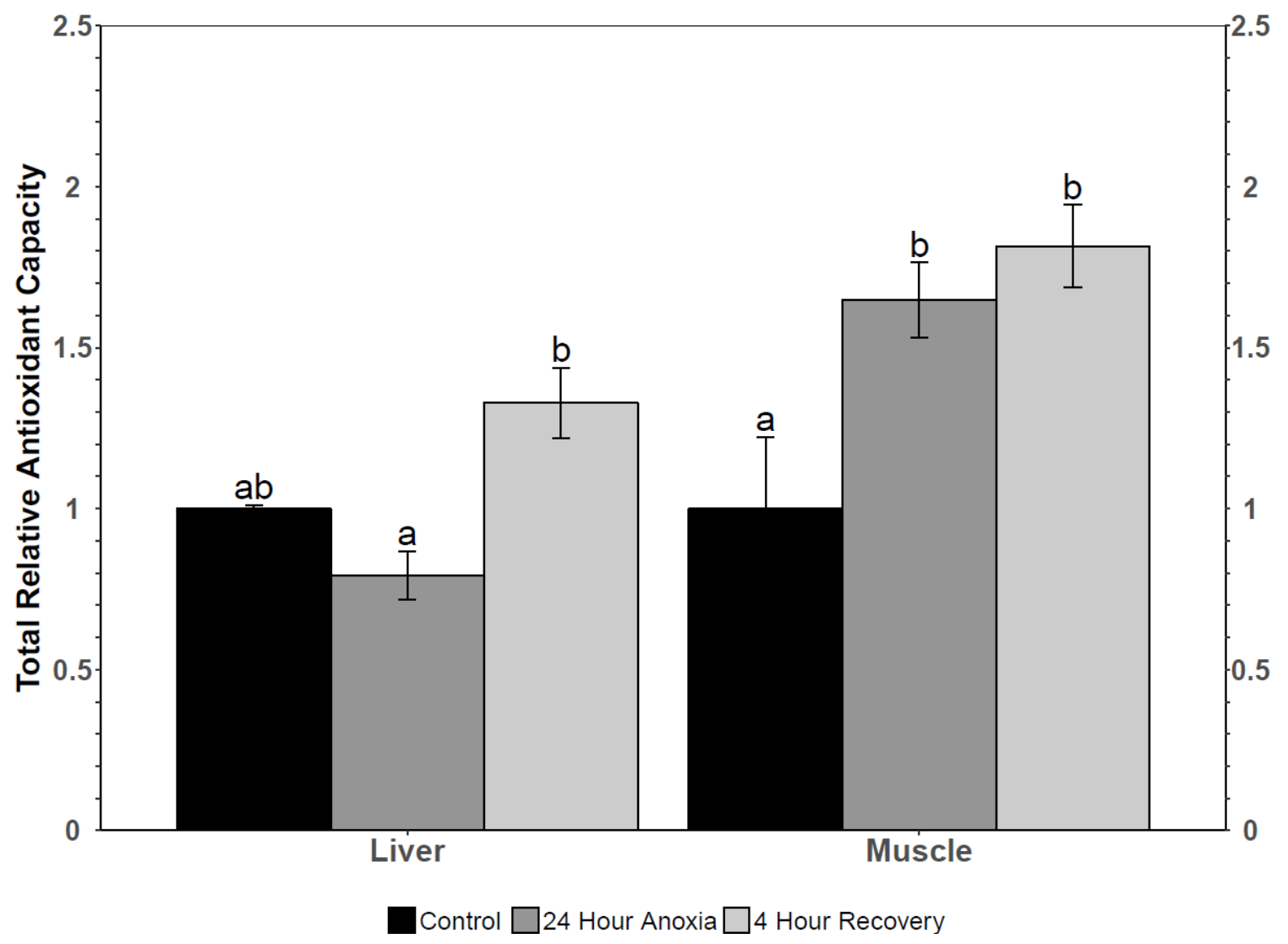

Figure 4.2: Total antioxidant capacity in $R$. sylvatica liver and muscle through an anoxiarecovery cycle. Total relative antioxidant capacity in control, 24 hour anoxia, and 4 hour aerobic recovery conditions. Data are means \pm SEM, $n=3-4$ independent trials. Oneway ANOVA and a Tukey's post-hoc test $(\mathrm{p}<0.05)$ were used for analysis; for each tissue, values that share the same letter are not significantly different from each other. 
A

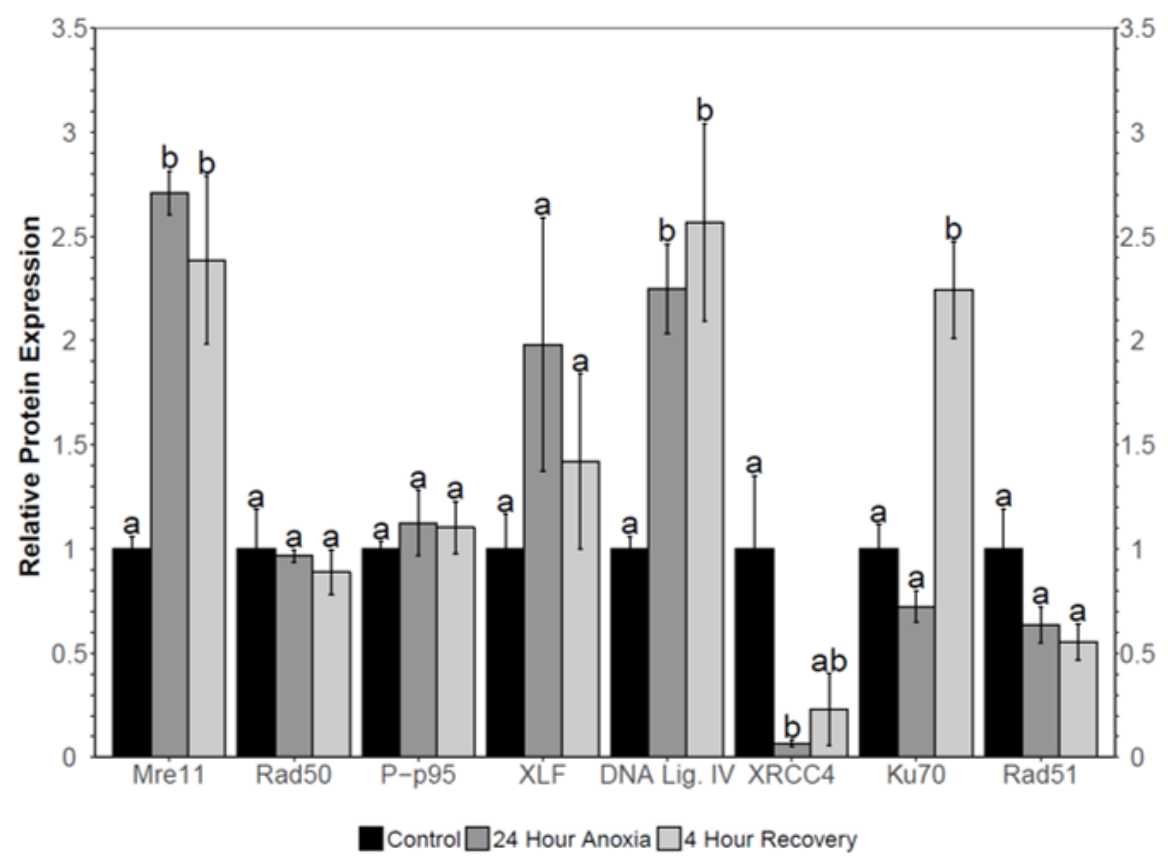

$\mathrm{B}$

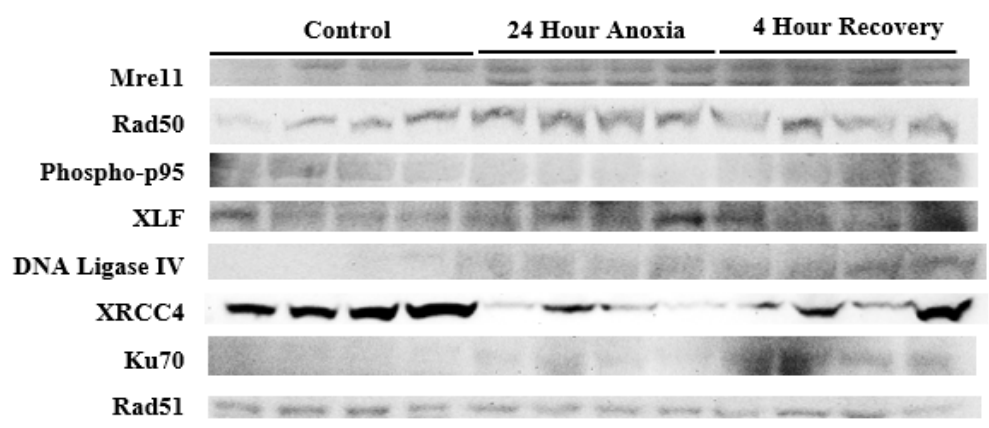

Figure 4.3: Western blot quantification of DSB repair protein expression in $R$. sylvatica liver through an anoxia-recovery cycle. A) Relative protein expression of protein targets in control, 24 hour anoxia, and 4 hour recovery conditions. Data are means \pm SEM, $\mathrm{n}=3$ 4 independent trials. One-way ANOVA and a Tukey's post-hoc test $(\mathrm{p}<0.05)$ were used for analysis; for each protein target, values that share the same letter are not significantly different from each other. B) Western blot of DSB repair protein targets in the corresponding experimental conditions. 
A

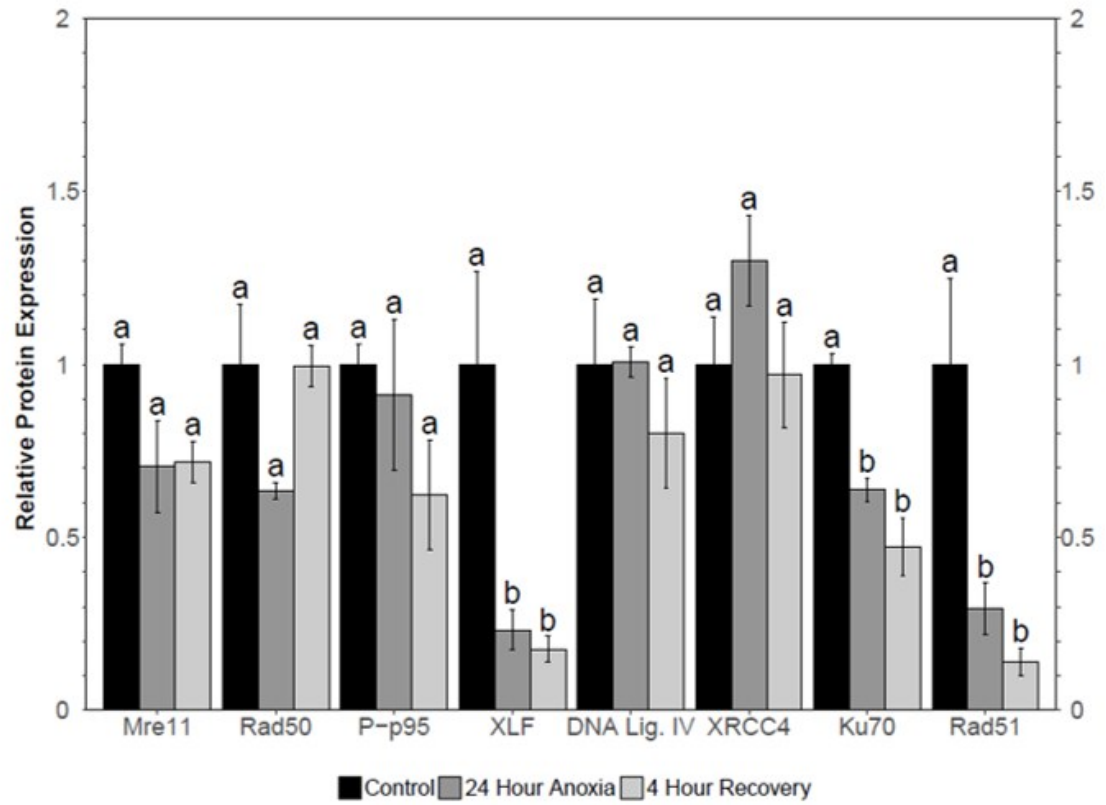

B

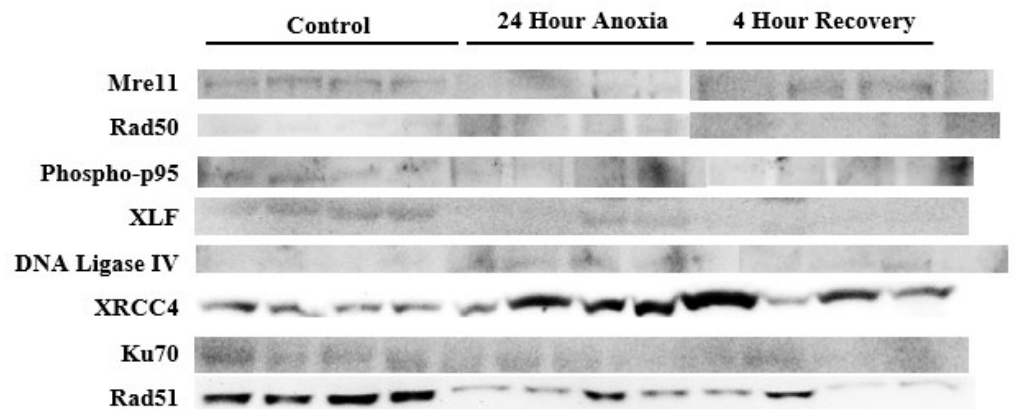

Figure 4.4: Western blot quantification of DSB repair protein expression in $R$. sylvatica skeletal muscle through an anoxia-recovery cycle. A) Relative protein expression of protein targets in control, 24 hour anoxia, and 4 hour recovery conditions. Data are means \pm SEM, $\mathrm{n}=3-4$ independent trials. One-way ANOVA and a Tukey's post-hoc test $(\mathrm{p}<$ 0.05) was used for analysis; for each protein target, values that share the same letter are not significantly different from each other. B) Western blot of DSB repair protein targets in the corresponding experimental conditions. 


\section{Chapter 5}

\section{General Discussion}




\subsection{Freeze tolerance and stress in $R$. sylvatica}

Organisms that live in climates with harsh winters must develop overwintering adaptations in order to survive. The wood frog (Rana sylvatica) is no exception as it has developed an overwintering strategy by freezing on the forest floor and dramatically reducing its metabolic rate. $R$. sylvatica can endure freezing of up to $65 \%$ of its total body water as extracellular ice. Ice nucleation is typically initiated upon epithelial contact with environmental ice, due to freezing of materials (plant matter, soil, etc.) in the moist surroundings of the hibernacula. Ice nucleation can also be triggered by the action of icenucleating bacteria on the skin or in the gut, as well as by INPs that are found in the blood (Costanzo and Lee, 1996; Storey and Storey, 1996). Once the wood frog is fully frozen and extracellular water is converted to ice, vital functions like breathing, muscle movement, nerve conductivity, and heartbeat are fully stopped. Interruption in blood flow prevents oxygen delivery to organs, which induces a state of anoxia and ischemia. As such, the electron transport chain becomes reduced and aerobic ATP production stops, thus, leaving cells to rely on anaerobic glycolysis for production of ATP (Storey and Storey, 2017). Given that the amount of ATP produced anaerobically is much less than the amount of ATP generated under aerobic conditions, cells reduce their metabolic rates to conserve the finite amount of ATP available and balance ATP production with ATP expenditure (Storey and Storey, 2004a; Costanzo and Lee, 2013).

In order to protect their cells while experiencing this stress, $R$. sylvatica elevates its glucose levels (from $5 \mathrm{mM}$ in normal conditions to $300 \mathrm{mM}$ during freezing) and uses it as the main cryoprotectant through the winter (Layne et al., 1996; Storey and Storey, 2017). This done by converting stored liver glycogen into glucose, which is then 
delivered to all other organs via the blood during the early hours as the frog is freezing (Larson and Barnes, 2016). Metabolic rate depression is achieved through whole body reduction of cellular processes and movement in order to reduce ATP demand and glycolytic waste accumulation (Regan et al., 2017). One of the most energy demanding process that is greatly reduced during metabolic rate depression is protein synthesis, as it is very sensitive to energy and amino acid availability; both of which are limited when the organism endures stress and starvation (DeGracia et al., 2002). This reduction in metabolic activity causes many metabolic pathways to exhibit differential expression while experiencing environmental stress.

As previously mentioned in Chapter 1.4, the wood frog has the ability to endure anoxia, dehydration, and hyperglycemia in association with freezing. Due to the multifaceted nature of freezing, wood frogs must be able to deal with the unique limitations of each stress. As such, many studies have demonstrated that there are stressspecific responses and regulation of many metabolic processes seen in the wood frog. For example, a recent study has shown that $R$. sylvatica exhibits stress specific regulation of enzymes involved in glycolysis and the urea cycle through reversible phosphorylation (Hawkins et al., 2019). This study not only shows the importance of reversible PTMs in adapting to stress but how key metabolic processes have unique adaptations to different stresses that are also tissue specific. Transcription factors involved in glucose transport and other important cellular processes have shown unique stress-specific regulation, and also demonstrate how transcription factor regulation in freezing may have originated in the organism's response to other stresses (anoxia in this case) (Hoyeck et al., 2017). Studies have also shown differences in cell cycle regulation between freezing, anoxia, 
and dehydration in $R$. sylvatica liver, again demonstrating the importance of stressspecific responses (Zhang and Storey, 2012). The plethora of studies that have demonstrated stress specific responses in $R$. sylvatica show the complexity of adapting to environmental stress and the importance of comparative studies in this model organism. Additionally, there are unique adaptations to each stress that might be developed for various medical applications; ranging from organ preservation to diabetes control to diseases related to ischemia (such as stroke and cardiovascular disease). The unique adaptations of the wood frog allow it to be an excellent animal model to study cellular processes through stress and recovery.

\subsection{Stress specific expression of DNA damage}

As previously discussed in Chapter 1.4 and Chapter 1.5, reperfusion and reoxygenation greatly increase the wood frog's susceptibility to increased ROS and subsequent oxidative damage to DNA. As such, oxidative damage to guanine species was observed in R. sylvatica liver and skeletal muscle through the freeze-thaw cycle (Chapter 3) and the anoxia-reoxygenation cycle (Chapter 4), and represents the first analysis of DNA oxidative damage in response to environmental stress in $R$. sylvatica. As seen in Figure 3.1, there were no significant changes in the expression of oxidized guanine species amid the freeze-thaw cycle in liver and skeletal muscle. This suggests that the level of oxidized guanine species remains constant through freezing and thawing, and that most likely preventative mechanisms such as antioxidant defence systems halt any increase of oxidative damage to DNA. Contrastingly, the anoxia-reoxygenation cycle (Figure 4.1) showed an increase in oxidized guanine species during $4 \mathrm{~h}$ aerobic 
recovery in the liver, but no changes in oxidized guanine species in skeletal muscle across the anoxia-reoxygenation cycle. In addition to the tissue specific responses that may occur as previously mentioned, these results suggest that aerobic recovery greatly increases susceptibility of wood frogs to oxidative damage in the liver as seen from evidence of increased levels of oxidized guanine species. Since it is well known that wood frogs can recover from anoxia unscathed, the observation of an increase in oxidized species suggests that they use antioxidant defences to minimize damage as well as repair mechanisms in place to counteract any damage and retain full genomic and metabolic integrity. Since only oxidized guanine species was observed, future research into the oxidation of other bases and of other macromolecules, such as lipids and proteins, which can also lead to DNA damage will allow for broadened insight into DNA damage through the freeze-thaw cycle and anoxia-reoxygenation cycle.

\subsection{Stress specific responses in total antioxidant capacity}

As discussed in Chapter 1.6, many enzymatic and non-enzymatic antioxidants work to detoxify ROS and prevent oxidative damage. Previous studies have shown upregulation and unique adaptations of prominent antioxidant enzymes (e.g. catalase and glutathione-utilizing enzymes) in the wood frog during freezing and thawing (Dawson and Storey, 2016; Dawson and Storey, 2017). By observing total antioxidant capacity of several non-enzymatic factors through freezing (Chapter 3) and anoxia (Chapter 4), this allowed for the observation of non-enzymatic antioxidant capacity across these stresses in conjunction with DNA oxidation (previously discussed in Chapter 5.2) and for any stress specific regulation to be determined. Figure 3.2 depicts the relative expression of 
several non-enzymatic antioxidant factors through the freeze-thaw cycle in liver and skeletal muscle. The results imply that non-enzymatic factors are being used in the liver during thawing since non-enzymatic antioxidant factors were depleted to counteract and detoxify ROS. The consistent expression of non-enzymatic antioxidant factors in skeletal muscle across the freeze-thaw cycle suggests that muscle may be exposed to consistent levels of ROS through freezing and thawing and therefore does not need to augment its antioxidant capacity through the cycle. As per the anoxia-reoxygenation cycle (Figure 4.2), there is an increase in relative antioxidant capacity during aerobic recovery in the liver and during anoxia and aerobic recovery in the skeletal muscle. This increase seen in both tissues suggests that non-enzymatic antioxidant factors are being produced in higher quantities to detoxify ROS and prevent oxidative damage. These results further demonstrate stress specific regulation of non-enzymatic antioxidant factors, and suggest that reoxygenation may generate higher threats of ROS in comparison to reperfusion. Further studies of more prominent enzymatic and non-enzymatic antioxidant defenses will be required to solidify knowledge of antioxidant capacity across stress/recovery in the wood frog.

\subsection{Stress specific regulation in DNA DSB repair}

When antioxidant defences are depleted or overwhelmed during stress, oxidative damage can occur and require repair mechanisms (Chapter 1.7). DNA DSB repair mechanisms have not been explored in the context of stress and recovery in R. sylvatica or similar animal models that undergo stress. However, a study of red-eared slider turtles (Trachemys scripta elegans) has demonstrated that $\mathrm{p} 53$, which does have a role in 
signaling DNA damage repair, is upregulated in response to oxygen deprivation (Zhang et al., 2013), suggesting that DNA repair could play a role in maintaining DNA integrity amid oxidative stress. As per the present study, it can be seen that many DNA DSB repair proteins are consistently expressed through stress and recovery under freezing and anoxia conditions in the liver and skeletal muscle (Figure 3.3, Figure 3.4, Figure 4.3, and Figure 4.4). Consistency in protein expression suggests that these proteins are conserved through stress and recovery in order to counteract any oxidative threat, but that perhaps oxidative damage to DNA is not significantly increased during stress and recovery. However, these results do show certain tissue specific and stress specific responses among selected DNA DSB repair targets suggesting that there are differences in oxidative stress and regulation of DNA repair mechanisms between freezing and anoxia. These stress specific differences can be mainly attributed to the difference in metabolic regulation and other cellular processes between freezing and anoxia that are needed in order to promote survival. This study only focused on eight major targets of NHEJ and HR, and therefore additional studies on further upstream and downstream proteins involved in these two pathways of DNA DSB repair will be required to validate and solidify insights into DSB repair through stress and recovery. Additionally, a study of additional DNA repair pathways (both of DSB and ssDNA breaks) will allow for observation of other potential DNA damage that occurs and which types of repair pathways are being promoted to preserve genomic integrity across cycles of freeze-thaw and anoxia-reoxygenation. 


\subsection{Conclusion}

R. sylvatica has the remarkable capacity to endure multiple different environmental stresses, including freezing and anoxia. As such, wood frogs modify and tightly regulate many cellular and metabolic processes in order to ensure survival and overcome any limitations through stress and recovery. One major limitation the wood frog must withstand is the impending threat of oxidative stress from ROS that arises upon reperfusion and reoxygenation. The wood frog can strategically adapt many cellular processes to prevent the onset of oxidative damage from ROS or use repair mechanisms to fix any damage that may occur from oxidative stress. The levels of oxidized DNA (observed as oxidized guanine species) was largely held constant under the many conditions assessed in this study. In conjunction with the observed expression of nonenzymatic antioxidant factors this suggests that antioxidant factors play a role in preventing DNA oxidative damage in the liver and skeletal muscle during environmental stress conditions that include freezing and oxygen limitation. Additionally, DNA DSB repair mechanisms are adapted to deal with oxidative damage that occurs, but is also adapted in a manner that can conserve energy amid MRD through cycles of freeze-thaw or anoxia-reoxygenation. As the first study of its type, the present thesis provides data that indicates mechanisms that preserve genomic integrity in the face of environmental stress is something that deserves further study in other animal models that endure extreme environmental stresses. 


\subsection{Future direction}

Although the studies in this thesis illuminate many aspects of DNA oxidative damage, antioxidant capacity, and DNA DSB repair mechanisms in the wood frog, there are still many factors that have yet to be studied to provide a comprehensive analysis of oxidative damage and preservation of genomic integrity through freezing and anoxia. To begin with, observing the oxidation of other DNA bases in addition to guanine, along with RNA oxidation, lipid peroxidation, and protein oxidation will allow for a more extensive and thorough view on oxidative damage through the freeze-thaw cycle and anoxia-reoxygenation. Observing the extent of oxidative stress and the different types of damage that occurs allows for targeted antioxidant defences and repair mechanism and a more complete view on how oxidative damage is prevented or minimized. Antioxidant defences and oxidative damage to DNA, lipids, and proteins have been observed in various organisms that endure environmental stresses (Hermes-Lima et al., 2001) However, only a few antioxidant enzymes are thoroughly characterized in the wood frog as catalase and glutathione reductase have been observed in the context of freezing (Dawson and Storey, 2016; Dawson and Storey, 2017). Antioxidant capacity is a complex synergetic effort of both enzymatic and non-enzymatic factors (Birben et al., 2012). Therefore, observing the enzymatic activity of other prominent antioxidant enzymes in depth (such as superoxide dismutase, glutathione peroxidase, peroxidases, etc.) in conjunction with non-enzymatic factors mentioned in this thesis in seclusion to 
analyze their unique expression through stress and recovery will provide more information on antioxidant capacity in response to ROS.

Due to its complexity, there are numerous proteins involved in DNA repair that were not analyzed in this study. DNA-dependent protein kinase, catalytic subunit (DNAPKcs), ataxia telangiectasia mutated (ATM), and ataxia telangiectasia Rad3-related protein (ATR) are three phosphatidylinositol 3-kinase-related kinases (PIKKs) heavily involved in DNA cell cycle checkpoints and signaling DNA damage to downstream targets (Falck et al., 2005; Awasthi et al., 2016). Studying these protein kinases will provide major insights into the regulation of DNA DSB pathway, and are thus important future targets to analyze in the context of DNA repair. There are also several other proteins involved in NHEJ that can be examined to determine their responses to freezing and anoxia conditions in $R$. sylvatica to better understand the regulation of NHEJ through stress and recovery. For example, Ku70 alone was studied in this thesis, but since it works as a heterodimer in conjunction with Ku80 (Fell and Schild-Poulter, 2015), a comparable analysis of Ku80 would provide a more detailed view of the action of the whole complex freezing and anoxia. Additionally, 53BPI is a protein that helps determine the choice of repair pathway by restricting resection and promoting NHEJ (Lee et al., 2010), thus making it an important marker to study in the context of NHEJ. Artemis is another prominent NHEJ target to be studied as it cuts damaged bases and works together with DNA-PKcs, ATM, and 53BPI (Chang and Lieber, 2016). The X family of DNA polymerases Pol $\lambda$ and Pol $\mu$ are also important and involved in filling in the base pairs of gaps in the damaged area (Yamtich and Sweasy, 2010). HR was not extensively studied in the present thesis, and therefore additional study of the proteins 
will improve our knowledge of the DNA DSB pathway choice and HR activity during freezing and anoxia. As previously mentioned in Chapter 1.7, Sgs 1 and Exo1 work together to unwind and cut single stranded DNA (ssDNA) during HR (Mimitou and Symington, 2008). BRCA1, RPA, and Rad52 are proteins involved in filament formation in HR (Wu et al., 2010; Suwaki et al., 2011), and are also important HR markers that could be studied. Rad54, GEN1, and SLX1/4 resolve the Holliday junction (Suwaki et al., 2011; Grabarz et al., 2012), and its analysis will provide additional insight into HR regulation under environmental stress in wood frogs. Additionally, studying BER, NER, and MMR will provide insights into how damaged base pairs are excised and corrected (Friedberg, 2003) and would allow exploration of other avenues of DNA repair that could be used by wood frogs. These targets can be explored using western blotting or as transcriptional studies using polymerase chain reaction (PCR).

Recent studies have illuminated the relationship between ATM, ATR and the teneleven translocation (TET) family of enzymes involved in DNA demethylation. These studies have shown that TET-1 demethylation during ATM activity further promotes DNA DSB repair, and has significant influence on Purkinje cell viability (Jiang et al., 2015). Additionally, DNA damage repair mediated by ATR also influences TET-3 activity and its demethylation activity (Jiang et al., 2017). The TET family can be studied using western blots, DNA dot blots, and activity kits. However, the two aforementioned studies of the TET family in conjunction with ATM and ATR analysis used additional techniques such as microarrays and DNA immunoprecipitation sequencing to validate their findings. Future studies of the responses of the TET family over the freeze-thaw or anoxia-reoxygenation cycles in the wood frog using these additional techniques will not 
only open an investigation of DNA demethylation in the wood frog, but also investigation in tandem with ATM and ATR, particularly in the brain, will allow for a link between epigenetics and DNA repair to be assessed.

As shown through many previous studies of R. sylvatica and in Chapter $\mathbf{3}$ and Chapter 4, the different roles of each organ during stress and recovery influence tissue specific regulation (Storey and Storey, 2017). The studies in this thesis only explored liver and skeletal muscle. Thus, future studies exploring DNA damage, antioxidant capacity, and DNA repair mechanisms in other tissues such as the brain, heart, lung, and kidney will provide a broader understanding of the whole body response to oxidative stress amid freeze-thaw and anoxia-reoxygenation cycles. As discussed in Chapter 1.4, R. sylvatica can also endure dehydration and hyperglycemia, each inducing unique adaptations to promote survival. Since each stress requires unique cellular and metabolic adaptations and prompts stress specific regulation, further analysis of DNA oxidative damage, non-enzymatic antioxidant capacity, and DNA repair in the context of dehydration and hyperglycemia will allow exploration of adaptations to different environmental stresses. Studies of cellular and metabolic processes involved in dehydration and hyperglycemia resistance could be of relevance to medical applications in these areas.

The aforementioned targets and experiments are just some examples of how research into DNA damage, antioxidant capacity, and DNA repair can be further advanced in the future. These experiments, using the incredible model that is $R$. sylvatica, will allow for the application of this research into diverse medical contexts (such as cryopreservation of cells/tissues/organs, diabetes, and ischemia related diseases, etc.). 
Additionally, as the compromise of DNA integrity is the basis of many medical conditions, research in this area has great potential to broaden understanding of the importance of DNA integrity and adaptations that promote maintenance and survival. 


\section{References}


Abboud, J. and Storey, K. B. (2013). Novel control of lactate dehydrogenase from the freeze tolerant wood frog: role of posttranslational modifications. PeerJ 1, e12.

Ahnesorg, P., Smith, P. and Jackson, S. P. (2006). XLF interacts with the XRCC4DNA Ligase IV complex to promote DNA nonhomologous end-joining. Cell. 124, $301-313$.

Al-attar, R., Wijenayake, S. and Storey, K. B. (2019). Metabolic reorganization in winter: Regulation of pyruvate dehydrogenase (PDH) during long-term freezing and anoxia. Cryobiology 86, 10-18.

Alnajjar, K. S. and Sweasy, J. B. (2019). A new perspective on oxidation of DNA repair proteins and cancer. DNA Repair (Amst). 76, 60-69.

Arnoult, N., Correia, A., Ma, J., Merlo, A., Garcia-Gomez, S., Maric, M., Tognetti, M., Benner, C. W., Boulton, S. J., Saghatelian, A., et al. (2017). Regulation of DNA repair pathway choice in S and G2 phases by the NHEJ inhibitor CYREN. Nature 549, 548-552.

Awasthi, P., Foiani, M. and Kumar, A. (2016). ATM and ATR signaling at a glance. $J$. Cell Sci.128, 4255-4262.

Balaban, R. S., Nemoto, S. and Finkel, T. (2005). Mitochondria, Oxidants, and Aging. Cell 120, 483-495.

Belhadj Slimen, I., Najar, T., Ghram, A., Dabbebi, H., Ben Mrad, M. and Abdrabbah, M. (2014). Reactive oxygen species, heat stress and oxidative-induced mitochondrial damage. A review. Int. J. Hyperth. 30, 513-523. 
Birben, E., Sahiner, U. M., Sackesen, C., Erzurum, S. and Kalayci, O. (2012).

Oxidative Stress and Antioxidant Defense. World Allergy Organ. J. 5, 9-19.

Burrows, C. J. and Muller, J. G. (1998). Oxidative Nucleobase Modifications Leading to Strand Scission. Chem. Rev. 98, 1109-1152.

Cannan, W. J. and Pederson, D. S. (2016). Mechanisms and Consequences of DoubleStrand DNA Break Formation in Chromatin. J. Cell. Physiol. 231, 3-14.

Ceccaldi, R., Rondinelli, B. and D'Andrea, A. D. (2016). Repair Pathway Choices and Consequences at the Double-Strand Break. Trends Cell Biol. 26, 52-64.

Chan, A. C. (1993). Partners in defense, vitamin E and vitamin C. Can. J. Physiol. Pharmacol. 71, 725-731.

Chang, H. H. Y. and Lieber, M. R. (2016). Structure-Specific nuclease activities of Artemis and the Artemis: DNA-PKcs complex. Nucleic Acids Res.44, 4991-4997.

Chang, H. H. Y., Pannunzio, N. R., Adachi, N. and Lieber, M. R. (2017). Nonhomologous DNA end joining and alternative pathways to double-strand break repair. Nat. Rev. Mol. Cell Biol. 18, 495-506.

Cooke, M. S., Evans, M. D., Dizdaroglu, M. and Lunec, J. (2003). Oxidative DNA damage: mechanisms, mutation, and disease. FASEB J. 17, 1195-1214.

Costanzo, J. P. (2005). Cryoprotection by urea in a terrestrially hibernating frog. J. Exp. Biol. 208, 4079-4089.

Costanzo, J. P. (2019). Overwintering adaptations and extreme freeze tolerance in a subarctic population of the wood frog, Rana sylvatica. J. Comp. Physiol. B 189, 1- 
15.

Costanzo, J. P. and Lee, R. E. (1996). Mini-review: Ice nucleation in freeze-tolerant vertebrates. Cryo-Letters. 17, 111-118.

Costanzo, J. P. and Lee, R. E. (2013). Avoidance and tolerance of freezing in ectothermic vertebrates. J. Exp. Biol. 216, 1961-1967.

Costanzo, J. P., Lee, R. J. and Lortz, P. H. (1993). Glucose Concentration Regulates Freeze Tolerance in the Wood Frog Rana Sylvatica. J. Exp. Biol.181, 245-255.

Costanzo, J. P., Callahan, P. A., Lee Jr, R. E. and Wright, M. F. (1997). Frogs reabsorb glucose from urinary bladder. Nature 389, 343-344.

Costanzo, J. P., Litzgus, J. D., Iverson, J. B. and Lee, R. J. (2000). Seasonal changes in physiology and development of cold hardiness in the hatchling painted turtle Chrysemys picta. J Exp Biol.203, 3459-3470.

Costanzo, J. P., Reynolds, A. M., do Amaral, M. C. F., Rosendale, A. J., Lee, R. E. and Jr. (2015). Cryoprotectants and extreme freeze tolerance in a subarctic population of the wood frog. PLoS One 10, e0117234.

Dawson, N. J. and Storey, K. B. (2016). A hydrogen peroxide safety valve: The reversible phosphorylation of catalase from the freeze-tolerant North American wood frog, Rana sylvatica. Biochim. Biophys. Acta - Gen. Subj. 1860, 476-485.

Dawson, N. J. and Storey, K. B. (2017). Passive regeneration of glutathione: glutathione reductase regulation in the freeze-tolerant North American wood frog, Rana sylvatica. J. Exp. Biol. 220, 3162-3171. 
DeGracia, D. J., Kumar, R., Owen, C. R., Krause, G. S. and White, B. C. (2002). Molecular Pathways of Protein Synthesis Inhibition during Brain Reperfusion: Implications for Neuronal Survival or Death. J. Cereb. Blood Flow Metab. 22, 127141.

Dutta, A., Eckelmann, B., Adhikari, S., Ahmed, K. M., Sengupta, S., Pandey, A., Hegde, P. M., Tsai, M. S., Tainer, J. A., Weinfeld, M., et al. (2017). Microhomology-mediated end joining is activated in irradiated human cells due to phosphorylation-dependent formation of the XRCC1 repair complex. Nucleic Acids Res.45, 2585-2599.

Elias, R. J., Kellerby, S. S. and Decker, E. A. (2008). Antioxidant Activity of Proteins and Peptides. Crit. Rev. Food Sci. Nutr. 48, 430-441.

Fago, A. and Jensen, F. B. (2015). Hypoxia Tolerance, Nitric Oxide, and Nitrite: Lessons From Extreme Animals. Physiology. 30, 116-126.

Falck, J., Coates, J. and Jackson, S. P. (2005). Conserved modes of recruitment of ATM, ATR and DNA-PKcs to sites of DNA damage. Nature. 434, 605-611.

Fattah, F. J., Kweon, J., Wang, Y., Lee, E. H., Kan, Y., Lichter, N., Weisensel, N. and Hendrickson, E. A. (2014). A role for XLF in DNA repair and recombination in human somatic cells. DNA Repair (Amst). 15, 39-53.

Fell, V. L. and Schild-Poulter, C. (2015). The Ku heterodimer: Function in DNA repair and beyond. Mutat. Res. Mutat. Res. 763, 15-29.

Finkel, T. (2011). Signal transduction by reactive oxygen species. J. Cell Biol. 194, 7- 
15.

Fleck, O. and Nielsen, O. (2004). DNA repair. J. Cell Sci. 117, 515-517.

Friedberg, E. C. (2003). DNA damage and repair. Nature. 421, 436-440.

Gerber, V. E. M., Wijenayake, S. and Storey, K. B. (2016). Anti-apoptotic response during anoxia and recovery in a freeze-tolerant wood frog (Rana sylvatica). PeerJ. 4, e1834.

Godin, S. K., Sullivan, M. R. and Bernstein, K. A. (2016). Novel insights into RAD51 activity and regulation during homologous recombination and DNA replication. Biochem. Cell Biol. 94, 407-418.

Grabarz, A., Barascu, A., Guirouilh-Barbat, J. and Lopez, B. S. (2012). Initiation of DNA double strand break repair: signaling and single-stranded resection dictate the choice between homologous recombination, non-homologous end-joining and alternative end-joining. Am. J. Cancer Res. 2, 249-268.

Grawunder, U., Wilm, M., Wu, X., Kulesza, P., Wilson, T. E., Mann, M. and Lieber, M. R. (1997). Activity of DNA ligase IV stimulated by complex formation with XRCC4 protein in mammalian cells. Nature. 388, 492-495.

Grounds, M. D. (1991). Towards Understanding Skeletal Muscle Regeneration. Pathol. Res. Pract. 187, 1-22.

Hawkins, L. J., Wang, M., Zhang, B., Xiao, Q., Wang, H. and Storey, K. B. (2019). Glucose and urea metabolic enzymes are differentially phosphorylated during freezing, anoxia, and dehydration exposures in a freeze tolerant frog. Comp. 
Biochem. Physiol. Part D Genomics Proteomics 30, 1-13.

Hemmings, S. J. and Storey, K. B. (2001). Characterization of sarcolemma and sarcoplasmic reticulum isolated from skeletal muscle of the freeze tolerant wood frog, Rana sylvatica: the $\beta(2)$-adrenergic receptor and calcium transport systems in control, frozen and thawed states. Cell Biochem. Funct. 19, 143-152.

Her, J. and Bunting, S. F. (2018). How cells ensure correct repair of DNA doublestrand breaks. J. Biol. Chem. 293, 10502-10511.

Hermes-Lima, M. (2004). Oxygen in biology and biochemistry: role of free radicals. In Functional Metabolism: Regulation and Adaptation (ed K.B. Storey), pp 319-368. Hoboken: John Wiley ad Sons Inc.

Hermes-Lima, M., Storey, J.M., and Storey K.B. (2001). Antioxidant defenses and animal adaptation to oxygen availability during environmental stress. In Cell and Molecular Response to Stress. Volume 2: Protein Adaptations and Signal Transduction (ed. K.B. Storey and J.M. Storey), pp 263-287. Amsterdam: Elsevier Press.

Hermes-Lima, M. and Zenteno-Savín, T. (2002). Animal response to drastic changes in oxygen availability and physiological oxidative stress. Comp. Biochem. Physiol. Part C Toxicol. Pharmacol. 133, 537-556.

Hoyeck, M. P., Hadj-Moussa, H. and Storey, K. B. (2017). The role of MEF2 transcription factors in dehydration and anoxia survival in Rana sylvatica skeletal muscle . PeerJ. 5, e4014. 
Irwin, J. T., Costanzo, J. P. and Lee, Jr., R. E. (2003). Postfreeze Reduction of Locomotor Endurance in the Freeze-Tolerant Wood Frog, Rana sylvatica. Physiol. Biochem. Zool. 76, 331-338.

Jackson, D. C. and Ultsch, G. R. (2010). Physiology of hibernation under the ice by turtles and frogs. J. Exp. Zool. Part A Ecol. Genet. Physiol. 313A, 311-327.

Jasin, M. and Rothstein, R. (2013). Repair of Strand Breaks by Homologous Recombination. Cold Spring Harb. Perspect. Biol. 5, a012740.

Jiang, D., Zhang, Y., Hart, R. P., Chen, J., Herrup, K. and Li, J. (2015). Alteration in 5-hydroxymethylcytosine-mediated epigenetic regulation leads to Purkinje cell vulnerability in ATM deficiency. Brain 138, 3520-3536.

Jiang, D., Wei, S., Chen, F., Zhang, Y. and Li, J. (2017). TET3-mediated DNA oxidation promotes ATR-dependent DNA damage response. EMBO Rep.5, 781-796.

Joanisse, D. R. and Storey, K. B. (1996). Oxidative damage and antioxidants in Rana sylvatica, the freeze-tolerant wood frog. Am. J. Physiol. Integr. Comp. Physiol. 271, $545-553$.

Koch, C. A., Agyei, R., Galicia, S., Metalnikov, P., O’Donnell, P., Starostine, A., Weinfeld, M. and Durocher, D. (2004). Xrce4 physically links DNA end processing by polynucleotide kinase to DNA ligation by DNA ligase IV. EMBO J. 23, 3874-3885.

Kumar, V., Alt, F. W. and Frock, R. L. (2016). PAXX and XLF DNA repair factors are functionally redundant in joining DNA breaks in a G1-arrested progenitor B-cell 
line. Proc. Natl. Acad. Sci. 113, 10619-10624.

Lamarche, B. J., Orazio, N. I. and Weitzman, M. D. (2010). The MRN complex in double-strand break repair and telomere maintenance. FEBS Lett. 584, 3682-3695.

Lans, H., Marteijn, J. A. and Vermeulen, W. (2012). ATP-dependent chromatin remodeling in the DNA-damage response. Epigenetics Chromatin 5, 4.

Larson, D. J. and Barnes, B. M. (2016). Cryoprotectant Production in Freeze-Tolerant Wood Frogs Is Augmented by Multiple Freeze-Thaw Cycles. Physiol. Biochem. Zool. 89, 340-346.

Layne, J. R. (1992). Postfreeze survival and muscle function in the leopard frog (Rana pipiens) and the wood frog (Rana sylvatica). J. Therm. Biol. 17, 121-124.

Layne, J. R., Lee, R. E. and Cutwa, M. M. (1996). Post-Hibernation Excretion of Glucose in Urine of the Freeze Tolerant Frog Rana sylvatica. J. Herpetol. 30, 85.

Lee, R. E., Costanzo, J. P., Davidson, E. C. and Layne, J. R. (1992). Dynamics of body water during freezing and thawing in a freeze-tolerant frog (Rana sylvatica). $J$. Therm. Biol. 17, 263-266.

Lee, J. H., Goodarzi, A. A., Jeggo, P. A. and Paull, T. T. (2010). 53BP1 promotes ATM activity through direct interactions with the MRN complex. EMBO J.29, 574585.

Ma, Y., Schwarz, K. and Lieber, M. R. (2005). The Artemis:DNA-PKcs endonuclease cleaves DNA loops, flaps, and gaps. DNA Repair (Amst). 4, 845-851.

Mao, Z., Bozzella, M., Seluanov, A. and Gorbunova, V. (2008). Comparison of 
nonhomologous end joining and homologous recombination in human cells. DNA Repair (Amst). 7, 1765-1771.

Marrocco, I., Altieri, F. and Peluso, I. (2017). Measurement and Clinical Significance of Biomarkers of Oxidative Stress in Humans. Oxid. Med. Cell. Longev. 2017, 1-32.

Mayer, A. and Vaupel, P. (2013). Hypoxia, Lactate Accumulation, and Acidosis: Siblings or Accomplices Driving Tumor Progression and Resistance to Therapy? In Advances in Experimental Medicine and Biology. 789, 203-209.

Merlin, C. and Liedvogel, M. (2019). The genetics and epigenetics of animal migration and orientation: birds, butterflies and beyond. J. Exp. Biol. 222, jeb191890.

Middle, L. B. and Barnes, B. M. (2001). Overwintering physiology of the wood frog, Rana sylvatica, in interior Alaska. Am. Zool.41, 1526-1527.

Mimitou, E. P. and Symington, L. S. (2008). Sae2, Exo1 and Sgs1 collaborate in DNA double-strand break processing. Nature. $\mathbf{4 5 5}, 770-774$.

Morrissey, R. E. and Baust, J. G. (1976). The ontogeny of cold tolerance in the gall fly, Eurosta solidagensis. J. Insect Physiol. 22, 431-437.

Nick McElhinny, S. A., Snowden, C. M., McCarville, J. and Ramsden, D. A. (2000). Ku Recruits the XRCC4-Ligase IV Complex to DNA Ends. Mol. Cell. Biol. 20, 2996-3003.

Niki, E. (2014). Role of vitamin E as a lipid-soluble peroxyl radical scavenger: in vitro and in vivo evidence. Free Radic. Biol. Med. 66, 3-12.

Oh, J. and Symington, L. (2018). Role of the Mre11 Complex in Preserving Genome 
Integrity. Genes (Basel). 9, 589.

Packard, G. C. and Packard, M. J. (2004). Natural freeze-tolerance in reptiles. CryoLetters. 25, 235-236.

Pamenter, M. E., Dzal, Y. A., Thompson, W. A. and Milsom, W. K. (2019). Do naked mole rats accumulate a metabolic acidosis or an oxygen debt in severe hypoxia? $J$. Exp. Biol. 222, jeb191197.

Rai, R., Hu, C., Broton, C., Chen, Y., Lei, M. and Chang, S. (2017). NBS1 Phosphorylation Status Dictates Repair Choice of Dysfunctional Telomeres. Mol. Cell 65, 801-817.e4.

Ray, P. D., Huang, B.-W. and Tsuji, Y. (2012). Reactive oxygen species (ROS) homeostasis and redox regulation in cellular signaling. Cell. Signal. 24, 981-990.

Regan, M. D., Gill, I. S. and Richards, J. G. (2017). Calorespirometry reveals that goldfish prioritize aerobic metabolism over metabolic rate depression in all but nearanoxic environments. J. Exp. Biol. 220, 564-572.

Rickards, J., Kelleher, M. J. and Storey, K. B. (1987). Strategies of freeze avoidance in larvae of the goldenrod gall moth, Epiblema scudderiana: Winter profiles of a natural population. J. Insect Physiol. 33, 443-450.

Rothkamm, K., Kruger, I., Thompson, L. H. and Lobrich, M. (2003). Pathways of DNA Double-Strand Break Repair during the Mammalian Cell Cycle. Mol. Cell. Biol. 23, 5706-5715.

Roufayel, R., Biggar, K. K. and Storey, K. B. (2011). Regulation of cell cycle 
components during exposure to anoxia or dehydration stress in the wood frog, Rana sylvatica. J. Exp. Zool. Part A Ecol. Genet. Physiol. 315A, 487-494.

Roy, S., de Melo, A. J., Xu, Y., Tadi, S. K., Négrel, A., Hendrickson, E., Modesti, M. and Meek, K. (2015). XRCC4/XLF Interaction Is Variably Required for DNA Repair and Is Not Required for Ligase IV Stimulation. Mol. Cell. Biol. 35, 3017-28.

Rubinsky, B., Wong, S. T., Hong, J. S., Gilbert, J., Roos, M. and Storey, K. B. (1994). 1H magnetic resonance imaging of freezing and thawing in freeze-tolerant frogs. Am. J. Physiol. Integr. Comp. Physiol. 266, 1771-1777.

Sautin, Y. Y. and Johnson, R. J. (2008). Uric Acid: The Oxidant-Antioxidant Paradox. Nucleosides, Nucleotides and Nucleic Acids 27, 608-619.

Schieber, M. and Chandel, N. S. (2014). ROS Function in Redox Signaling and Oxidative Stress. Curr. Biol. 24, 453-462.

Schmid, W. (1982). Survival of frogs in low temperature. Science. 215, 697-698.

Sies, H. (1986). Biochemistry of Oxidative Stress. Angew. Chemie Int. Ed. English 25, $1058-1071$.

Sinclair, B. J., Stinziano, J. R., Williams, C. M., MacMillan, H. A., Marshall, K. E. and Storey, K. B. (2013). Real-time measurement of metabolic rate during freezing and thawing of the wood frog, Rana sylvatica : implications for overwinter energy use. J. Exp. Biol. 216, 292-302.

Srinivas, U. S., Tan, B. W. Q., Vellayappan, B. A. and Jeyasekharan, A. D. (2018). ROS and the DNA damage response in cancer. Redox Biol. 101084. 
Stocker, R., Yamamoto, Y., McDonagh, A., Glazer, A. and Ames, B. (1987). Bilirubin is an antioxidant of possible physiological importance. Science. 235, 1043-1046.

Storey, K. B. (1990). Life in a frozen state: adaptive strategies for natural freeze tolerance in amphibians and reptiles. Am. J. Physiol. Integr. Comp. Physiol. 258, $559-568$.

Storey, K. B. (2015). Regulation of hypometabolism: insights into epigenetic controls. $J$. Exp. Biol. 218, 150-159.

Storey, K. B. and Storey, J. M. (1984). Biochemical adaption for freezing tolerance in the wood frog, Rana sylvatica. J. Comp. Physiol. B 155, 29-36.

Storey, J.M. and Storey, K.B. (1985). Triggering of cryoprotectant synthesis by the initiation of ice nucleation in the freeze tolerant frog, Rana sylvatica. J. Comp. Physiol. B 156, 191-195

Storey, K. B. and Storey, J. M. (1986). Freeze tolerant frogs: cryoprotectants and tissue metabolism during freeze-thaw cycles. Can. J. Zool. 64, 49-56.

Storey, K. B. and Storey, J. M. (1988). Freeze tolerance in animals. Physiol. Rev. 68, $27-84$.

Storey, K. B. and Storey, J. M. (1992). Natural freeze tolerance in ectothermic vertabrates. Annu. Rev. Physiol. 54, 619-637.

Storey, K. B. and Storey, J. M. (1996). Natural freezing survival in animals. Annu. Rev. Ecol. Syst. 27, 365-386. 
Storey, K.B. and Storey J.M. (2001). Signal transduction and gene expression in the regulation of natural freezing survival. In Cell and Molecular Response to Stress. Volume 2: Protein Adaptations and Signal Transduction (ed. K.B. Storey and J.M. Storey), pp 1-19. Amsterdam: Elsevier Press.

Storey, K. B. and Storey, J. M. (2004a). Metabolic rate depression in animals: transcriptional and translational controls. Biol. Rev. 79, 207-233.

Storey, K.B., and Storey J.M. (2004b). Oxygen limitation and metabolic rate depression. In Functional Metabolism: Regulation and Adaptation (ed K.B. Storey), pp 415-442. Hoboken: John Wiley ad Sons Inc.

Storey, K. B. and Storey, J. M. (2007). Tribute to P. L. Lutz: putting life on ‘pause’ molecular regulation of hypometabolism. J. Exp. Biol. 210, 1700-1714.

Storey, K. B. and Storey, J. M. (2012). Insect cold hardiness: metabolic, gene, and protein adaptation . Can. J. Zool. 90, 456-475.

Storey, K. B. and Storey, J. M. (2013). Molecular Biology of Freezing Tolerance. Compr Physiol.3, 1283-1308.

Storey, K. B. and Storey, J. M. (2017). Molecular Physiology of Freeze Tolerance in Vertebrates. Physiol. Rev. 97, 623-665.

\section{Storey, K. B., Storey, J. M., Brooks, P. S. J., Churchill, T. A. and Brooks, R. J.} (1988). Hatchling turtles survive freezing during winter hibernation. Proc. Natl. Acad. Sci. U. S. A. 85, 8350-8354.

Sullivan, M. R. and Bernstein, K. A. (2018). RAD-ical New Insights into RAD51 
Regulation. Genes.9, E629.

Suwaki, N., Klare, K. and Tarsounas, M. (2011). RAD51 paralogs: Roles in DNA damage signalling, recombinational repair and tumorigenesis. Semin. Cell Dev. Biol. 22, 898-905.

Truong, L. N., Li, Y., Shi, L. Z., Hwang, P. Y.-H., He, J., Wang, H., Razavian, N., Berns, M. W. and Wu, X. (2013). Microhomology-mediated End Joining and Homologous Recombination share the initial end resection step to repair DNA double-strand breaks in mammalian cells. Proc. Natl. Acad. Sci. 110, 7720-7725.

Wahlqvist, M. L. (2013). Antioxidant relevance to human health. Asia Pac. J. Clin. Nutr.22, 171-176.

Wijenayake, S. and Storey, K. B. (2016). The role of DNA methylation during anoxia tolerance in a freshwater turtle (Trachemys scripta elegans). J. Comp. Physiol. B Biochem. Syst. Environ. Physiol.186, 333-342.

Williams, R. S., Williams, J. S. and Tainer, J. A. (2007). Mre11-Rad50-Nbs1 is a keystone complex connecting DNA repair machinery, double-strand break signaling, and the chromatin template. Biochem. Cell Biol. 85, 509-520.

Wu, J., Lu, L. Y. and Yu, X. (2010). The role of BRCA1 in DNA damage response. Protein Cell. 1, 117-123.

Wu, C.-W., Tessier, S. N. and Storey, K. B. (2018). Stress-induced antioxidant defense and protein chaperone response in the freeze-tolerant wood frog Rana sylvatica. Cell Stress Chaperones 23, 1205-1217. 
Xiong, Z. J. and Storey, K. B. (2012). Regulation of liver lactate dehydrogenase by reversible phosphorylation in response to anoxia in a freshwater turtle. Comp. Biochem. Physiol. Part B Biochem. Mol. Biol. 163, 221-228.

Yamtich, J. and Sweasy, J. B. (2010). DNA polymerase Family X: Function, structure, and cellular roles. Biochim. Biophys. Acta - Proteins Proteomics.1804, 1136-1150.

Zachariassen, K. E. and Kristiansen, E. (2000). Ice nucleation and antinucleation in nature.Cryobiology. 41, 257-279.

Zhang, J. and Storey, K. B. (2012). Cell cycle regulation in the freeze tolerant wood frog, Rana sylvatica. Cell Cycle 11, 1727-1742.

Zhang, J. and Storey, K. B. (2016). RBioplot: an easy-to-use R pipeline for automated statistical analysis and data visualization in molecular biology and biochemistry. PeerJ. 4, e2436.

Zhang, J., Biggar, K. K. and Storey, K. B. (2013). Regulation of p53 by reversible post-transcriptional and post-translational mechanisms in liver and skeletal muscle of an anoxia tolerant turtle, Trachemys scripta elegans. Gene. 513, 147-155.

\section{Zhang, W., Larson, D. J., Middle, L., Barnes, B. M., Duman, J., Vu, H. and} Serianni, A. S. (2014). Wood frog adaptations to overwintering in Alaska: new limits to freezing tolerance. J. Exp. Biol.217, 193-200. 
Appendices 
Appendix A: Western blot antibody information and supplier

\begin{tabular}{|l|l|l|}
\hline Protein Target & Supplier & Catalogue Number \\
\hline Mre11 & Cell Signaling & 4847 \\
\hline Rad50 & Cell Signaling & 3427 \\
\hline Phospho-p95 (NSB1) & Cell Signaling & 3001 \\
\hline XLF & Cell Signaling & 2854 \\
\hline DNA Ligase IV & GeneTex & GTX100100 \\
\hline XRCC4 & GeneTex & GTX100094 \\
\hline Ku70 & GeneTex & GTX101848 \\
\hline Rad51 & GeneTex & GTX100469 \\
\hline
\end{tabular}


Appendix B: Western blot experimental conditions

B1: Western blot optimization for freeze-thaw tissues

\begin{tabular}{|c|c|c|c|c|c|c|}
\hline $\begin{array}{l}\text { Protein } \\
\text { Target }\end{array}$ & Tissue & $\begin{array}{c}\text { Protein } \\
\text { amount } \\
(\mu \mathrm{g})\end{array}$ & Gel & $\begin{array}{l}\text { Blocking } \\
\text { conditions }\end{array}$ & $\begin{array}{c}1^{\circ} \\
\text { Antibody }\end{array}$ & $\begin{array}{c}2^{\circ} \\
\text { Antibody }\end{array}$ \\
\hline \multirow[t]{2}{*}{ Mre11 } & Liver & 50 & 10 & $\begin{array}{l}3 \% \text { milk, } \\
30 \text { mins }\end{array}$ & $\begin{array}{c}\text { 1:1000, } \\
\text { overnight }\end{array}$ & $\begin{array}{l}1: 7000, \\
30 \text { mins }\end{array}$ \\
\hline & Muscle & 50 & 10 & $\begin{array}{l}2 \% \text { milk, } \\
30 \text { mins }\end{array}$ & $\begin{array}{c}\text { 1:1000, } \\
\text { overnight }\end{array}$ & $\begin{array}{c}1: 7000, \\
30 \text { mins }\end{array}$ \\
\hline \multirow[t]{2}{*}{$\operatorname{Rad} 50$} & Liver & 50 & 8 & $\begin{array}{l}1 \% \text { milk } \\
30 \text { mins }\end{array}$ & $\begin{array}{c}1: 1000,2 \\
\text { nights }\end{array}$ & $\begin{array}{c}1: 6000, \\
30 \text { mins }\end{array}$ \\
\hline & Muscle & 50 & 8 & $\begin{array}{l}1 \% \text { milk, } \\
15 \text { mins }\end{array}$ & $\begin{array}{c}\text { 1:1000, } \\
\text { overnight }\end{array}$ & $\begin{array}{c}1: 6000, \\
30 \text { mins }\end{array}$ \\
\hline \multirow[t]{2}{*}{$\begin{array}{l}\text { Phospho- } \\
\text { p95 }\end{array}$} & Liver & 50 & 10 & $\begin{array}{l}1 \% \text { milk } \\
30 \text { mins }\end{array}$ & $\begin{array}{c}\text { 1:1000, } \\
\text { overnight }\end{array}$ & $\begin{array}{c}1: 6000, \\
30 \text { mins }\end{array}$ \\
\hline & Muscle & 50 & 10 & $\begin{array}{l}\% \text { milk, } \\
30 \text { mins }\end{array}$ & $\begin{array}{c}\text { 1:1000, } \\
\text { overnight }\end{array}$ & $\begin{array}{c}1: 6000, \\
30 \text { mins }\end{array}$ \\
\hline \multirow[t]{2}{*}{ XLF } & Liver & 25 & 12 & $\begin{array}{l}5 \% \text { milk, } \\
30 \text { mins }\end{array}$ & $\begin{array}{c}\text { 1:1000, } \\
\text { overnight }\end{array}$ & $\begin{array}{c}1: 7000 \\
30 \text { mins }\end{array}$ \\
\hline & Muscle & 25 & 12 & $\begin{array}{l}2 \% \text { milk, } \\
30 \text { mins }\end{array}$ & $\begin{array}{c}1: 1000, \\
\text { overnight }\end{array}$ & $\begin{array}{c}1: 7000, \\
30 \text { mins }\end{array}$ \\
\hline \multirow[t]{2}{*}{$\begin{array}{c}\text { DNA } \\
\text { Ligase IV }\end{array}$} & Liver & 25 & 10 & $\begin{array}{l}2 \% \text { milk, } \\
30 \text { mins }\end{array}$ & $\begin{array}{c}1: 1000, \\
\text { overnight }\end{array}$ & $\begin{array}{l}1: 6000, \\
30 \text { mins }\end{array}$ \\
\hline & Muscle & 25 & 10 & $\begin{array}{l}2 \% \text { milk, } \\
30 \text { mins }\end{array}$ & $\begin{array}{c}\text { 1:1000, } \\
\text { overnight }\end{array}$ & $\begin{array}{l}\text { 1:6000, } \\
30 \text { mins }\end{array}$ \\
\hline \multirow[t]{2}{*}{ XRCC4 } & Liver & 25 & 12 & $\begin{array}{l}6 \% \text { milk, } \\
30 \text { mins }\end{array}$ & $\begin{array}{c}1: 1000, \\
\text { overnight }\end{array}$ & $\begin{array}{c}1: 8000, \\
30 \text { mins }\end{array}$ \\
\hline & Muscle & 25 & 12 & $\begin{array}{l}6 \% \text { milk, } \\
30 \text { mins }\end{array}$ & $\begin{array}{c}\text { 1:1000, } \\
\text { overnight }\end{array}$ & $\begin{array}{c}1: 8000 \\
30 \text { mins }\end{array}$ \\
\hline \multirow[t]{2}{*}{$\mathrm{Ku} 70$} & Liver & 25 & 10 & $\begin{array}{l}3 \% \text { milk, } \\
30 \text { mins }\end{array}$ & $\begin{array}{c}1: 1000, \\
\text { overnight }\end{array}$ & $\begin{array}{c}1: 7000, \\
30 \text { mins }\end{array}$ \\
\hline & Muscle & 25 & 10 & $\begin{array}{l}3 \% \text { milk, } \\
30 \text { mins }\end{array}$ & $\begin{array}{c}\text { 1:1000, } \\
\text { overnight }\end{array}$ & $\begin{array}{c}1: 7000, \\
30 \text { mins }\end{array}$ \\
\hline \multirow[t]{2}{*}{ Rad51 } & Liver & 25 & 12 & $\begin{array}{l}5 \% \text { milk } \\
30 \text { mins }\end{array}$ & $\begin{array}{c}\text { 1:1000, } \\
\text { overnight }\end{array}$ & $\begin{array}{l}\text { 1:7000, } \\
30 \text { mins }\end{array}$ \\
\hline & Muscle & 25 & 12 & $\begin{array}{l}5 \% \text { milk, } \\
30 \text { mins }\end{array}$ & $\begin{array}{c}1: 1000, \\
\text { overnight }\end{array}$ & $\begin{array}{c}1: 7000, \\
30 \text { mins }\end{array}$ \\
\hline
\end{tabular}


B2: Western blot optimizations for anoxia-recovery tissues

\begin{tabular}{|c|c|c|c|c|c|c|}
\hline $\begin{array}{l}\text { Protein } \\
\text { Target }\end{array}$ & Tissue & $\begin{array}{c}\text { Protein } \\
\text { amount } \\
(\mu \mathrm{g})\end{array}$ & Gel & $\begin{array}{l}\text { Blocking } \\
\text { conditions }\end{array}$ & $\begin{array}{c}1^{\circ} \\
\text { Antibody }\end{array}$ & $\begin{array}{c}2^{\circ} \\
\text { Antibody }\end{array}$ \\
\hline \multirow[t]{2}{*}{ Mre11 } & Liver & 50 & 10 & $\begin{array}{l}3 \% \text { milk, } \\
30 \text { mins }\end{array}$ & $\begin{array}{c}\text { 1:1000, } \\
\text { overnight }\end{array}$ & $\begin{array}{l}1: 7000, \\
30 \text { mins }\end{array}$ \\
\hline & Muscle & 50 & 10 & $\begin{array}{l}5 \% \text { milk, } \\
30 \text { mins }\end{array}$ & $\begin{array}{c}\text { 1:1000, } \\
\text { overnight }\end{array}$ & $\begin{array}{l}1: 7000, \\
30 \text { mins }\end{array}$ \\
\hline \multirow[t]{2}{*}{ Rad50 } & Liver & 50 & 8 & $\begin{array}{c}\text { No } \\
\text { blocking }\end{array}$ & $\begin{array}{c}\begin{array}{c}1: 1000,2 \\
\text { nights }\end{array} \\
\end{array}$ & $\begin{array}{c}1: 6000, \\
30 \text { mins } \\
\end{array}$ \\
\hline & Muscle & 50 & 8 & $\begin{array}{c}\text { No } \\
\text { blocking }\end{array}$ & $\begin{array}{c}1: 1000,2 \\
\text { nights }\end{array}$ & $\begin{array}{c}1: 6000, \\
30 \text { mins }\end{array}$ \\
\hline \multirow[t]{2}{*}{$\begin{array}{l}\text { Phospho- } \\
\text { p95 }\end{array}$} & Liver & 50 & 10 & $\begin{array}{c}\text { No } \\
\text { blocking }\end{array}$ & $\begin{array}{c}\text { 1:1000, } \\
\text { overnight }\end{array}$ & $\begin{array}{l}1: 6000, \\
30 \text { mins }\end{array}$ \\
\hline & Muscle & 50 & 10 & $\begin{array}{c}\text { No } \\
\text { blocking }\end{array}$ & $\begin{array}{c}\text { 1:1000, } \\
\text { overnight }\end{array}$ & $\begin{array}{l}1: 6000, \\
30 \text { mins }\end{array}$ \\
\hline \multirow[t]{2}{*}{ XLF } & Liver & 25 & 12 & $\begin{array}{l}5 \% \text { milk, } \\
30 \text { mins }\end{array}$ & $\begin{array}{c}1: 1000, \\
\text { overnight }\end{array}$ & $\begin{array}{l}1: 7000, \\
30 \text { mins }\end{array}$ \\
\hline & Muscle & 25 & 12 & $\begin{array}{l}2 \% \text { milk, } \\
30 \text { mins }\end{array}$ & $\begin{array}{c}\text { 1:1000, } \\
\text { overnight }\end{array}$ & $\begin{array}{l}1: 7000, \\
30 \text { mins }\end{array}$ \\
\hline \multirow[t]{2}{*}{$\begin{array}{c}\text { DNA } \\
\text { Ligase IV }\end{array}$} & Liver & 25 & 10 & $\begin{array}{c}\text { No } \\
\text { blocking }\end{array}$ & $\begin{array}{c}1: 1000, \\
\text { overnight }\end{array}$ & $\begin{array}{l}1: 6000, \\
30 \text { mins }\end{array}$ \\
\hline & Muscle & 25 & 10 & $\begin{array}{c}\text { No } \\
\text { blocking }\end{array}$ & $\begin{array}{c}1: 1000, \\
\text { overnight }\end{array}$ & $\begin{array}{l}1: 6000, \\
30 \text { mins }\end{array}$ \\
\hline \multirow[t]{2}{*}{ XRCC4 } & Liver & 25 & 12 & $\begin{array}{l}6 \% \text { milk, } \\
30 \text { mins }\end{array}$ & $\begin{array}{c}1: 1000, \\
\text { overnight }\end{array}$ & $\begin{array}{l}1: 8000, \\
30 \text { mins }\end{array}$ \\
\hline & Muscle & 25 & 12 & $\begin{array}{l}6 \% \text { milk, } \\
30 \text { mins }\end{array}$ & $\begin{array}{c}1: 1000, \\
\text { overnight }\end{array}$ & $\begin{array}{c}1: 8000, \\
30 \text { mins }\end{array}$ \\
\hline \multirow[t]{2}{*}{$\mathrm{Ku} 70$} & Liver & 25 & 10 & $\begin{array}{l}3 \% \text { milk, } \\
30 \text { mins }\end{array}$ & $\begin{array}{c}\text { 1:1000, } \\
\text { overnight }\end{array}$ & $\begin{array}{l}1: 7000, \\
30 \text { mins }\end{array}$ \\
\hline & Muscle & 25 & 10 & $\begin{array}{l}3 \% \text { milk, } \\
30 \text { mins }\end{array}$ & $\begin{array}{c}\text { 1:1000, } \\
\text { overnight }\end{array}$ & $\begin{array}{l}1: 7000, \\
30 \text { mins }\end{array}$ \\
\hline \multirow[t]{2}{*}{ Rad51 } & Liver & 25 & 12 & $\begin{array}{l}5 \% \text { milk } \\
30 \text { mins } \\
\end{array}$ & $\begin{array}{c}\text { 1:1000, } \\
\text { overnight }\end{array}$ & $\begin{array}{l}1: 7000, \\
30 \text { mins } \\
\end{array}$ \\
\hline & Muscle & 25 & 12 & $\begin{array}{l}5 \% \text { milk, } \\
30 \text { mins }\end{array}$ & $\begin{array}{c}\text { 1:1000, } \\
\text { overnight }\end{array}$ & $\begin{array}{l}1: 7000, \\
30 \text { mins }\end{array}$ \\
\hline
\end{tabular}


Appendix C: Representative western blots

C1: Whole image of ECL-detected membrane using the control, 24 hour frozen and 8 hour thawed liver samples probed with XRCC4 antibody 
C2: Coomassie stained membrane of control, 24 hour frozen and 8 hour thawed liver samples probed with XRCC4 antibody. Band of interest was standardized against the summed intensity of multiple Coomassie-stained bands from the same lane.

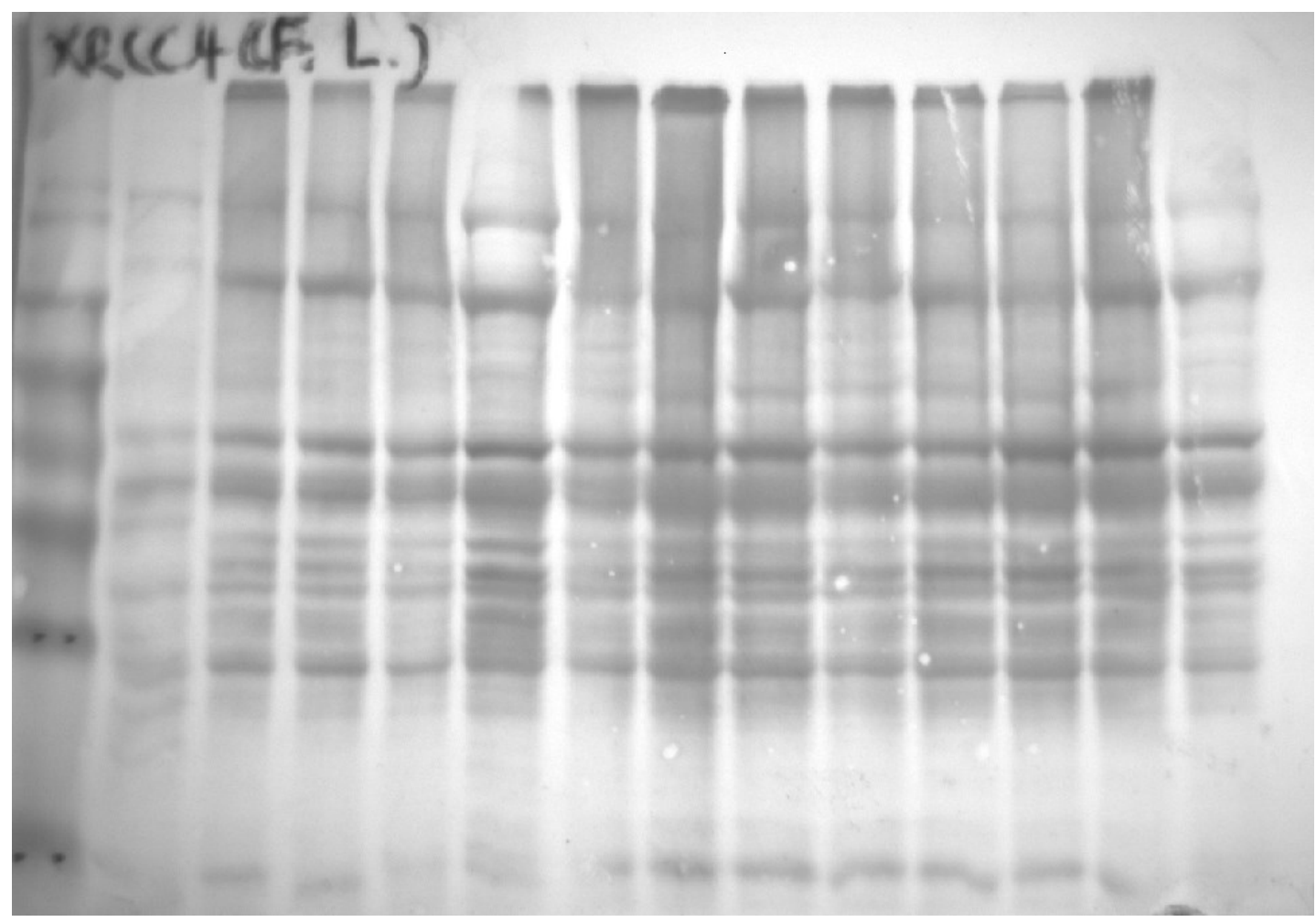

